\title{
Better together
}

Citation for published version (APA):

Pelser, J. (2016). Better together: investigating the psychology behind successful channel partner programs. [Doctoral Thesis, Maastricht University]. Datawyse / Universitaire Pers Maastricht. https://doi.org/10.26481/dis.20160915jp

Document status and date:

Published: 01/01/2016

DOI:

10.26481/dis.20160915jp

Document Version:

Publisher's PDF, also known as Version of record

\section{Document license:}

Unspecified

\section{Please check the document version of this publication:}

- A submitted manuscript is the version of the article upon submission and before peer-review. There can be important differences between the submitted version and the official published version of record.

People interested in the research are advised to contact the author for the final version of the publication, or visit the DOI to the publisher's website.

- The final author version and the galley proof are versions of the publication after peer review.

- The final published version features the final layout of the paper including the volume, issue and page numbers.

Link to publication

\footnotetext{
General rights rights.

- You may freely distribute the URL identifying the publication in the public portal. please follow below link for the End User Agreement:

www.umlib.nl/taverne-license

Take down policy

If you believe that this document breaches copyright please contact us at:

repository@maastrichtuniversity.nl

providing details and we will investigate your claim.
}

Copyright and moral rights for the publications made accessible in the public portal are retained by the authors and/or other copyright owners and it is a condition of accessing publications that users recognise and abide by the legal requirements associated with these

- Users may download and print one copy of any publication from the public portal for the purpose of private study or research.

- You may not further distribute the material or use it for any profit-making activity or commercial gain

If the publication is distributed under the terms of Article $25 \mathrm{fa}$ of the Dutch Copyright Act, indicated by the "Taverne" license above, 


\title{
Better Together
}

\section{Investigating the psychology behind successful channel partner programs}

\author{
Jan Pelser
}

Maastricht University 
Copyright Jan Pelser, Maastricht 2016

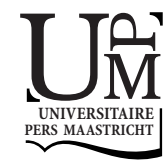

ISBN: 9789461595997

Cover design by: Sarah Böckenhüser

Printing by: Datawyse | Universitaire Pers Maastricht

All rights reserved. No part of this publication may be reprinted or utilized in any form or by any electronic, mechanical or other means, now known, or hereafter invented, including photocopying and recording, or in any information storage or retrieval system, without permission from the copyright owner. 


\title{
Better Together
}

\section{Investigating the psychology behind successful channel partner programs}

\author{
DISSERTATION \\ to obtain the degree of Doctor at Maastricht University, \\ on the authority of the Rector Magnificus, Prof. Rianne M. Letschert, \\ in accordance with the decision of the Board of Deans, to be defended in public on \\ Thursday, 15 September, 2016 at 12:00 hrs. \\ by Jan Pelser
}




\section{Supervisors:}

Prof. Dr. Ko de Ruyter

Prof. Dr. Martin Wetzels

Prof. Dr. Dhruv Grewal, Babson College, USA

\section{Assessment Committee:}

Prof. Dr. Jos Lemmink (chair)

Prof. Dr. Janjaap Semeijn

Prof. Dr. Chris Storey, University of Sussex, United Kingdom

Prof. Dr. Daniel Wentzel, RWTH Aachen University, Germany 


\section{Acknowledgments}


In this dissertation, I have studied the implications of gratitude and even though the word appears approximately 250 times in this document, I would like to add a few more words to express my own appreciation. I now know how important gratitude is in the context of relationships, but more than that - these words are heartfelt. So, "Thank You" to everyone who supported me throughout the process of writing this dissertation and who accompanied me on this journey. I won't be able to mention each and every one, but my hope is that those who had a part in this know who they are and that I am eternally grateful to them - to you!

The years I spent working on this dissertation were some of the most challenging but also most fulfilling years of my life. Through highs and lows, I have had the opportunity to meet some of the most interesting and smart people I know, and to work with truly great mentors.

Ko, it was an honor to work with and learn from you. You have provided me with many great opportunities, from business partnerships to speaking invitations and beyond. Perhaps most of all, I appreciate having had the chance to learn about theory building and crafting engaging stories from one of the best - thank you for the many interesting and inspiring moments. Martin, it was a great opportunity to write my dissertation with you, and also to teach in your course Research for Marketing Decision Making for several years. Both were a lot fun, but I have also learned a great deal from you about applying the right kind of tools in a given situation and to understand the context first, be it in terms of theory or data. Thank you. Dhruv, it was a privilege working with you. As one of the most productive and successful academics, you have taught me many things about academia itself but also about good ideas and being creative yet pragmatic. Thank you. David, it has always been both fun and extremely inspiring working with you. You are a great role model for interacting with clients, business partners, coauthors and coworkers - being positive, motivating, engaging and convincing, all at the same time. Thank you for everything.

Ryan, thank you very much for the opportunity to work with and for you and your teams. It was an honor and it was always especially fun when we had the chance to meet up in person. I hope we get the chance to do just that again in the near future.

I also want to thank my office mates and colleagues from the Marketing department at Maastricht University, who were a constant source of motivation, knowledge and positivity throughout the years. Jacqueline and Stefan, you had a huge impact on me during the first years of my $\mathrm{PhD}$ and were great role models. Without you, I definitely would have taken even longer ;). Klemens, it was a lot of fun teaching alongside you and our late-night exam corrections were ridiculous in the best possible way - as were our talks about all things Apple. Matthias, Hannes, Anne, Johannes, you were always super helpful, professional, fun and just great to be around. Thank you for that! Theo, your sense of humor is amazing and our philosophical discussions are deeply missed. Catching up soon is a must. Liz, it was and is great to have you as a colleague and to work with you as a co-author. I really appreciate everything you do. Dominik, your drive, openness and creativity are an inspiration and I hope we keep in touch over many more dinners and discussions, possibly including one or two glasses of wine. Alex, 
Robert and Ile - you guys are simply awesome and the times we shared are among my most treasured memories, not only from Maastricht. Thanks for being great friends! Jan "HfM", we've had some of the both deepest and funniest discussions about research, music and life. I keep learning from you and I am happy we are keeping our friendship up even at a physical distance. Nina, you're a true friend and partner in crime and it's an honor to work with you again. May the legendary party nights never end, just like our musings about life in general.

My heartfelt thanks also go out to my amazing friends from Krefeld, Maastricht, and other places around the world for endless amounts of fun, love and support throughout the years. Luzi, Stachel, André, Christoph, Demian, Ken, Charly, Christian, Yvonne, you guys have always been there for me - thank you, from the bottom of my heart. Eline, thank you for being a friend, an inspiration and an all-around awesome person. Linda, I almost don't know what to say because it would take more than one book to write out everything. But without you, I would never have made it this far and I - for sure - would be a different person. Thank you for everything!

Last, but absolutely not least, I want to thank my family, especially my brother Jochen and my parents, Angelika and Hans-Joachim, for being absolutely, incredibly supportive and patient in every possible way over many, many years. This work is dedicated to you. Danke für alles! 



\section{Table of Contents}

Acknowledgments $\quad 5$

$\begin{array}{lll}\text { Chapter One } & \text { Introduction } & 11\end{array}$

Chapter Two B2B Channel Partner Programs: Disentangling Indebtedness from Gratitude $\quad 23$

Chapter Three When They've Lost That Learning Feeling... Balancing Customer and Sales Orientations to Prevent Disengagement in Channel Partner Programs

Chapter Four Conclusion

References

Appendix

Valorization Addendum 103

Curriculum Vitae

109 



\section{Chapter One Introduction}



"There's nothing more important to HP than our channel partners"

Meg Whitman - CEO, Hewlett Packard

In today's marketplace, companies no longer operate as isolated entities as they increasingly rely on actors outside the firm to contribute to their service and sales processes (Prahalad and Ramaswamy 2004). Developing channel partnerships is a high-impact strategy for growth as successful partnerships provide access to new customers and references leading to new business opportunities (Cazalot 2013). In the IT sector, channel partners produced $67 \%$ of sales for the largest suppliers in 2007 (Lamkin 2013). As just one example, for SAP this translates to US\$220 billion in revenue realized through its worldwide channel partners network (Whiting 2013). And whereas the prominent role of channel partners may be most recognized in the IT sector, similar percentages are reported in other business sectors, such as the home improvement industry (e.g. Grohe's Enjoy Rewards program, Grohe 2013).

Channel partner relationships have the potential to increase sales, decrease time to market, and unlock access to markets that have been inaccessible before (Cazalot 2013). Therefore, managing these relationships has become critical for firms (Bairstow and Young 2012; De Ruyter et al. 2001). However, managing international - and often worldwide - networks of independent companies and relationships is not a trivial task. Companies need to coordinate and communicate with large numbers of channel partner firms and employees within those firms. In addition, these partner firms frequently also sell competitors' products and services. This often translates into less loyalty towards each individual manufacturer and can also lead to less in-depth knowledge on each manufacturer's products and services. Building tightly knit relationships thus becomes even more critical for the manufacturer - both at the channel partner firm and individual-employee level (Fiorletta 2014).

In light of these challenges, firms increasingly turn to channel partner programs (CPP) that incentivize selling and learning as a tool to foster strong relationships with partners, including value-added resellers, consultants, original equipment manufacturers and distributors (Rouse 2014; TSL Marketing 2013). A 2005 survey of firms including mainly manufacturers and service providers showed that approximately half of the surveyed companies made use of incentive programs (Incentivecentral.org 2008).

\section{CHANNEL ENABLEMENT AND PARTNER PROGRAMS}

An increasing emphasis on indirect sales channels (Bairstow and Young 2012) implies that channel partners are involved in distributing products and services to endcustomers. Notwithstanding the clear benefits of this approach, the manufacturer gives up control of these interactions, as well as direct access to customers in many cases. For this reason, suppliers need to find ways to ensure up-to-date knowledge and high quality of service provided by their partners. This has led to a strong focus on training business partners. Training is seen as necessary to achieve and retain a strong market position as 
well-trained sellers are better able to market the supplier's products while solving their customers' problems (Bettencourt et al. 2002). This is even more true today, as the overall business-to-business landscape has evolved towards increased competition due to globalization and better informed customers demanding increased levels of customer service (Román et al. 2002). Addressing these changes requires salespeople to continually update and evolve their skills (Dubinsky 1999; Filipczak et al. 1991). An additional important development for business leaders is the fact that technology is becoming more and more intertwined (Fiorletta 2013). This poses a challenge to channel partners who have to consult their end-customers on complex business problems. Partners need to continually maintain and grow their expertise in order to advise their customers on these increasingly interconnected solutions (Fiorletta 2013). Furthermore, training is a vital component of the onboarding phase of new employees as well as the ongoing development of sales representatives (Christiansen et al. 1996). It is therefore no surprise that for a company like Dell, partner training and enablement is one of their top areas of focus for the coming years, as illustrated by this quote:

"We believe that if we have the best trained and most enabled partners, not only will it help them and make them happier they're our partners, but it also will help them be better partners to us and sell more effectively. We've conducted research that has proven... their businesses are stronger and they're just more profitable."

Kathleen Schneider - Exec. Director of Global Channel Marketing and Programs, Dell

Academic research mirrors these conclusions; while some discussion persists about boundary conditions, it has shown that in general, salesperson learning results in higher sales performance (Sujan, Sujan, and Bettman 1988; Weitz, Sujan, and Sujan 1986). In fact, channel partner sales training has become a major priority for many manufacturers in recent years (Sager et al. 2014; Sarin et al. 2010) and major manufacturers such as HP, Microsoft, Dell offer extensive training and e-learning facilities (Kalyanam and Brar 2009; Microsoft 2010) as important components of their channel partner programs. In order to increase sales of the manufacturers products and services, channel partners receive both general and specific product and marketing training, technical support, lead generation tools and other information and resources tailored to their needs (Rouse 2014).

To facilitate learning in the channel, manufacturers provide a variety of assets, tools, incentive programs, training courses, and other benefits to their channel partners with the explicit intention of helping them to sell more of their products. For this reason, the content and benefits offered in channel partner programs are typically focused on helping the partners to position the products, have customer discussions about the products and services, as well as to incentivize and empower them to sell, implement and support the products (Bright 2012). Many practitioners also use the term "partner enablement" to refer to such activities associated with "helping partners to more rapidly establish and grow their businesses and more successfully position, sell, implement and support ven- 
dor-provided products and services" (Bright 2012, p. 1), which is considered part of a "channel partner program" throughout this dissertation.

It should be noted that incentives have come to play a more and more prominent role in partner programs in recent years (Incentivecentral.org 2008; Spellecy 2014). As partners are faced with a multitude of obligations and short-term to-dos, training and education sessions are often perceived as relatively low priority. To increase the likelihood that resellers do participate in training, vendors have begun tying rewards and incentives to training program and certification completion (Fiorletta 2012). Next to incentives for training, programs also frequently feature specific incentives for sales of a specific product or service to increase the vendor's market reach with said offering. Further incentives may include awards, industry recognition at dedicated events, as well as additional marketing resources (Rouse 2014). As incentives drive behavior, vendors hope that tying education to rewards can raise partner interest and provide encouragement to participate in training modules and courses. In practice, this takes different forms, including points that are earned and flow to an ongoing loyalty or channel partner program, a certain dollar amount flowing to sales performance incentive funds for course completion; or rewards tied at the partner-entity level (Fiorletta 2013; Fiorletta 2012).

The incentives given out for training participation represent significant investments on part of the supplier firms (Gilliland 2004). However, while executives acknowledge their importance, they do not seem be as universally effective as hoped. Recent industry surveys report mixed results to many programs, with only short-term rises in performance that drop off quickly (Sharir 2014). As these programs are key mechanisms through which manufacturers hope to increase both loyalty and knowledge in their channel partners, it is important to find out under which conditions these programs are indeed effective, how they work, and for what channel partners they may be particularly well-suited. This dissertation therefore aims to investigate factors influencing the effectiveness of channel partner programs in building and maintaining the relationship, as well as in enhancing bottom-line-returns for the manufacturer or service provider offering the program.

\section{PARTNER EMOTIONAL RESPONSES TO CHANNEL PARTNER PROGRAMS}

Partner programs offering dedicated and optimized training for the channel, incentives for module completion, and additional incentives for selling represent a high resource investment for manufacturers. Channel partners value these investments as they benefit from the training and incentives offered (Incentivecentral.org 2008). Recent literature in marketing highlights the construct of gratitude as a construct with important implications on relationships. It is conceptualized as the "emotional appreciation for benefits received" (Palmatier et al. 2009, p. 1) and seen as a means by which relationship investments - such as investments in partner programs - translate into positive ROI for 
firms. As valuable benefits lead to gratitude (Lane and Anderson 1976), channel partners who value the programs, trainings and incentives offered should feel grateful - just as a consumer might feel grateful for receiving superior service in a retail store setting (Palmatier et al. 2009). In addition, gratitude is a universal response, which has been identified and positively encouraged in all cultures and major religions (Emmons and Crumpler 2000), which makes it particularly relevant considering the international nature of channel partner programs today. In a marketing sense, gratitude is important for firms as grateful people behave more generously toward the people that benefitted them (Tsang 2006), which should lead to improved bottom-line results (Raggio et al. 2013) and potentially improved relationships (Bono and McCullough 2006; McCullough et al. 2008). While gratitude plays an important role in relationships, the role of gratitude in a structured relationship program such as the channel partner programs that are discussed in this dissertation is not fully understood at this point (cf. Palmatier et al. 2009). As gratitude is one of the key ways through which relationship investments pay off, it seems important assess its in channel partner programs, as well as examining under which conditions it will be exhibited.

A concept closely related to gratitude that has been less researched is found in indebtedness. Indebtedness is an aspect related to social exchanges and has been defined as "a state of obligation to repay another" (Greenberg 1980, p. 4). It stems from the norm of reciprocity, which states that "(1) people should help those who have helped them, and (2) people should not injure those who have helped them'" (Gouldner 1960, p. 171). In contrast with gratitude however, psychology literature has identified it as an unpleasant state (Watkins et al. 2006) that is accompanied by negative emotions (Greenberg 1980). As negative emotional states are unpleasant to the individual, indebtedness could negatively impact the partner relationship. It therefore seems important to incorporate indebtedness in this research in order to achieve a more complete understanding of the channel partner's emotional responses to the channel partner program.

As opposing effects are expected for indebtedness and gratitude, it is important for managers to understand when either would mainly occur in response to their programs. The foundational literature on both constructs mentions the intentionality behind benefit provision (i.e. the motives perceived by the benefit recipient) as one important determinant of these emotional responses (e.g. Gouldner, 1960, Greenberg 1980). In the context of channel partner programs, this means that the channel partner's perception of the manufacturer's motives for providing these programs will play an important role in producing gratitude and indebtedness.

An additional, important aspect of channel partner programs is the heterogeneous nature of its audience. Partners include a range of salespeople in different companies, markets and also different performance levels. Recent industry reports highlight the fact that high performing, self-confident salespeople (Davis 2012; DeWolf 2013) hold very different expectations of their suppliers. Some partners have a pervasive sense that they are entitled to more than others and expect their manufacturers to offer consistent benefits (Campbell et al. 2004; Wetzel et al. 2013). This influences how grateful they are, which could the program's benefits for the supplier. It is thus important to investigate 
the effect of entitlement in relation to gratitude and indebtedness in channel partner programs as ultimately these emotional responses will play a large role in determining program success.

\section{DISENGAGEMENT FROM THE PROGRAM}

"Everybody is always trying to figure out how to better engage their channel"

Ehren Maedge - VP Sales and Marketing, LiveLink Mobile

Despite the fact that industry experts resoundingly confirm the importance of partner learning, ensuring program participation and completion in practice poses an acute challenge for vendors and manufacturers (Fiorletta 2012). Yet, it is critical that partners engage, meaning that partners not only take the trainings and training modules, but that they pay attention to them and absorb the information so that they can put this information into practice successfully.

Engagement has received increased attention in the literature on employee commitment and performance in recent years (e.g., Christian et al. 2011; Menguc et al. 2013; Rich et al. 2010) and is defined as "the simultaneous employment and expression of a person's 'preferred self' in task behaviors that promote connections to work and to others, personal presence (...) and active, full performances" (1990, p. 700). Stated more simply, engaged employees invest their "hands, head, \& heart" in their work performances (Ashforth \& Humphrey, 1995, p.110). It follows that only in the case that partners actually engage, partners and suppliers can both reap the maximum benefit from the training programs. Next to partner emotional responses to the program, it is therefore important to understand how partners behave and engage within the program over time.

Yet, as one of the main common problems in online learning programs is a high dropout rate (Frankola 2001), an issue even more pertinent and urgent may be the one of disengagement form the program. Disengagement is a decrease in the state of engagement and can be expected to lead to opposite outcomes (Kahn 1990). Despite its apparent importance however, research on disengagement is severely limited at this point. And while sales enablement plays a key role in unlocking salespeople's long-term performance (Pettijohn et al. 2009), disengagement from channel partner programs thus far largely been ignored in academic research. It is therefore necessary to understand what makes partners disengage from the training and partner program.

Many different reasons thus exist why partners may not engage optimally in the training or stop engaging altogether. An attitude often observed with salespeople is that they could learn more effectively from interacting with customers - i.e. through learning by doing - rather than through training or workshops. Some even consider training "not the best use of their time" (Powell 2001, p.43).

In addition, the sales role has increased in complexity and relational intensity, which makes the job more time-consuming and also requires more effort from salespeople. 
Partners may thus simply not have the time (Cron 2005) or energy to fully engage in training. This does not mean that partners do not value the training, or that they think it is not important - It simply highlights the challenge of fitting the training around "business as usual" (Marnes 2013, p.1). Naturally, it must also be considered that what is typically most important to channel partners is to make money. Therefore, a channel program should be designed so that it can aid in doing this in a convenient way for the partner (Incentivecentral.org 2008). Today's prevalence of online learning modules is an important development when viewed from this perspective. Online learning allows salespeople to learn during downtime, which is less disruptive and possibly enables them to better balance the training with their daily tasks. It should be clear though that the partner does have constraints that may limit the amount and intensity of the training (Marnes 2013).

One important factor influencing whether and how partners engage with learning is their general orientation regarding the sales role. For instance, certain partners are more strongly oriented towards helping the customer reach their goals and fulfill their needs, while others focus mostly on closing the sale (e.g., Harris 2005). While these two orientations seemingly conflict, they may both play a role simultaneously as the very best salespeople, arguably, would combine elements of both orientations to successfully close deals while keeping their customers satisfied. While not all employees are similarly capable of acting on seemingly conflicting goals, this ability - called ambidexterity (Simsek 2009) - has been shown to lead to positive outcomes when employees face conflicting demands (Jasmand et al. 2012; Yu et al. 2013). Ambidexterity should also be relevant to channel partner programs; Partners who successfully reconcile these seemingly conflicting orientations may be less prone to disengaging from sales training modules as they aim to close the sale while still having their customer's needs and interests at heart.

\section{OUTLINE AND STRUCTURE}

To address the overall research question of which factors at the reseller firm and salesperson level enable channel partner program success, this dissertation is based on two main empirical studies in the B2B domain. A database was collected using multi-wave surveys, with additional behavioral and secondary data collected and matched to supplement this data for a more complete and accurate perspective on the examined effects. In addition, a laboratory study in the $\mathrm{B} 2 \mathrm{C}$ domain was as also implemented and utilized as a robustness test for the study presented in chapter two. The field study data in chapters two and three was collected in close collaboration multiple firms internationally, including one of the leading manufacturers and service providers in the information technology sector.

Even though the studies presented in chapters two and three are both concerned with channel partner program members, the chapters diverge in their main foci. Chapter two mainly focuses on the channel partners' grateful and indebted emotional responses to 
the program being offered and assesses how these responses help to turn investments in these programs into bottom-line results. Chapter three, on the other hand, focuses mainly on sustaining the partners' engaged participation in the program and thus centers on disengagement and how the partner's ability to balance seemingly conflicting orientations prevents disengagement from occurring. In the following, we introduce both studies and summarize their empirical findings.

\section{CHAPTER 2: B2B CHANNEL PARTNER PROGRAMS: DISENTANGLING INDEBTEDNESS FROM GRATITUDE}

Chapter 2 focuses on the emotional responses of the channel partner to the program and how these influence important outcomes for the supplier. In this chapter, we describe a two-wave field study in which we investigate the roles of indebtedness and gratitude in channel partner programs and how these emotional responses to the program influence the future of the relationship and performance. Our results from the field study show that indebtedness has negative effects on commitment to the supplier, as well as the reseller's effort selling the manufacturer's products and services. Gratitude on the other hand has positive effects and simultaneously attenuates the effects of indebtedness on sales effort and commitment, thus offering a buffer against indebtedness' detrimental effects. An additional laboratory study in the B2C domain was performed as a robustness test for this interaction effect, providing further support for its occurrence. This chapter thus highlights indebtedness' and gratitude's important, yet contrasting roles in relationship marketing in general and channel partner programs in particular. In addition, our study examines the role of perceived supplier motives for providing the program and finds motives to be of importance of as they differentially predict indebtedness and gratitude. Benevolent motives thereby are found to increase gratitude, whereas ulterior motives do not influence it. Ulterior motives do, however, increase indebtedness. Finally, the results of our analyses also reveal the intricate role of entitlement in channel partner programs. We find that it decreases the positive effect of perceived program value on partner gratitude while increasing the effect of ulterior motives on indebtedness. This chapter also elucidates the implications for suppliers and marketers aiming to navigate the complexity associated with realizing the full benefits of channel partner programs, as well as for further research.

\section{CHAPTER 3: WHEN THEY'VE LOST THAT LEARNING FEELING... BALANCING CUSTOMER AND SALES ORIENTATIONS TO PREVENT DISENGAGEMENT IN CHANNEL PARTNER PROGRAMS}

Chapter 3 focuses on the salesperson's engagement in, and disengagement from the channel partner program. Business partner sales training has become a major priority for 
firms (Sager et al. 2014) and our results show that training disengagement plays an important role in partner programs as it negatively impacts performance and foreshadows problems underlying the relationship. More specifically, results from our field study show empirically that salesperson disengagement from supplier-provided training over time leads to lower relationship satisfaction and decreases sales performance of the reseller salesperson. Second, in this chapter we demonstrate the role of salesperson ambidexterity in the form of balancing customer orientation and selling orientation in training disengagement. As one of the first studies assessing individual-level ambidexterity, we find that salespeople who are able to reconcile these seemingly conflicting orientations are less prone to disengaging from the training modules. To offer a more fine-grained view on engagement effects in channel partner programs, we also distinguish between state (dis-)engagement as assessed through our survey and objectively assessed behavioral engagement. Our results show that the effects of ambidexterity on disengagement differ based on the seller's prior behavioral engagement in the program. Finally, we investigate the role of the reseller firm culture, in specifically highlighting the effects of a bottom-line mentality (Greenbaum et al. 2012). Our findings show that a strong bottom-line mentality increases the impact of disengagement on the reseller's satisfaction with the supplier relationship.

To summarize, Figure 1.1. briefly illustrates the headline constructs and relationships in this dissertation before the details of our studies in chapters two and three are presented.

\section{CHAPTER 4: CONCLUSION}

In chapters two and three, we address each main research question and detail our hypotheses, research, and results and relating to these questions. Chapter 4 finally concludes this dissertation by summarizing the main findings on the reseller salesperson's responses to and engagement in channel partner programs as well as the concordant implications for the channel relationship and ongoing performance. Drawing on our findings, we then discuss the broader conceptual implications, highlight further research opportunities and offer suggestions for managers. 


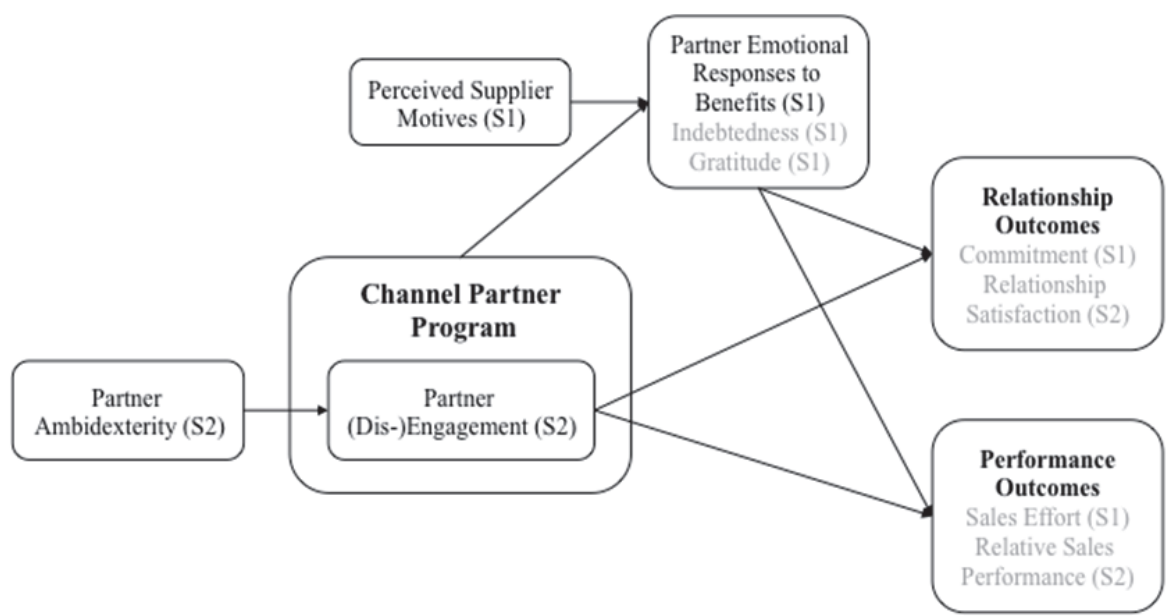

Figure 1.1 Key Constructs and Relationships of this Dissertation NB: Grey text indicates included constructs in study 1 (S1) and study 2 (S2) 



\section{Chapter Two B2B Channel Partner Programs: Disentangling Indebtedness from Gratitude}

Pelser, J., de Ruyter, K., Wetzels, M., Grewal, D., Cox, D., \& van Beuningen, J. (2015). B2B Channel Partner Programs: Disentangling Indebtedness from Gratitude. Journal of Retailing, 91(4), 660-678. 


\begin{abstract}
Many suppliers invest heavily in channel partner programs that incentivize selling and learning. The authors conduct a multi-wave field study to investigate the roles of indebtedness and gratitude in transforming these investments into returns. The results show that indebtedness has negative effects on commitment to the supplier, as well as the reseller's sales effort. Gratitude however attenuates the effects of indebtedness on sales effort and commitment, and thus offers a buffer against indebtedness' negative effects. Indebtedness and gratitude thus play key roles in channel partner programs. In addition, the results highlight the importance of perceived motives as they differentially predict these two states. Benevolent motives are found to increase gratitude, though ulterior motives do not detract from it. Ulterior motives do however increase indebtedness. Finally, the results also reveal how entitlement negatively impacts channel partner programs: It decreases the positive effect of perceived program value on partner gratitude while increasing the effect of ulterior motives on indebtedness. This study thus assesses the simultaneous yet contrasting role of gratitude and indebtedness, as well as the complexity associated with realizing the full benefits of channel partner programs. The findings have implications for suppliers, marketers, and further research.
\end{abstract}




\section{INTRODUCTION}

For supplier firms that use vertical networks to create superior value (Lusch et al. 2007), managing indirect sales channel relationships is critical (Bairstow and Young 2012; De Ruyter et al. 2001). In the IT sector, channel partners produced $67 \%$ of sales of the largest manufacturers in 2007 (Lamkin 2013). For example, worldwide channel partners of SAP account for US $\$ 220$ billion in revenue (Whiting 2013). These partnerships are immensely important to manufacturers and they actively invest in programs to incentivize their partners' selling and learning efforts (TSL Marketing 2013). Firms like Oracle and Microsoft offer learning modules on a variety of topics to their partners and incentivize them through reward points or discounts.

Yet, market surveys report that only $33 \%$ of senior sales and marketing executives are satisfied with these programs (Fiorletta 2011; SAS \& Loyalty 360 2012). It appears that even when the partners indicate appreciation for the programs (Bateman 2009), they remain suspicious of their true intentions and sense an obligation to repay in some way (Incentivecentral.org 2008). As one practitioner notes: "You must have a compelling answer to the question "What can we do for them?" - Not just selfish interest in what they can do for you" (Andrews 2013, p. 1).

Moreover, the programs target a mixed audience of heterogeneous resellers, including high performing, self-confident salespeople (Davis 2012), who express widely varying expectations of their suppliers. For this reason, "channel chiefs routinely struggle with the number of partners in their programs that are living off the channel equivalent of entitlement programs" (Vizard 2012, p. 1). To learn the best ways to invest in channel partner programs, we need a more detailed understanding of how business partners perceive and evaluate them.

Recent marketing theory highlights the relational construct of gratitude, or the "emotional appreciation for benefits received" (Palmatier et al. 2009, p. 1), as a means by which relationship investments transform into returns. Yet, indebtedness, which is also a basic feature of social exchanges (Greenberg 1980), remains largely neglected. Indebtedness is defined as "a state of obligation to repay another" (Greenberg 1980, p. 4) and is generally is perceived as unpleasant (Watkins et al. 2006), accompanied by negative emotions, and related to avoidance goals (Greenberg 1980). Gratitude and indebtedness can potentially occur in conjunction (Naito et al. 2005; Watkins et al. 2006), yet we lack an in-depth understanding of their interplay or a clear differentiation between these two distinct constructs (e.g., Komter 2004). Ambiguity also exists with regard to the determinants of both gratitude and indebtedness.

Another potentially important characteristic of heterogeneous partners pertains to the extent to which they exhibit a pervasive sense of being entitled to more than others and expect suppliers to offer consistent benefits (Campbell et al. 2004; Wetzel et al. 2013). Feelings of entitlement and inflated expectations likely influence partners' responses to supplier programs, such as by causing them to feel less appreciative, which reduces the program's benefits for the supplier. We also do not know how entitlement 
affects indebtedness or gratitude. With this study, we seek to examine how these emotional states and facets can help explain channel partner program success.

In turn, this study makes three main contributions. First, we propose that indebtedness is a central element of channel partner programs. We also investigate the unique and joint impacts of indebtedness and gratitude as distinct emotional states that relate to the receipt of a benefit. We need to distinguish between them (Schaumberg and Flynn 2009; Watkins et al. 2006) while also considering and explicating their possible simultaneous occurrence (cf. Morales 2005). In channel partner contexts, gratitude affects relational outcomes, such as commitment and trust, as well as sales performance and effort (e.g., Palmatier et al. 2009). We extend existing literature by integrating feelings of appreciation and obligation into a wider nomological framework, then explicitly assessing the interplay of gratitude and indebtedness. Previous literature implies that positive emotions can undo the damage created by negative emotions (Fredrickson et al. 2000), which in turn suggests a novel perspective on gratitude, in that it may mitigate the negative impact of indebtedness.

Second, we examine conditions that favor the dominance of either gratitude or indebtedness. Scant empirical evidence describes situational or personal characteristics that might predominantly produce one or the other (Schaumberg and Flynn 2009), though Morales (2005) establishes the role of personal favors in eliciting indebtedness as well as gratitude, in contrast with general reciprocity, which only leads to gratitude. Palmatier et al. (2009) also highlight the role of perceived motives in enhancing gratitude. We affirm the influence of perceived motives on gratitude and investigate their role in driving indebtedness. We also propose a more nuanced view of the multiple motives at play simultaneously in channel relationships. Specifically, we treat benevolent and self-serving motives as orthogonal and assess their simultaneous, differential effects on gratitude and indebtedness.

Third, we detail a source of heterogeneity in this context. Building on recent relationship marketing research (Wetzel et al. 2013), we investigate the role of entitlement in channel partner programs, which may influence how partners respond to the program, namely, by mitigating the positive effects of program value on partner gratitude. Because entitlement likely alters partners' perceptions and expectations, we investigate the combined effect of entitlement and perceived ulterior motives on indebtedness, such that we consider how entitlement moderates the effects of various drivers of gratitude and indebtedness.

In the next section, we review literature on gratitude and indebtedness as well as their conceptual connections and distinctions between them. After we introduce our conceptual framework and the hypotheses, we describe our multi-wave longitudinal study, with a worldwide sample of business channel partners, supplemented with objective performance data. We present the results and discuss the main findings from both theoretical and managerial perspectives. Finally, we note some limitations and opportunities for further research. 


\section{CONCEPTUAL BACKGROUND}

Because gratitude and indebtedness are two conceptually distinct states, resulting from the receipt of a benefit, they are particularly relevant for understanding channel partner programs, for which the benefits of knowledge and rewards are foundations. Gratitude has received increased research attention recently, though it remains understudied (Palmatier et al. 2009), and literature in both psychology and marketing often fails to differentiate between gratitude and indebtedness (Haisley and Loewenstein 2011; Watkins et al. 2006).

\section{Gratitude and Indebtedness}

Gratitude has been conceptualized as a moral virtue, an attitude, a trait, or a coping response (Emmons et al. 2003; Lambert et al. 2009), as well as a state of thankfulness (e.g., Steindl-Rast 2004) or appreciation (e.g., Adler and Fagley 2005). Substantial research treats gratitude as a response to an interpersonal benefit transfer (Lambert et al. 2009), such as when Emmons (2004) conceptualizes it as a feeling of thankful appreciation for favors received. Gratitude as a form of emotional appreciation is universal, evident in all cultures and encouraged by all major religions (Emmons and Crumpler 2000), which is important for international channel partner programs. McCullough et al. (2002, p. 112) suggest that gratitude also has a dispositional dimension, prompting "a generalized tendency to recognize and respond with grateful emotion to the roles of other people's benevolence in the positive experiences and outcomes that one obtains." The value of a benefit determines the extent to which people feel gratitude (Lane and Anderson 1976). Grateful people then tend to behave more generously toward benefactors (Tsang 2006); in a marketing context, this tendency should imply improved results (Raggio et al. 2013) and stronger social relationships (Bono and McCullough 2006; McCullough et al. 2008). Thus, gratitude represents a key mechanism by which firms' relationship investments translate into results, with a broad range of positive outcomes in terms of both performance and relationship enhancements (Fredrickson 2001; Palmatier et al. 2009). However, we know little about its potential role in structured relationship marketing efforts, such as a channel partner programs (Palmatier et al. 2009).

The fact that gratitude is of relevance in channel partner programs, however, is illustrated by this quote of a channel partner:

"The first impactful reward program I ever participated in was the Kodak Rewards Program... I mean it actually made me focus on selling Kodak and caused me to actively recommend Kodak over similar or equal products. As a result I earned many Kodak Points that I could spend on a few hundred different merchandise items. I ordered a few items including an iPod, Canon Camera, and even a TV. But the one that probably left the most lasting impression was a toothbrush... The OB Electric Toothbrush changed everything. I remember the enjoyment of brushing my teeth, of looking in the mirror and thinking, Thank You, Kodak. Thank You, Kodak..." (Movethechannel.com 2015, p.1) 
Indebtedness also is a basic feature of social exchanges, defined as "a state of obligation to repay another" (Greenberg 1980, p. 4). Indebtedness stems from the norm of reciprocity, which states that "(1) people should help those who have helped them, and (2) people should not injure those who have helped them" (Gouldner 1960, p. 171). In contrast with gratitude, it is an unpleasant state (Watkins et al. 2006), accompanied by negative emotions (Greenberg 1980), such that it is aversive (Greenberg and Shapiro 1971). In particular, it constitutes a violation of the sense of "ought" while repayment has not yet been made (Heider 1958), which may invoke feelings of guilt (Greenberg and Shapiro 1971).

Indebtedness also could be perceived as a threat to the recipient's status or power (Blau 1968; Homans 1961). In marketing and consumer research, indebtedness mostly appears in studies of gift giving or receiving (Babin et al. 2007; Larsen and Watson 2001), because receiving gifts can lead the recipient to feel indebted and perceive a need to reciprocate, which can further produce embarrassment or a sense of dependence (Belk and Coon 1993; Joy 2001). In psychology research, indebtedness goes hand-inhand with perceived inequity and restrained freedom (Marcoux 2009), which may invoke reactance. The amount of felt indebtedness increases with the value of the benefit, and actions to repay generally follow an exchange norm, such that they should not exceed the value of the original benefit - a situation distinct from that provoked by gratitude (Watkins et al. 2006; Wilke and Lanzetta 1982). Finally, empirical research suggests that feelings of indebtedness can harm relationships, because they lead the recipient to try to avoid the benefactor (McCullough et al. 2008).

Despite their potential simultaneous occurrence, extant literature offers sparse insight into the relationship between gratitude and indebtedness and their interplay. In one exception, Watkins et al. (2006) show, across two studies, that gratitude and indebtedness correlate positively but also are clearly dissociated.

\section{Antecedents of Gratitude and Indebtedness}

Previous literature offers little insight into common or distinct antecedents of gratitude and indebtedness (Schaumberg and Flynn 2009), despite the evident value of such insights. For example, a costly favor should lead to stronger feelings of gratitude and indebtedness than a less costly one (Greenberg 1980; Lane and Anderson 1976; Tesser et al. 1968); gratitude and indebtedness both may arise if one person benefits from someone else's effort. In the context of channel partner programs, this would mean that more valuable programs would generate more gratitude or indebtedness. While different conceptualizations exist in the marketing literature (see e.g., Lapierre 2000; Sweeney 2001), most research defines perceived value as an assessment of the utility of a product or service, based on perceptions of benefits versus costs (Dodds et al. 1991). Other researchers (e.g., Hunt and Morgan 1995; Hamel and Prahalad 1994) view value as determined more by the benefits; therefore we conceptualize program value as an overall assessment of the perceived benefits of the channel partner program. 
For gratitude to result, the recipient must also believe that the benefactor has provided the benefit with good intentions (McAdams and Bauer 2004); that is, to feel grateful, the recipient must recognize that a benefit was given intentionally and attribute positive intentions to the giver (Gouldner 1960). Several experimental studies indicate that a benefactor's intentionality strongly elicits gratitude (Tsang 2006, 2007), such that participants experience stronger gratitude toward benefactors who help them out of benevolent rather than ulterior motives.

Basing on earlier literature (Bendapudi et al. 1996; Martin 1994, Rifon 2004), we thereby conceptualize ulterior motives as perception of the supplier's motives as being ultimately concerned with increasing the supplier's own welfare. Benevolent motives, in contrast, have the perceived goal of enhancing the welfare of the person who receives the benefit (Bendapudi et al. 1996; Martin 1994). Yet research that operationalizes benevolent and ulterior motives as opposite ends of a spectrum may not reflect reality, because suppliers often try to achieve multiple goals simultaneously when investing in partner programs. In addition, a benefit recipient likely feels indebted if he or she perceives that the benefactor is more concerned with the recipient's benefit than his or her own welfare. Greenberg and Frisch (1972) show that receiving deliberate, as opposed to accidental, help causes more intense feelings of indebtedness and obligation.

\section{Entitlement}

Entitlement is "an expectation that one should or ought to receive something" (Xia et al. 2010 , p. 3), based on existing norms, such that a person's claim of entitlement rests on the presence of some attribute in a social context (Feather 2003). Gouldner's (1960) formulation of the norm of reciprocity offers a "good example of a generally applicable standard of entitlement" (Lerner 1987, p. 108), because reciprocity, as an element of a social structure, can give rise to entitlement if granting someone else a benefit leads the provider to demand repayment of a similar favor. Psychological entitlement is the "stable and pervasive sense that one deserves more and is entitled to more than others" (Campbell et al. 2004, p. 31), and it could determine the amount of gratitude and indebtedness a person feels. Psychological entitlement is a component of narcissism, which suggests a personal baseline level of entitlement.

A sense of entitlement also might reflect situational factors, however (Haisley and Loewenstein 2011). Most empirical research on entitlement stems from narcissism literature in social psychology (Campbell et al. 2004). Entitled people typically expect a reward in accordance with a social contract, rather than directly in exchange for their own efforts or character (Campbell et al. 2004). Campbell et al. (2004) also show that entitlement is stable across time, and it occurs across cultures (Butori 2010), so it seems particularly relevant for international channel partner programs. 


\section{HYPOTHESES}

\section{Simultaneous Effects of Gratitude and Indebtedness}

Gratitude represents a positive feeling (Lazarus and Lazarus 1994) or pleasant state that has social effects, in that it helps secure supportive social relationships (Bono and McCullough 2006) and prompts prosocial responses (Naito et al. 2005). That is, gratitude helps maintain close relationships and solidify new ones (McCullough et al. 2008), often through reappraisals of the benefactor's positive qualities (Algoe et al. 2008; Young 2006). Because feelings affect judgments, people decide whether to trust someone by interpreting their feelings (Jones and George 1998).

In line with previous work (Palmatier et al. 2009), we expect that gratitude will increase a channel partner's commitment to the supplier. Gratitude can further invoke broad, creative thoughts and actions and lead to a broad range of positive outcomes (Fredrickson 2001, 2004). When people feel grateful, they behave more generously toward their benefactors (Tsang 2006) and are more willing to explore various actions to repay them (Bartlett and DeSteno 2006; Fredrickson 2001). In many situations, they even go beyond repayment of a perceived debt (Tsang 2006), such that gratitude could help ensure the payoff of firms' investments in partner relationships. Feelings of gratitude lead consumers to alter their purchase behaviors (Dahl et al. 2003; Morales 2005) and business customers to increase their share of wallet and sales. We therefore expect gratitude to have a positive impact on the effort the retailer salesperson expends when selling and promoting the manufacturer's products and services.

Social exchange literature also highlights the role of indebtedness, though many researchers conceptually and empirically equate gratitude with indebtedness (e.g., Komter 2004). We instead regard them as distinct and anticipate that they yield different action tendencies (Frijda 1986). Indebtedness may be perceived as a threat to the recipient's status (Homans 1961) or power (Blau 1968) or reduce his or her perceived freedom (Brehm and Cole 1966). This unpleasant state (Watkins et al. 2006) likely invokes mixed emotions (Greenberg 1980). Indebtedness also relates more to avoidance than approach goals (Greenberg 1980), such as desires to avoid the benefactor (Watkins et al. 2006).

The indebted channel partner may thus seek to avoid the supplier that provided the program benefits. Because feeling indebted is aversive, people are motivated to reduce the feeling when it occurs, whether by repaying or by reinterpreting the situation (Greenberg 1980). Illustrating this, one participant in a recent qualitative study mentioned: "indebtedness is when you receive something but you think you need to compensate. And I don't like being in that position" (p. 12, Schmit 2012). If repayment gets induced, it is likely to follow a direct exchange norm. This means that the amount repaid will at most be equal to the benefit received (Watkins et al. 2006).

In some situations, however, it may not be obvious how to repay the benefactor. While some channel partners consider selling more of the supplier's products as a form of repayment for training and incentives, others may look for more direct ways of re- 
payment and fail to contrive viable options. Even when repayment does occur, this averse feeling might lead to a reduced repayment as negative emotions narrow individuals' thought-action repertoires by calling forth specific action tendencies and thus narrowing attention (Fredrickson et al. 2003; Fredrickson and Branigan 2005). In addition, feeling indebted after receiving a benefit may be closely related with feelings of subjugation or oppression due to expectations in the relationship (Marcoux 2009). Individuals feeling the pressure of having to repay a benefit might lead to the individual disliking the benefactor (Gergen, Ellsworth, Maslach, \& Seipel, 1975). In this case, partners should not be expected to expend their full effort promoting the manufacturer's products and services. In turn, firms that provide benefits to channel partners might not achieve the payoffs they expect.

Despite the apparent contrast between indebtedness and gratitude, one of the few studies that examine these constructs simultaneously indicates that both can occur simultaneously within a person (Watkins et al. 2006). A channel partner, for example, may feel grateful for provided training when the training increased her knowledge on a particular technical innovation featured in this and other suppliers' recent products. At the same time she may feel slightly obligated to promote the focal supplier's products over others' because of their investment in her education. This may result in mixed feelings about the training and the supplier.

In situations in which positive and negative emotions occur simultaneously, the broaden-and-build theory of emotions predicts that the adverse effects of negative emotions get counterbalanced or even undone by positive emotions (Fredrickson 2001, 2004). Specifically, positive and negative emotions have distinct, complementary functions and physiological effects (Tugade and Fredrickson 2007), and positive emotions in particular seem able to physiologically down-regulate negative emotions or responses (Fredrickson and Levenson 1998; Tugade and Fredrickson 2007) by enlarging the cognitive context (Isen 1987), which increases dopamine in the brain (Ashby and Isen 1999). Thus positive emotions do not necessarily undo negative emotions; rather, they undo their effects on a broad array of outcomes (Tugade and Fredrickson 2004). The channel partner in our example may thus be more likely to feel and act positively, as gratitude dampens the effects of feelings of obligation and indebtedness. We thus predict that the negative effects of indebtedness on relational and performance outcomes get buffered by higher levels of gratitude.

H1: Gratitude attenuates the negative impacts of indebtedness on (a) sales effort, and (b) commitment

\section{Antecedents of Gratitude and Indebtedness}

Feeling grateful includes "the benefit, the beneficiary, and the benefactor" (Lambert et al. 2009, p. 1194) and occurs when the benefit provided is costly, intentional, voluntary, and of value to the beneficiary (McCullough et al. 2008; Schaumberg and Flynn 2009). For example, a costly favor elicits stronger feelings of gratitude than a less costly one in experimental studies (Lane and Anderson 1976; Tesser et al. 1968). Building on sociol- 
ogy research, Palmatier et al. (2009) show that relationship investments lead to more gratitude in business-to-business settings. A positive assessment of the value of a channel partner program thus should lead to gratitude among participating salespeople; the more valuable they perceive the program to be, the higher their gratitude.

Similarly, when indebtedness is evoked, it should be greater when the benefit is of higher value to the recipient (Greenberg 1980); the costs to the benefactor and benefits for the recipient increase reported levels of indebtedness (e.g., Greenberg and Shapiro 1971; Wilke and Lanzetta 1982). Although Tsang (2007) rejects this notion empirically in a laboratory study, we expect that favor value increases indebtedness, such that if the channel partner perceives the relationship program to be useful and of value, indebtedness should increase.

H2: Higher program value increases (a) partner gratitude and (b) partner indebtedness

Another critical determinant of gratitude is whether the benefit has been provided with good intentions (McAdams and Bauer 2004). If an action is not intentional, it might not generate gratitude (Bonnie and de Waal 2004). In addition, the recipient must attribute good intentions to the benefactor (Gouldner 1960). In a buyer-seller relationship, actors infer their exchange partners' motives and intentions, including whether they are likely to be beneficial (Ganesan 1994). These inferences then define their perceptions of marketers' actions, which may have positive or negative consequences (Campbell and Kirmani 2000).

A partner with benevolent motives subordinates its immediate self-interest for the long-term benefit of both parties (Geyskens et al. 1998), unlike those focused on their own welfare. General perceptions of the supplier's benevolence likely vary among participants in the program, according to their prior experiences with the supplier or their assessments of the supplier's prior transaction-specific investments (Ganesan 1994). The recognition that the supplier provides the partner program intentionally should generate more positive attributions regarding its motives, engage the partner's emotional systems, and increase feelings of gratitude (Palmatier et al. 2009; Schaumberg and Flynn 2009).

Based on literature on interpersonal relationships (Heider 1958), indebtedness literature suggests that the motives behind benefit provision also play an important role in indebtedness. Greenberg (1980) argues that people are socialized to recognize and respond to altruistic or benevolent acts as reinforcing the benefactor's altruism leads to more stable and predictable outcomes for the individual over time. From a societal or group perspective, when partners are socialized to recognize altruism, they are obligated to reciprocate when a benefit is received. Hence, benevolent motives should lead to higher levels of indebtedness.

H3: Perceived benevolent motives lead to (a) higher gratitude and (b) higher indebtedness 
We have little evidence to predict when gratitude or indebtedness is more likely (Schaumberg and Flynn 2009). Watkins et al. (2006) show that following a favor, greater expectations of returns reduce feelings of gratitude and increase feelings of indebtedness. Accordingly, we propose that if partners perceive ulterior motives for the channel partner program, such as the supplier's own profit, they experience indebtedness rather than gratitude. The suspicion of ulterior motives makes the exchange relationship more salient and prompts specific relationship norms and expectations, including a tit-for-tat mentality (Clark and Mills 1979). Because they perceive an implied expectation to repay the supplier in some form for the benefit (i.e., partner program), salespeople may sense obligation and feel indebted (Watkins et al. 2006).

H4. Perceived ulterior motives lead to higher indebtedness.

\section{The Moderating Role of Entitlement}

Entitlement, or the expectation of receiving something, is not necessarily based on equitable exchanges (Campbell et al. 2004; Singer 1981; Xia et al. 2010). More entitled people are less likely to give and more likely to accept gifts (Harvey and Martinko 2009). When they receive benefits, they tend to construe it as a reward rather than benevolence (Campbell et al. 2004), so they experience less gratitude. Furthermore, entitled partners expect suppliers to go out of their way continuously to help and benefit them. Even if she or he regards it as valuable, an entitled partner therefore feels less grateful for a program than does a less entitled person.

As we argue, ulterior motives are expected to give salience to the exchange nature of the relationship and related relationship norms, priming a tit-for-tat mentality and an implied expectation to repay the supplier (Clark and Mills 1979; Watkins et al. 2006). In a situation in which exchange norms are triggered by ulterior motives, this should be even more impactful for entitled partners as they tend to be more suspicious of others' motives (Emmons 1984), expect exchange processes to be exploitative (Boyd and Helms 2005), and are more selfish than prosocial (van Dijk and De Cremer 2006). These expectations lead to a biased perception of relational exchanges. Consequently, a channel partner high in entitlement - when compared to a partner low in entitlement - may feel an even stronger obligation to repay benefits which are perceived to be motivated by supplier self-interest. We thus expect entitlement to increase the effect of ulterior motives on indebtedness.

H5. Entitlement (a) attenuates the positive impact of perceived program value on gratitude and (b) increases the positive effect of ulterior motives on indebtedness.

Shown in Figure 2.1, our conceptual model builds on prior relationship marketing research that investigates commitment and gratitude as foundations for closer, more profitable relationships (Morgan and Hunt 1994; Palmatier et al. 2006, 2009). We add a consideration of indebtedness, which relates to but is distinct from gratitude, and their interplay. We also integrate the important moderating role of entitlement. 


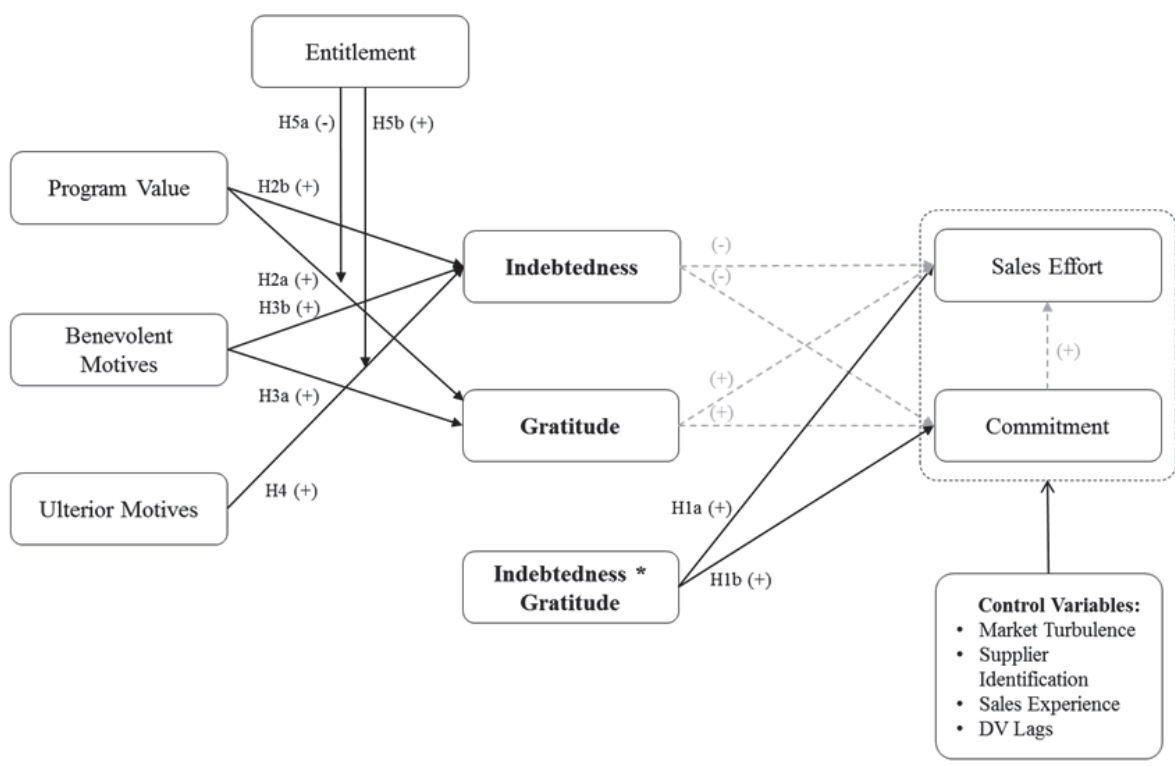

Figure 2.1: Conceptual Model

NB: Dashed arrows represent non-hypothesized relationships

\section{RESEARCH SETTING}

To test our hypotheses, we conducted an international field study in cooperation with a market-leading, global, Fortune 100 computer technology service and solutions provider. We collected a database of multi-wave survey and secondary data from salespeople who participated in the firm's channel partner program; 2,664 reseller salespeople were randomly selected from the database of active program participants, invited by e-mail to participate, and promised bonus points in the channel partner program as incentives to encourage their participation. We then collected the data for this study in three international survey waves during one program year (the measures, scale sources, and item loadings are in Appendix 2.1).

The channel partner program launches each year, with new content and communications. The first survey wave was sent out shortly after re-launch, the second wave three months later and the third and final wave was sent approximately seven months after the second. While the main measures in our study are derived from waves one and three, we also measured our dependent variables in wave two in order to include lagged terms for the dependent variables in our analysis. 


\section{Sample}

The final sample consisted of 284 reseller salespeople who completed the full questionnaires for all waves, for a total response rate of $10.6 \%$. The salespeople responded to scales that measured their satisfaction with the program and its offered rewards, their perceptions of the supplier's motives for providing the partner program, and their feelings of gratitude and indebtedness. They also indicated their sense of entitlement and the amount of effort they put into the learning modules. Finally, the respondents completed scales measuring their commitment to the supplier and their own perceived sales effort relative to other sellers in the organization.

In addition to the online survey, we obtained sales data from company records for some of the respondents, namely, those who exploited the option of logging their sales in the program to gain additional rewards. We received data about the logged sales of 51 resellers during the six months prior to and after the final survey wave.

\section{Validity and Reliability}

We evaluated the psychometric properties of the constructs in our field study using SmartPLS version 3.0 (Ringle et al. 2015). The indicator items' loadings on the latent variables were greater than .6, indicating good indicator reliability. The composite reliability scores above .8 exceeded the recommended minimum levels, in support of good internal consistency (Nunnally and Bernstein 1994). In support of convergent validity, the average variances extracted (AVE) of the constructs were greater than .5 (Hair et al. 2011; Hair et al. 2014); the minimum AVE was .61. As the correlations in Table 2.1 reveal, several constructs correlate significantly.

To assess the discriminant validity of the measurement model, we employed Fornell and Larcker's (1981) criterion; each latent construct shared more variance with its assigned indicators than with any other latent variable in the structural model. Finally, as a test of common method bias, we produced a Schmid-Leiman solution (Podsakoff et al. 2003; Schmid and Leiman 1957; Wolff and Preising 2005) in R using the psych package (Revelle 2015). The general factor accounted for $32 \%$ of the variance on average, indicating no issues. 


\section{CHAPTER TWO}

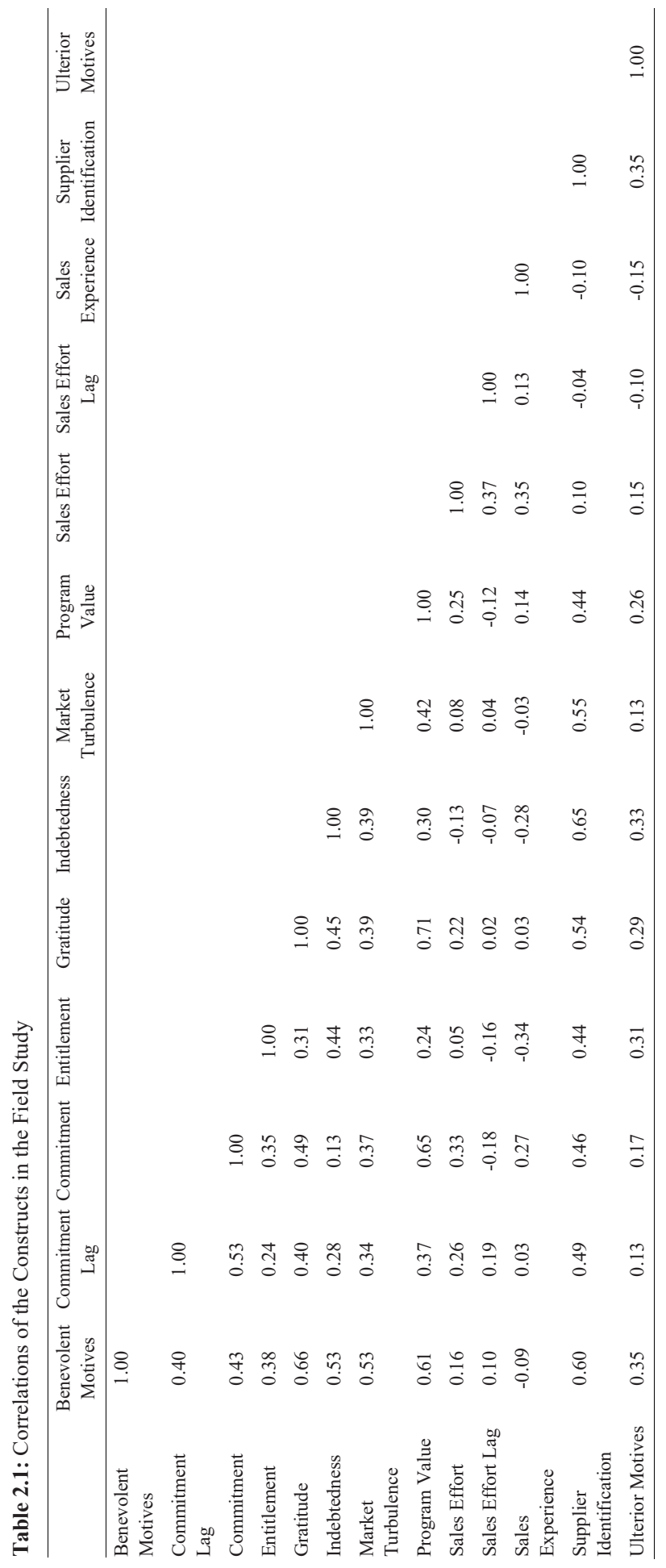




\section{RESULTS}

\section{Main Analyses}

Because our measurement scales proved reliable, with high levels of validity, we used a partial least squares (PLS) model to test our hypotheses, with SmartPLS v3.0 (Ringle et al. 2015) for both the measurement and the structural model (Hair et al. 2012). We chose PLS path modeling for its suitability in estimating complex models (Chin 1998), its superior performance compared with regression analysis or covariance-based methods when testing moderating hypotheses, and its superior predictive performance (Chin et al. 2003). We used bootstrapping with 1000 resamples to obtain the standard errors for the estimates, which allowed us to test the statistical significance of the parameter estimates (t-values). Interaction effects were estimated using a two-stage interaction model (Goodhue et al. 2007), which is the default approach in SmartPLS v3.0 (Ringle et al. 2015). It employs latent variable scores of the latent predictor and latent moderator variable from the main effects model without the interaction term. These latent variable scores are consequently saved and used to calculate the product indicator for the second stage analysis, which adds the interaction term to the first stage model (Ringle et al. 2015).

We investigated the R-square values for the endogenous variables to assess model quality (Cohen 1988), which was acceptable. To assess potential multicollinearity, we calculated the variance inflation factor (VIF). This highest VIF statistic observed across our analyses was 2.61, suggesting no multicollinearity issues (Hair et al. 2011). In addition, we calculated the Q-square statistic for all endogenous variables to assess the predictive validity of the independent variables and mediators (Hair et al. 2012). The crossvalidated redundancy measures (Q2) were at least equal to .24, indicating the predictive relevance of the variables. In line with Tenenhaus et al. (2005), we calculated a global goodness-of-fit (GoF) criterion for our model, using the geometric mean of the average communality and average R-square, yielding a GoF index of .62. Thus, our model performed well (Wetzels et al. 2009).

Table 2.2: Field Study Results for Sales Effort and Commitment

\begin{tabular}{|c|c|c|c|c|}
\hline \multirow[t]{2}{*}{ Constructs } & \multicolumn{2}{|c|}{ Sales Effort } & \multirow[b]{2}{*}{$\beta$} & \multirow{2}{*}{ Commitment } \\
\hline & $\beta$ & t-values & & \\
\hline Gratitude & 0.20 & 2.31 & 0.42 & 6.76 \\
\hline Indebtedness & -0.19 & 2.30 & -0.31 & 6.06 \\
\hline Commitment & 0.27 & 3.49 & & \\
\hline Gratitude * Indebtedness & 0.10 & 1.93 & 0.18 & 5.24 \\
\hline Supplier Identification (control) & 0.06 & 0.64 & 0.29 & 4.57 \\
\hline Market Turbulence (control) & -0.05 & 0.66 & 0.11 & 2.30 \\
\hline Sales Experience (control) & 0.16 & 2.81 & 0.16 & 4.07 \\
\hline Commitment lag (control) & & & 0.30 & 5.87 \\
\hline Sales Effort lag (control) & 0.42 & 6.40 & & \\
\hline R Squared & & 0.37 & & 0.55 \\
\hline
\end{tabular}


Table 2.3: Field Study Results for Gratitude and Indebtedness

\begin{tabular}{llllll}
\hline Constructs & Gratitude & & & \multicolumn{2}{l}{ Indebtedness } \\
\cline { 2 - 3 } \cline { 5 - 6 } & $\beta$ & t-values & & $\beta$ & t-values \\
\hline Program Value & 0.46 & 5.63 & & -0.05 & 0.65 \\
Ulterior Motives & 0.04 & 0.63 & & 0.12 & 1.69 \\
Benevolent Motives & 0.33 & 3.39 & & 0.41 & 4.41 \\
Entitlement & 0.11 & 1.80 & & 0.26 & 4.43 \\
Entitlement * Program Value & -0.18 & 3.46 & & \\
Entitlement * Ulterior Motives & & 0.08 & & 1.77 & \\
\hline R Squared & & 0.62 & & 0.37
\end{tabular}

The results of our main analyses can be seen in Tables 2.2 and 2.3. Because the twostage approach to interaction analysis we employ is based on latent variable scores, which can be considered a continuous variable with arbitrary values, we also employ Floodlight tests (Spiller et al. 2013) with the Johnson-Neyman point (cf. Johnson and Neyman, 1936; Preacher et al., 2006). These tests and the respective plots were produced in $\mathrm{R}$ using the rockchalk package on the basis of asymptotic standard errors (Johnson 2015).

We find that gratitude exerted a significant, positive, main effect on both dependent variables: sales effort $(\beta=.20, \mathrm{t}=2.31, p<.01)$ and commitment $(\beta=.42, \mathrm{t}=6.76, p<$ $.01)$. Indebtedness instead had a negative effect on sales effort $(\beta=-.19, \mathrm{t}=2.30, p<.01)$ and commitment $(\beta=-.31, \mathrm{t}=6.06, p<.01)$. The interaction term between gratitude and indebtedness had a significant and positive effect on sales effort $(\beta=.10, \mathrm{t}=1.93, p<.05$ one sided) and commitment $(\beta=.18, \mathrm{t}=5.24, p<.01)$. Figure 2.2a illustrates this interaction effect, as indebtedness shows a negative effect on sales effort at lower levels of gratitude. This effect decreases for higher levels of gratitude. Figure 2.3a shows a similar pattern for commitment, illustrating that gratitude buffers against the negative effect of indebtedness.

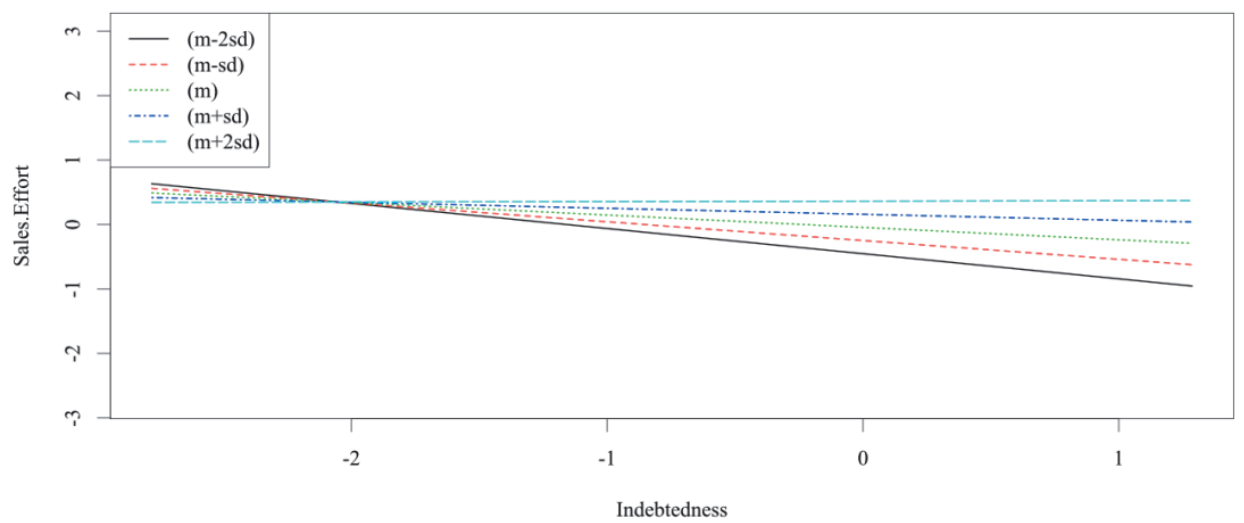

Figure 2.2a: Effects of Indebtedness on Sales Effort at Different Levels of Gratitude 


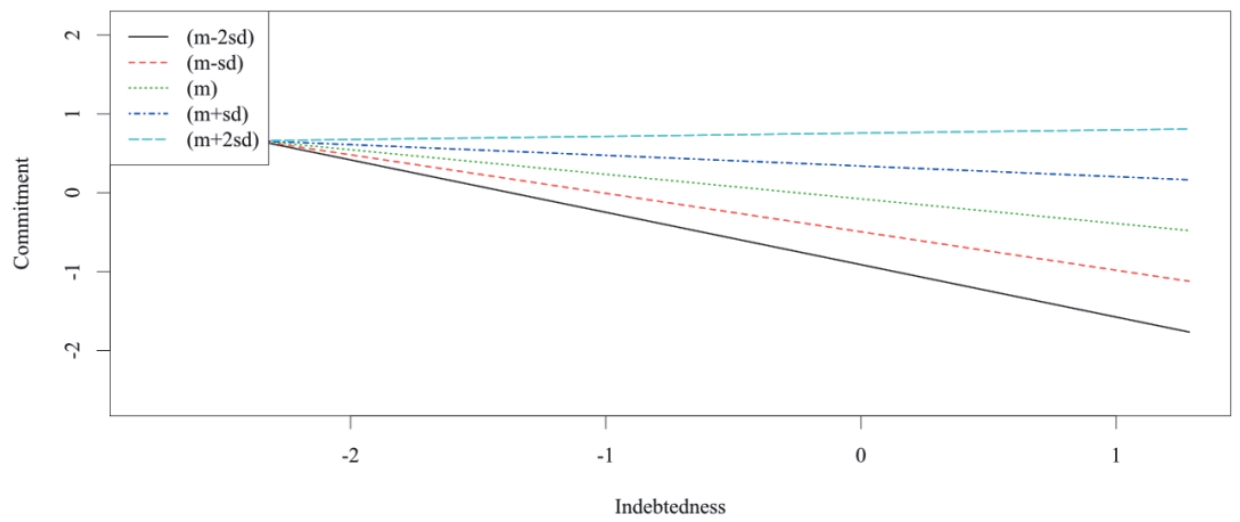

Figure 2.3a: Effects of Indebtedness on Commitment at Different Levels of Gratitude

Figure $2.2 \mathrm{~b}$ shows the marginal effect of indebtedness at different levels of gratitude. ${ }^{1}$ The shaded region in this type of graph represents values of the moderator at which the effect of the independent variable will be statistically significant. In this case, the negative effect of indebtedness on sales effort becomes insignificant at values of gratitude higher than 0.56 standard deviations from the mean. Figure $2.3 \mathrm{~b}$ shows a similar pattern for commitment, as the negative effect of indebtedness approaches insignificance at high levels of gratitude. ${ }^{2}$ We thus found support for both, H1a and H1b.

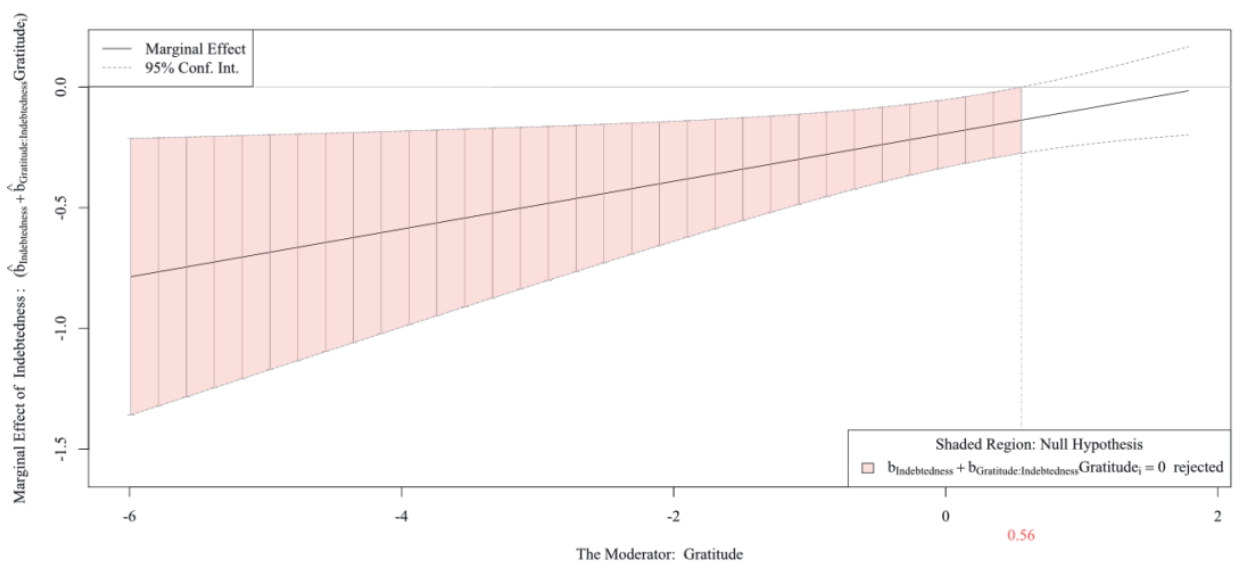

Figure 2.2b: Marginal Effect of Indebtedness on Sales Effort at Different Levels of Gratitude

\footnotetext{
${ }^{1}$ Variables in the analysis are standardized; for the unstandardized gratitude construct, $\mathrm{M}_{\text {Gratitude }}=6.07$, $\sigma_{\text {Gratitude }}$ $=0.82$.

${ }^{2}$ We found the same substantive results for trust as dependent variable (scale adapted from Morgan and Hunt 1994). For the sake of brevity, we focus only on the results for commitment in this manuscript.
} 


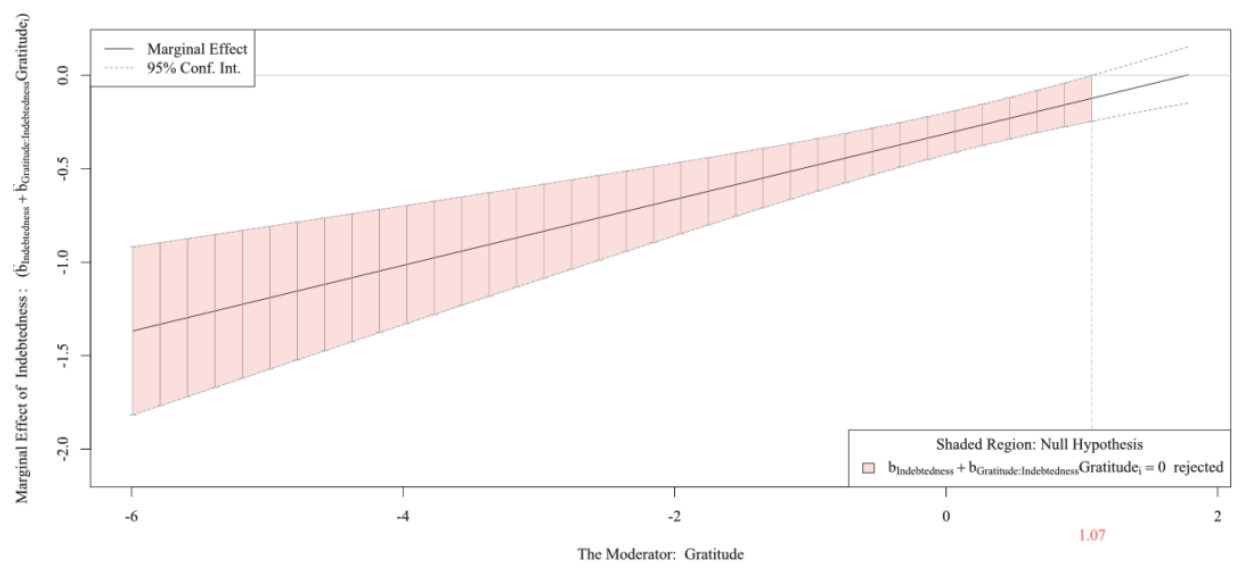

Figure 2.3b: Marginal Effects of Indebtedness on Commitment at Different Levels of Gratitude

For the drivers of gratitude and indebtedness, we found a significant, positive impact of perceived program value on gratitude $(\beta=.46, \mathrm{t}=5.63, p<.01)$, in support of $\mathrm{H} 2 \mathrm{a}$, but no significant impact on indebtedness $(\beta=-.05, \mathrm{t}=.65$, n.s. $)$, in contrast with $\mathrm{H} 2 \mathrm{~b}$. Perceptions of benevolent motives increased both gratitude $(\beta=.33, \mathrm{t}=3.39, p<.01)$ and indebtedness $(\beta=.41, \mathrm{t}=4.41, p<.01)$; perceptions of ulterior motives increased indebtedness $(\beta=.12, \mathrm{t}=1.69, p<.05$, one-sided $)$ but not gratitude $(\beta=.04, \mathrm{t}=.63$, n.s.). Therefore, $\mathrm{H} 3 \mathrm{a}, \mathrm{H} 3 \mathrm{~b}$, and $\mathrm{H} 4$ received support.

Entitlement decreased the positive effect of program value on gratitude $(\beta=-.18, \mathrm{t}=$ $3.46, p<.01)$, in line with H5a, and strengthened the sense of indebtedness triggered by ulterior motives $(\beta=.08, \mathrm{t}=1.77, p<.05$ one sided $)$, in support of H5b. To facilitate the interpretation of these interactions, we once again employed the $\mathrm{R}$ package rockchalk for further analyses (Johnson 2015; Spiller et al. 2013). As illustrated in Figure $2.4 \mathrm{a}$, we find that program value has a considerable effect on gratitude when entitlement is high. At lower levels of entitlement, however, this effect becomes much less pronounced. Figure 2.5a shows how strongly perceived ulterior motives increase indebtedness for channel partners with high entitlement. On the other hand, ulterior motives do not seem to trigger indebtedness in partners with low entitlement. 


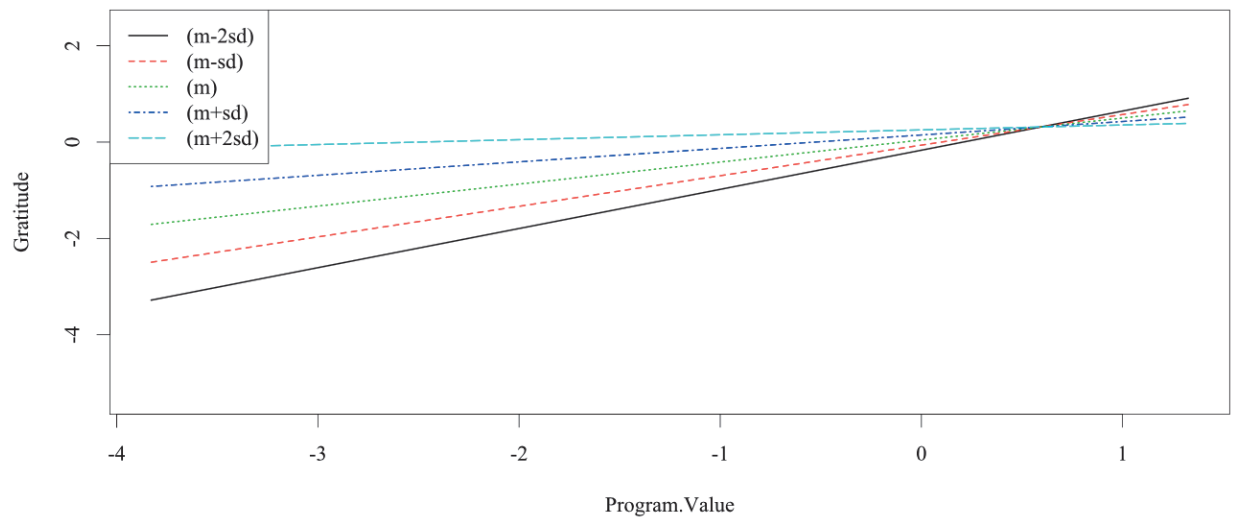

Figure 2.4a: Effects of Program Value on Gratitude at Different Levels of Entitlement

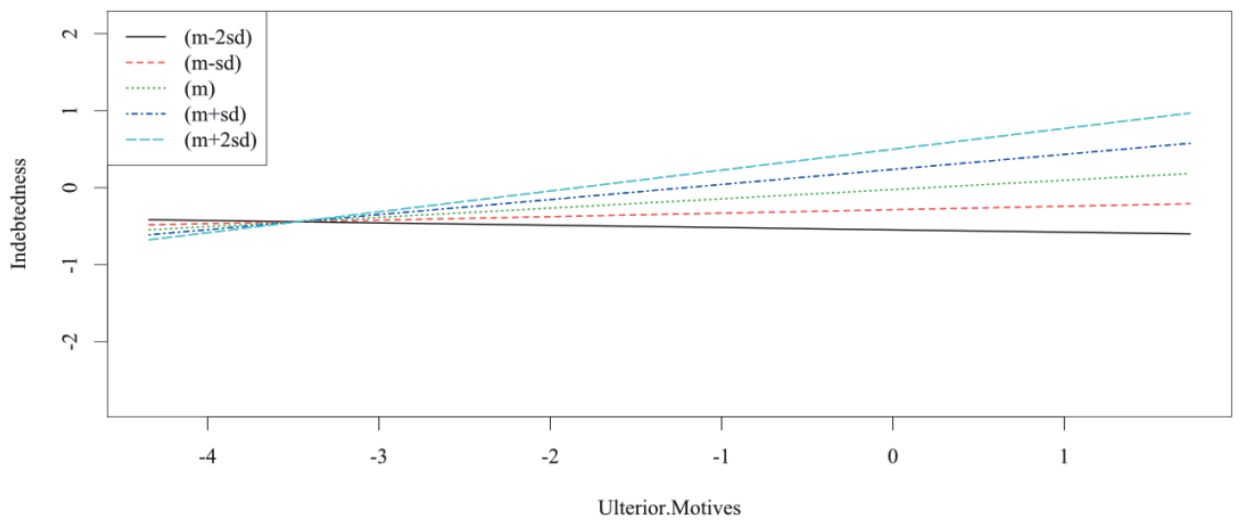

Figure 2.5a: Effects of Ulterior Motives on Indebtedness at Different Levels of Entitlement

Figure $2.4 \mathrm{~b}$ illustrates the marginal effect of program value on gratitude at different levels of entitlement. ${ }^{3} \mathrm{We}$ observe that the effect of program value becomes insignificant at values of entitlement greater than 1.55 standard deviations from the mean.

\footnotetext{
${ }^{3}$ Variables in the analysis are standardized; for the unstandardized entitlement construct, $\mathrm{M}_{\text {Entitlement }}=4.80$, $\sigma_{\text {Entitlement }}=1.09$.
} 


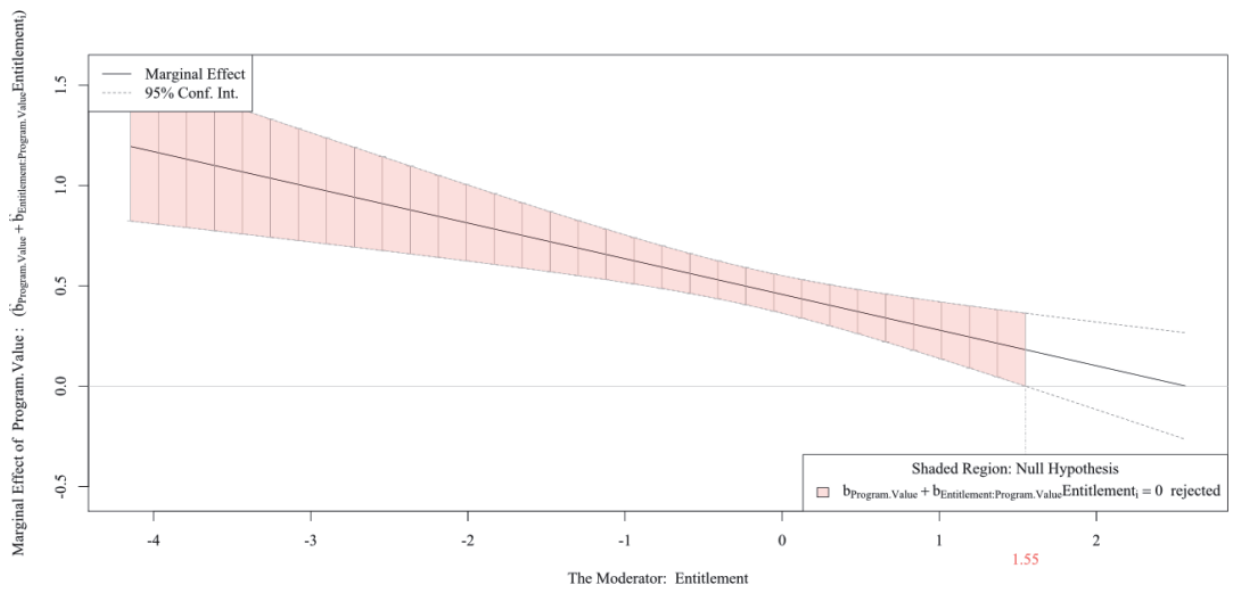

Figure 2.4b: Marginal Effects of Program Value on Gratitude at Different Levels of Entitlement

Figure $2.5 \mathrm{~b}$ on the other hand, shows that the effect of ulterior motives on indebtedness becomes insignificant at levels lower than -0.22 standard deviations from the mean of entitlement. These results provide further support for $\mathrm{H} 5 \mathrm{a}$ and $\mathrm{H} 5 \mathrm{~b}$.

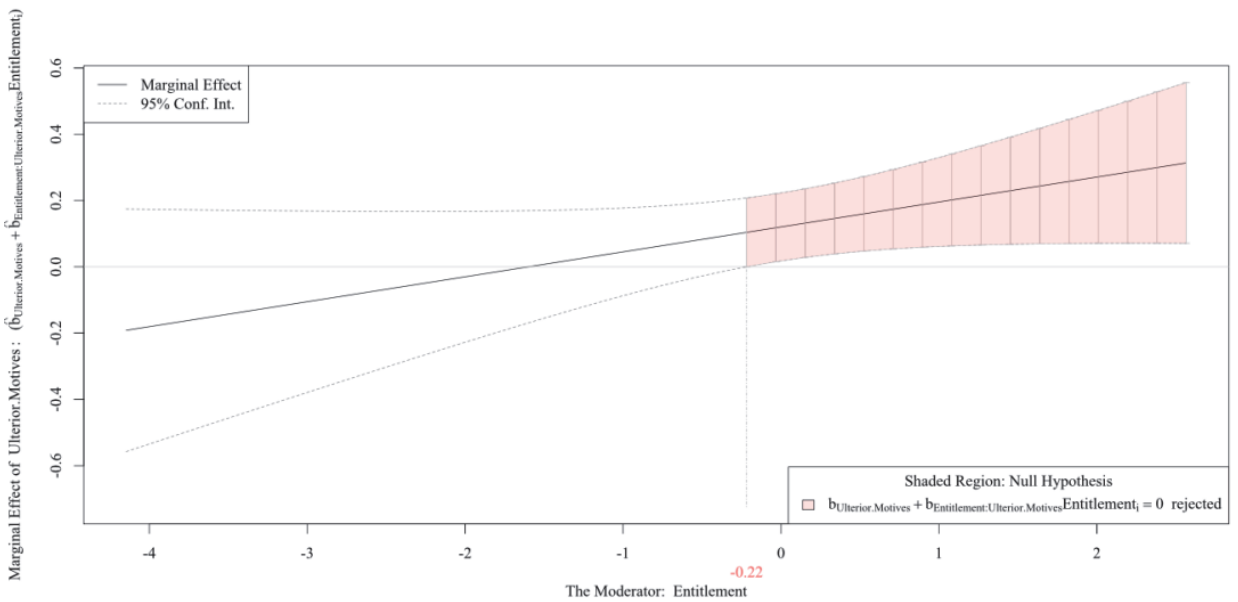

Figure 2.5b: Marginal Effects of Ulterior Motives on Indebtedness at Different Levels of Entitlement

For our dependent variables, we included several seller-level variables as controls. Sales experience significantly influenced sales effort $(\beta=.16, \mathrm{t}=2.81, p<.01)$ and commitment $(\beta=.16, \mathrm{t}=4.07, p<.01)$. Supplier identification had significant effects only on commitment $(\beta=.29, \mathrm{t}=4.57 p<.01)$, which holds true also for market turbulence $(\beta=$ $.11, \mathrm{t}=2.30, p<.05)$. In addition, we controlled for the lagged effect of each dependent variable; it exerted a significant impact on sales effort in the final wave of our survey ( $\beta$ $=.42, \mathrm{t}=6.40, p<.01)$, as it did on commitment $(\beta=.30, \mathrm{t}=5.87, p<.01)$. 


\section{Robustness Test}

As a robustness test, we assessed the interplay of gratitude and indebtedness in a $2 \times 2$ between-subjects experimental design, with data collected from 124 business students. In this laboratory setting, participants assigned randomly to a condition recalled and described a shopping interaction with a salesperson that made them feel grateful, indebted, or both, or they completed a control condition (Petty et al. 1993; Watkins et al. 2003, 2006; Wood et al. 2010). Participants then indicated their attitude towards the store or company on a 3-item scale adapted from Mittal (1990) as well as their gratitude and indebtedness on scales similar to those in our field study that were slightly adapted to the context. Manipulation checks confirmed the mood induction; the factor analysis indicated good psychometric properties for the constructs (Netemeyer et al. 2003).

To evaluate whether gratitude buffered the deleterious effects of indebtedness, we employed planned contrasts, while controlling for how long ago the shopping experience took place $(M=7.98$ months $)$. The overall interaction was not significant $(p>.1)$, yet respondents in the indebtedness-only condition expressed significantly less positive attitudes toward the store $(M=5.12)$ than any other condition $(p<.05)$. The difference between gratitude conditions with $(\mathrm{M}=5.83)$ and without $(\mathrm{M}=5.91)$ indebtedness was not significant $(\mathrm{p}=.76)$. This finding lends further support to the prediction that gratitude buffers the negative effect of indebtedness. It also confirmed our choice of measures and the treatment of gratitude and indebtedness as distinct constructs.

\section{GENERAL DISCUSSION}

To refine currently prevailing perspectives on relational exchanges focusing on gratitude (e.g., Palmatier et al. 2009), we have introduced a related but distinct construct, indebtedness, as an important element that has the potential to diminish important relationship and performance outcomes. We assess not only its direct effects but also its interplay with gratitude. To provide a better understanding of the causes of both gratitude and indebtedness, we assess the conditions that favor grateful versus indebted responses in business-to-business channel partner programs, highlighting particularly the role of benevolent and ulterior motives. Finally, we add to recent relationship marketing research by shedding light on the influence of entitlement in relation to drivers of gratitude and indebtedness.

As our major contribution, we propose that gratitude and indebtedness are central elements of channel partner programs, with important individual and joint impacts. Emergent marketing theory highlights the centrality of gratitude in business relationships (Palmatier et al. 2009; Wetzel et al. 2013) and illustrates how it can transform investments in customers and business partners into positive firm outcomes. However, with some notable exceptions (Samaha et al. 2011; Steinhoff and Palmatier 2014), existing marketing research has focused on the positive side of relational exchanges and neglected indebtedness, thus failing to capture the intricacies of an ongoing exchange 
and underestimating its performance-harming aspects. In addition, recent research has consistently called for research to incorporate longitudinal research designs to disentangle the intricate effects in relationship marketing (Palmatier et al. 2007; Palmatier et al. 2013). We build on this emerging literature base and adopt a multi-wave approach to study indebtedness and gratitude.

Although indebtedness and gratitude are often used interchangeably, they are distinct (McCullough et al. 2008) and invoke different outcomes. Few studies explicitly differentiate between them; to the best of our knowledge, this article is the first to investigate the interplay of gratitude and indebtedness in relationship marketing programs.

In our field study, gratitude had significant, positive effects on the channel partner's commitment to the supplier, as well as the reseller's sales effort; indebtedness however had negative effects on these outcomes. This is in line with prior research suggesting that indebted people tend to avoid their benefactors and become less likely to help them on unrelated dimensions (Greenberg 1980; McCullough et al. 2008).

For instance, when a firm like Cisco makes their partners feel like they owed something to the company for providing training and incentives in their partner program, partners may avoid their benefactor (Cisco) and be promote other suppliers' products to their customers. As a consequence, they are and be less likely to build or maintain a good relationship with their Cisco representative. This finding also highlights that firms that expect to increase their channel partners' productivity through partner programs may fail to achieve their expected returns. To enhance their performance, supplier firms should thus aim to prevent channel partners from feeling indebted. In addition, our results show that gratitude acted as a buffer against the negative effects of indebtedness. In line with the broaden-and-build theory of emotions (Fredrickson 2001), the positive emotion of gratitude thus reduced and even undid the effects of the negative emotion of indebtedness. This means that a channel partner who feels indebted to the supplier for having benefitted from the provided training may still expend higher effort selling the suppliers' products if he also feels grateful for the benefits received.

Taken together, these results help explain some prior equivocal findings regarding the outcomes of indebtedness or obligation (e.g., De Ruyter and Wetzels 2000; Goei and Boster 2005; Watkins et al. 2006). On the basis of our results, we expect positive outcomes when both gratitude and indebtedness are invoked but negative outcomes in situations in which indebtedness predominates or cannot be buffered by gratitude. The effect of gratitude appears positive for all outcomes.

In addition to the self-reported items in our field survey, we assessed actual sales logged by some resellers over a 6-month period after the survey; the post hoc tests $(\mathrm{n}=$ $51)$ showed that gratitude had a positive effect on actual logged sales $(p<.05$, onesided, 1000 bootstrap replications). Neither the main effect of indebtedness nor its interaction with gratitude reached significance in this post hoc test, however. This may at least in part be due to the small sample size for the objective data $(n=51)$, which was also the reason we were not able to replicate the whole conceptual model in this test. 


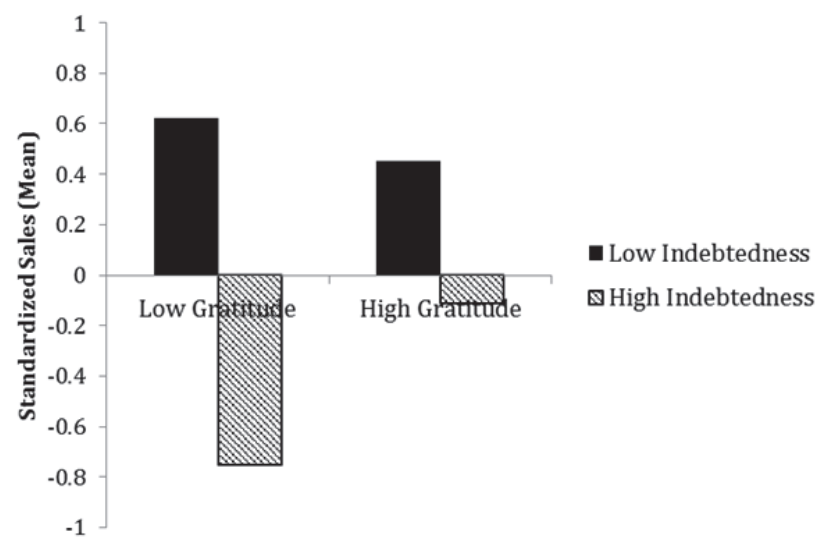

Figure 2.6: Post-Hoc Analysis of Gratitude and Indebtedness Effects on Actual Sales

To investigate this issue further, we employed a median split on the gratitude and indebtedness measurements and assessed actual logged sales (standardized for confidentiality reasons) in the resulting groups. The results are shown in Figure 2.6 and highlight two trends. First, the high-indebtedness groups both have much lower average sales than the low-indebtedness groups. Second, in the high-indebtedness conditions, this difference seems to be dramatically reduced when gratitude is high. This provides anecdotal support for our earlier findings on the buffering effect of gratitude on indebtedness.

On the basis of these post hoc findings, we posit that the positive effects of gratitude, as reported in prior research (e.g., Bono and McCullough 2006; McCullough et al. 2008) may have been due, at least in part, to the protection that gratitude offers against indebtedness' negative impact, rather than purely to a positive main effect. To assess the potential effects of relational exchanges more accurately, marketing research should embrace a dual perspective and examine gratitude and indebtedness simultaneously.

As a second major contribution, we shed light on factors that favor the dominance of either gratitude or indebtedness. Our findings confirm the influence of benefit value, because higher perceived program value significantly increases channel partner gratitude. However, post hoc tests indicate that adding reward value separately does not increase explanatory power $(p>.10)$. Channel partners seemingly evaluate the program holistically, rather than viewing the rewards as a separate factor. Overall then, program value is a determinant of gratitude. Motives also strongly determine channel partner gratitude, providing support for theorizing in early gratitude literature (Tesser et al. 1968). Unlike research that regards motives on a continuum, from benevolent to ulterior (e.g., Tsang 2006), we demonstrate that partner program members actually perceive motives in a more nuanced way. Benevolent motives increase gratitude, but ulterior motives do not detract from it. In a business-to-business setting, partners appear to allow for some measure of self-interest by suppliers. Further research could explore the boundaries for this effect. In combination though, the high percentage of variance explained in gratitude $\left(\mathrm{R}^{2}=.59\right)$ affirms the importance of benefit value and motives in determining gratitude in channel partner programs. 
Prior research on the conditions for indebtedness is more rare. In contrast with prior predictions (Greenberg 1980), we did not find that perceived program value effectively predicted indebtedness. Despite the different context, it seems relevant to note that Tsang (2007) also did not find that higher value increased self-reported gratitude in response to a favor. Therefore, further research should clarify the importance of favor value. However, in line with prior psychology research (Greenberg and Frisch 1972), this study shows that the motives for benefit provision help determine the level of indebtedness felt by program participants. That is, the perception of benevolent motives increases indebtedness, in line with Greenberg's (1980) predictions. Yet in contrast with gratitude, ulterior motives also increase indebtedness. Perhaps these ulterior motives make the exchange nature of the relationship more salient to the partner and thus trigger different relationship norms and expectations (Clark and Mills 1979) such that resellers then perceive an implied expectation to repay the supplier (Watkins et al. 2006).

In our study, motives have a direct effect, in line with theorizing in psychology literature pertaining to obligation and indebtedness (Gouldner 1960). In addition, these findings are notable in light of Morales's (2005) assertion that indebtedness relates more to personal benefits than does gratitude, and they provide empirical support for her claim that perceived motives are what matter, independent of a benefactor's actual motives.

In a business-to-business context, perceived ulterior and benevolent motives coexist, exerting different effects. We presume that in marketing relationships, suppliers and sellers frequently have multiple, possibly competing motives. For example, a salesperson may seek to increase sales - and thus her or his commission — while also searching to find a solution that pleases the customer. Nascent literature on ambidexterity at the individual level highlights a similar apparent paradox (Jasmand et al. 2012). We recognize that some salespeople, and especially experienced ones (on average, the salespeople in our sample had 8 years of experience in the sales function), likely know that their suppliers have their own agenda but still might want the best for their partners. The correlation between ulterior and benevolent motives in our sample is $.35(p<.01)$. Thus the two constructs, though related, are independent for practical purposes. Motives seem to play an important role in channel partner programs, which may be even more complicated than previously established.

As a third contribution, we highlight entitlement as an important source of heterogeneity with regard to the drivers of gratitude and indebtedness. In a channel partner program, entitlement decreases the positive effect of perceived program value on partner gratitude. Entitled channel partners expect to receive benefits from the supplier; even when they value them highly, they are less grateful than partners who feel less entitled. Entitlement relates to indebtedness in a different way, which further differentiates between gratitude and indebtedness. Our results show that partners with a heightened sense of entitlement are more prone to interpret suppliers' ulterior motives as a sign of an exchange relationship and to feel indebted. Entitlement thus indirectly and negatively affects the relational and performance outcomes of partner programs. Psychological entitlement constitutes part of a narcissistic personality; in a channel partner context, 
partners develop a sense of entitlement when they receive special treatment in the early stages of the relationship (Boyd and Helms 2005; Wetzel et al. 2013). Additional research should investigate ways firms might grant special attention to new partners, without increasing their entitlement. One way to facilitate and manage communication in these relationships is the he usage of new forms of communication, such as social media (Rapp et al. 2013). Therefore, researchers need to identify ways to combat feelings of entitlement in business-to-business relationships.

\section{Limitations and Further Research}

Although we draw our data from professional salespeople across multiple channel partner firms and geographies, our study is based on one channel partner program, operated by one supplier in the high-tech sector. The model likely would generalize to similar partner programs, but the generalizability of our findings to other industries may be limited. Further research should aim to replicate our findings across an array of programs to establish their validity in a broader range of channel partnerships and program designs. In addition, because we employed a survey as our main method of data collection, we cannot distinguish between person-specific effects, such as dispositional tendencies to be skeptical of seller programs, from construct-specific effects, such as the effects of perceived ulterior motives. Future research should test and extend our conceptual framework using different study designs and methods of data collection, to shed light on this distinction.

Although our experimental study provided further evidence of a buffering effect of gratitude in a consumer context, applications of our complete conceptual model to consumer markets require further testing. Because our results are the first to illustrate buffering effects of gratitude in a marketing setting, further research should replicate this effect and test its robustness across different scenarios, which may reveal some boundary conditions and explain additional heterogeneity.

This research also highlights the potential negative effects of indebtedness on reseller sales effort and commitment. In our post hoc analysis of objective sales data with a smaller sample of resellers, this effect did not reach statistical significance. This could be due, at least partially, to the small sample size $(\mathrm{n}=51)$, but an additional "gap" also might exist between the attitudinal outcomes and more objective outcomes, similar to the frequently observed gap between consumer intentions and behavior (e.g., Bagozzi and Dholakia 1999). Especially in our research context, where closing a sale can take multiple calls, we simply might not see these effects as clearly in the objective performance data. Therefore, further research should study this issue in more detail and seek to replicate the negative effects of indebtedness in different contexts, especially using objective performance data.

Our longitudinal approach effectively addresses concerns about common method bias and responds to calls for more longitudinal research to investigate the effects of gratitude over time (Palmatier et al. 2009). Additional research should continue to clarify the developments of different member segments, such as newcomers or experienced pro- 
gram members, and the impacts of gratitude and indebtedness along differing relationship trajectories.

In examining the drivers of gratitude and indebtedness, we have focused on perceived program value, perceived program motives, and the influence of entitlement. Although the R-square values for gratitude and indebtedness (average $=.49$ ) were substantial, other significant drivers still could exist. Additional research might try to identify other influential program factors and consider multiple partner programs. Furthermore, in our sample, satisfaction with the rewards did not contribute additional explanatory power, but other reward-related factors, such as selection or perceived reward value, may influence gratitude and indebtedness. Another factor to research as a potential trigger of indebtedness or gratitude is benefit framing. Inferred motives help determine the occurrence of gratitude or indebtedness; further research should clarify which aspects might be influenced when program providers communicate its benefits in certain ways.

Finally, we shed light on the moderating role of entitlement; further research should continue to refine the entitlement construct and other narcissistic tendencies, investigate subtleties with regard to trait versus state entitlement (cf. Haisley and Loewenstein 2011), and uncover ways that firms might grant special attention to new partners without increasing their entitlement. Such efforts could help clarify the overall impact of entitlement in channel partner programs.

\section{MANAGERIAL IMPLICATIONS}

For marketers, our research provides additional evidence of the importance of gratitude; some researchers suggest a smaller role of gratitude in structured relationship programs (e.g, Palmatier et al. 2009), but our results highlight its impact, even in a formal channel partner program. With our sample of worldwide channel partner salespeople, we affirm that gratitude appears culturally neutral, with robust effects. Thus program managers can confidently invest in program features that invoke gratitude, across the globe; other investments that do not trigger gratitude to a comparable extent, or which do not contribute to gratitude additionally such as the rewards in our post-hoc analysis, may be less culturally universal and less global in their impact. Yet managers also must realize the strict reciprocity can produce negative effects, so they need to manage their channel partner programs - and possibly all partner relationships - in a way that is conducive to gratitude but unlikely to cause feelings of indebtedness.

In terms of program-related implications, our results align with evidence that suggests avoiding any communication about expected repayments (Watkins et al. 2006). Rather, managers should carefully avoid any impression that they have mainly ulterior motives for providing these programs and also avoid explicitly or implicitly asking their partners to return any favors provided. For example, communications with channel partners should include explicit statements, such as "There is absolutely no obligation," to frame the situation appropriately and reduce any sense of indebtedness. 
Because the long-term returns on high-quality programs will be low when entitlement is high, managers should work to identify their most entitled partners. In general, the most successful sellers are those who feel entitled and act like prima donnas (Davis 2013), and our post hoc analysis confirms that exclusive resellers feel more entitled than multivendor partners. Therefore, managers should focus on their best, most exclusive resellers and conduct partner surveys to identify any overly inflated expectations. In dialogue with these partners, the supplier could encourage them to reflect on their behavior and share concrete expectations, while stressing the relational character of the relationship rather than focusing on bottom-line results (Davis 2013).

In addition, interactions with top performers may include recognition of their achievements, to mitigate the negative effects of entitlement by increasing the sense of deservingness (Davis 2012; Feather 2003). Finally, managers must acknowledge their own behaviors that encourage entitlement expectations. Instead of simply praising top performers for their achieved performance, program managers might periodically highlight and give feedback about partners' invested effort. Business-to-consumer relationship programs, such as loyalty programs, periodically send members updates about their point balances. In addition, a differentiation is often made between status-related tier points and earned points. Channel partner programs could adopt similar practices, with a special focus on the effort a partner has exerted in performing behaviors (e.g., training completion, sales) to achieve the earned points. This focus on effort and achievement could reduce psychological entitlement, in that it lowers the emphasis on credentials, status, and hierarchy, all of which are closely related to entitlement.

\section{ACKNOWLEDGMENTS}

The authors thank the employees of the global Fortune 100 supplier company for their close and rewarding partnerships. 



\title{
Chapter Three
} When They've Lost That Learning Feeling...

\author{
Balancing Customer and Sales Orientations \\ to Prevent Disengagement in Channel Partner \\ Programs
}




\begin{abstract}
In an international field study, we investigate the issue of disengagement from channel partner sales training, which has become a major priority for manufacturers. First, we demonstrate empirically that disengagement from training occurs over time and represents a hazard to program success. Second, we illustrate how salesperson ambidexterity in the form of balancing customer and selling orientations influences disengagement as salespeople who successfully reconcile these seemingly conflicting orientations are less prone to disengaging. Third, we further elucidate the critical role of disengagement as it hinders performance and indicates problems underlying the relationship. We also show that a bottom-line mentality at the level of the reseller firm (Greenbaum et al. 2012) exaggerates the impact of disengagement on the reseller's satisfaction with the supplier relationship, adding to our understanding of this construct. Our proposed conceptual model, including drivers, outcomes, and moderating variables, is strongly supported in our analysis. We derive implications and finally discuss recommendations for managers and researchers.
\end{abstract}




\section{INTRODUCTION}

Business partner sales training has become a major priority for manufacturers in an effort to help salespeople to cope in an increasingly complex and dynamic marketplace (Sager et al. 2014; Sarin et al. 2010). U.S. companies alone spend \$15 billion on sales training every year (Kumar et al. 2015), and recent industry surveys report an average spending of approximately $\$ 2,000$ on training per salesperson (CSO Insights 2013). As firms increasingly employ indirect sales channels (Bairstow and Young 2012), suppliers train their business partners in order to achieve or retain a strong market position (Bettencourt et al. 2002). Examples include major suppliers such as Microsoft, Dell, and others, who provide extensive training and e-learning facilities (Kalyanam and Brar 2009; Microsoft 2010) in their channel partner programs (CPPs). These programs incentivize training participation (Gilliland 2004), representing significant investments of the supplier firms. Yet, recent industry surveys report mixed results, with only short-term rises in performance that drop off quickly (Sharir 2014). Companies are faced with business partners who do not feel engaged in the training. It has been suggested that one reason for this may be that salespeople are not able to manage to balance short-term sales and building customer relationships through better knowledge and service (Snider 2015; Ingram et al. 2007). In addition, B2B resellers often have a firm culture that puts a strong focus on a narrow set of success measures such as sales and market share (O'Boyle et al. 2013). Such an environment, in which the business partner's non-core activities including learning become scrutinized, may exacerbate the problem. It thus seems vital to learn what causes resellers to disengage from training programs, and how to prevent this from affecting performance and the future of the partnership.

In recent years, engagement has taken center stage in the literature on employee commitment and performance (e.g., Christian et al. 2011; Menguc et al. 2013; Rich et al. 2010) as it leads to a broad range of beneficial outcomes for companies (Bakker et al. 2012; Christian et al. 2011). Research on disengagement, however, is limited. Disengagement can be thought of as a reduction in engagement and is expected to entail opposite effects (Kahn 1990). Despite the fact that sales enablement is viewed as critical to salespeople's long-term performance (Pettijohn et al. 2009), disengagement from learning and training has been largely neglected in the academic marketing literature. Furthermore, much of the relevant research has taken a static perspective (cf., Bakker and Bal 2010; Ouweneel et al. 2013), suggesting a need to assess disengagement from training using a longitudinal perspective. In addition, relatively little is known about the antecedents of disengagement (Wollard and Shuck 2011), with knowledge on what predisposes employees to disengage from sales training in particular being even scarcer.

One important consideration is that for salespeople, taking training modules naturally reduces the immediate time and attention available for the sales task itself. Whether salespeople are highly focused on closing deals or focused more strongly on satisfying the customer's needs (Saxe \& Weitz 1982) should influence how they make this tradeoff and consequently choose to allocate their time, effort and attention. While extant research has rarely examined customer orientation and selling orientations simulta- 
neously (Guenzi et al. 2011), recent research has brought ambidexterity to the marketing literature (Jasmand et al. 2012) and has surfaced that selling and customer orientation are a balancing act. We zoom in on these conflicting pressures as studies in other domains show the ability of individuals to simultaneously pursue diverging goals to have a very positive impact on their performance (Jasmand et al. 2012; Yu et al. 2013). We therefore assess the effect of this ability on disengagement from training over time.

Next to antecedents of disengagement, little research has illuminated boundary conditions for its outcomes (Kane-Frieder et al. 2013), despite calls for this in the literature (e.g., Parker and Griffin 2011). One potentially important aspect is the fact that B2B reselling is an environment with fierce competition, which causes many companies strongly focus on the bottom-line. The organizational context has a dramatic influence on employees, channel relationships, and long-term performance though (Barney 1986; Langerak 2001), and the notion of bottom-line mentality (BLM) has been linked to negative outcomes such as unethical behavior and social undermining in the workplace (Barsky 2008; Greenbaum et al. 2012; Shah et al. 2002). Such an environment may encourage scrutinizing of all core and non-core activities related to the sales role and may be at odds with channel enablement, which often is relational in nature. As of yet, the impact of BLM however has not been fully integrated into research that examines the organizational frontline (Greenbaum et al. 2012). We thus examine how a firm's BLM interplays with disengagement from training over time. The main purpose of the paper is to investigate the issue of disengagement from manufacturer-provided sales training in channel partner programs, which may impede long-term program success. Specifically, we intend to make three key contributions.

First, we review the construct of disengagement and investigate its role in the context of supplier-provided training in channel partner programs. Prior research has put great emphasis on its positive counterpart (engagement) and has typically viewed it to be persistent over time (Schaufeli et al. 2002). Psychological states are intrinsically bound in time however (Weiss and Kurek 2003), which suggests such static perspectives to be incomplete. This gives rise to the phenomenon of disengagement, which means that it is natural for partners to disengage over time. In marketing research, dynamic perspectives are often neglected though, despite their superior potential to predict future outcomes (e.g, Palmatier et al. 2013). We, therefore, operationalize disengagement as a reduction in state engagement (Rich et al. 2010) over time, concordant with theorizing in extant literature (Kahn 1990, 1992).

Second, we investigate how partners' customer and selling orientations influence disengagement from supplier-provided sales training in a CPP. We thereby assess whether salespeople high in sales orientation are more prone to disengage after gaining the most relevant knowledge during initial training stages. Highly customer-oriented salespeople may be less likely to disengage, as they strive to continually improve in order to deliver high quality service to customers. In addition, we argue that whether salespeople are able to reconcile these - seemingly conflicting - orientations may determine disengagement from the training. We thus supplement recent work by Zablah et al. (2012) on how customer orientation impacts performance by assessing its effect on training disengagement 
over time. We simultaneously investigate the impact of selling orientation, extending recent research on ambidexterity at the individual level, by assessing the balancing of customer and selling orientation and its impact on disengagement.

Third, we propose disengagement from supplier-provided training to be a key predictor of future relationship health and business performance. In interpersonal relationships, disengagement is viewed as an important indicator of future relationship issues. We assess whether disengagement is similarly predictive of negative outcomes in channel partner relationships. We further aim to explain heterogeneity in outcomes by investigating the role of the reseller firm. In particular, we examine how a prevailing BLM (Greenbaum et al. 2012) at the level of the reseller firm influences the impact of disengagement on the partner relationship and performance. We thus contribute to the literature on disengagement by adopting a dual perspective highlighting both, individual salespersons' orientations, as well as the reseller firm context.

In order to make these contributions, this paper proceeds as follows. First, we review the literature on disengagement, salesperson orientations and ambidexterity, as well as bottom-line mentality. We develop our hypotheses and describe our sample of B2B salespeople in the information technology (IT) sector. We then present our results and discuss the implications from a theoretical and practical perspective. Finally, we review our study's limitations and present avenues for further research.

\section{CONCEPTUAL BACKGROUND}

While the concept of engagement has received ample attention in the marketing and organizational literature in recent years (Macey and Schneider 2008; Yu et al. 2013), Disengagement has rarely been explicitly addressed. This may be due to the fact that prior literature mostly assumed engagement to be a relatively enduring state (Macey and Schneider 2008). This is somewhat surprising, given the fact that psychological states are intrinsically bound in time (Weiss and Kurek 2003). In fact, psychological presence - the essence of the state of engagement - can be draining in terms of the personal effort required and the pool of energy and resources available to employees for engagement is finite (Kahn 1992). For this reason, disengagement should be a regular occurrence, frequently observed over time. Kahn (1990, p. 694) conceptualizes personal disengagement as "the uncoupling of selves from work roles; in disengagement, people withdraw and defend themselves physically, cognitively, or emotionally during the role performances." Disengagement can thus be seen as a reduction in state engagement over time, or the "simultaneous withdrawal and defense of a person's preferred self in behaviors that promote a lack of connections, physical, cognitive, and emotional absence, and passive, incomplete role performances" (Kahn 1992, p. 701). Overall, it can be said engaged employees invest their "hands, head, \& heart" in their work performances (Ashforth and Humphrey 1995, p.110). In the context of channel partner learning, a partner can be called disengaged when he or she becomes less committed, present and 
attentive over time while taking learning modules - thus investing less of their hands, head and heart in learning.

Generally, disengagement stems from the psychological unavailability of an individual. Employees decide to engage based on the potential return on investments of the self in the role performance. They ask; "(1) How meaningful is it for me to bring myself into this performance? (2) How safe is it to do so? and (3) How available am I to do so?" (Rich 2010, p. 620). Engagement will remain high when employees find their roles to call for behavior consistent with their preferred self-image as this makes it more meaningful (Rich 2010, Kahn 1992). Conversely, the less psychologically available an employee is, for example due to competing personal priorities, the more likely they will disengage over time. Unfortunately, at this point not much research has explicitly focused on disengagement (e.g., Macey and Schneider 2008) and especially its antecedents in practice are unclear. We therefore investigate the causes and effects of disengagement in partner learning over time.

\section{Salesperson Selling Orientation and Customer Orientation}

In their landmark article, Saxe and Weitz (1982) introduced a conceptualization of the sales role that centers around the notion that salespeople may opt to give up short-term sales and personal benefits in favor of a focus on establishing and maintaining longterm, mutually beneficial relationships with customers (Plouffe et al. 2009; Schwepker Jr 2003). This practice of customer orientation (CO) (Saxe and Weitz 1982) has gained prominence as an embodiment of the marketing concept at the salesperson level (Guenzi 2011). It is defined as “ ... the degree to which salespeople practice the marketing concept by trying to help their customers make purchase decisions that will satisfy customer needs" (Saxe and Weitz 1982, p. 344). Putting a clear focus on understanding their customers' needs, customer oriented salespeople help them to identify and evaluate alternatives and find optimal solutions (Boles et al. 2001a; Jaramillo et al. 2007; Johnston and Marshall 2008). Salespeople who are primarily customer oriented typically avoid shortsighted sales tactics that sacrifice customer interest (Ehret 2004; Saxe and Weitz 1982). All of these characteristics may make customer oriented sellers more likely to engage in continual learning as they realize that high levels of up-to-date knowledge are necessary to enable such levels of customer service. The second subdimension in this conceptualization is selling orientation (SO). A salesperson can be called "sales oriented" when he or she is focused primarily on activities that emphasize getting the sale (Boles et al. 2001a; Schultz and Good 2000). While this approach can result in short term sales, it may come at the expense of customer satisfaction, as selling-oriented salespeople tend to have a short-term horizon and focus on short-term goals, potentially at the expense of the customer's true needs (Saxe and Weitz 1982, Guenzi 2011) and activities not directly related to making the sale.

Prior literature has argued for the impact of sales and customer orientations on the organization, its employees, as well as its customers and found a positive impact on many relevant outcome variables (Jaramillo 2007). On an employee level, attitudes such 
as job satisfaction and commitment to the organization are affected (Pettijohn et al. 2002; Siguaw and Honeycutt 1995), as well as important constructs like adaptive selling (McIntyre et al. 2000) and salesperson motivation (Pettijohn et al. 2002). This suggests an influence on employee engagement (Zablah et al. 2012) and learning as it is related to performance in the sales role. Despite elaborate research on SOCO, empirical findings regarding the ultimate performance impact of SOCO have been equivocal, however, as even recent meta-analyses report mixed findings (Singh and Koshy 2010).

One of the reasons for these mixed findings may be the fact SOCO consists of two dimensions while most research thus far has either focused mostly on $\mathrm{CO}$, or treated SO and $\mathrm{CO}$ as opposite ends of a spectrum. These two dimensions have therefore hardly ever been investigated separately (Guenzi et al. 2011). In fact, in their meta-analysis, Jaramillo et al. (2007) did not find sufficient studies examining both facets separately in order to include this aspect in their analysis. Further, reviewing extant literature, Periatt et al. (2004) lament "a dearth of research on selling orientation" (p. 53). This is unfortunate, as examining SO separately from CO may bear valuable new insights for marketers. For instance, while Boles et al. (2001a) found a positive relationship between customer orientation and sales ability, sales orientation did not significantly influence performance. This implies that $\mathrm{SO}$ and $\mathrm{CO}$ are not simply opposite ends of a continuum but that, rather, salespeople can be high or low in both (Harris 2005). Guenzi et al. (2011) therefore call for research focusing specifically on the facet of SO as current research had only "scratched the surface of this important managerial issue" (2011, p 281). This, as well as the fact that current research also disregards the fact that individuals may be able to balance these seemingly conflicting orientations, leads us to address this in the following.

\section{Balancing Seemingly Conflicting Selling and Customer Orientations}

Recent research highlights the phenomenon of ambidexterity, which refers to the alignment or simultaneous pursuit of dual and, seemingly conflicting goals (Simsek 2009). Ambidexterity has received attention from different literature streams, including management, organizational learning, design and innovation ( $\mathrm{Yu}$ et al. 2013) and holds important clues to the prevention of disengagement. Most current research on ambidexterity is at the organizational level, viewing it as a firm's ability to pursue the seemingly conflicting goals of exploiting existing competencies and exploring new opportunities (Raisch and Birkinshaw 2008). This balance has been argued to boost organizational performance (O'Reilly and Tushman 2013; Raisch and Birkinshaw 2008), which a recent meta-analysis supported by finding that, on average, ambidexterity had a significant, positive impact (Junni et al. 2013).

Ambidexterity at the firm level stems from the individual employee's ability to manage disparate task demands and integrate them for cross-fertilization (Raisch et al. 2009). Ambidextrous organizations need ambidextrous teams and managers to achieve success (O Reilly and Tushman 2004). It can therefore be argued that individual ambidexterity should strongly influence organizational performance; however, current un- 
derstanding of employee-level ambidexterity is only slowly emerging (Jasmand et al. 2012; Raisch et al. 2009). Accordingly, recent literature calls for a more micro-level approach to ambidexterity (Nosella et al. 2012; Raisch et al. 2009; Rosing et al. 2011). Mom et al. $(2007,2009)$ provide evidence that ambidexterity can indeed be pursued at the individual employee-level, with more recent research in marketing supporting this for front-line-employees and sales assistants and managers (Bonesso et al. 2014; Jasmand et al. 2012).

What makes individual-level ambidexterity particularly relevant is that firms increasingly aim to motivate frontline employees to add to their predominately customer service or sales role the responsibility for achieving both sales and service targets (Patterson et al. 2014). This reflects a dual-emphasis strategy (Mittal et al. 2005; Rust et al. 2002) as firms adopt a cost and a revenue emphasis simultaneously to generate profits through both efficiencies and customer satisfaction (Patterson et al. 2014). Selling is often perceived as incommensurate with service though, which creates psychological barriers to creating a balance and simultaneously pursuing both of these functions successfully (Jasmand et al. 2012). And although service and sales goals are not entirely incompatible in their required abilities, engaging in ambidextrous behavior requires customer-service representatives to manage seemingly conflicting task demands, which is challenging to the employee (Jasmand et al. 2012). Bonesso et al. (2014) also highlight the fact that key to ambidexterity on the job is whether individuals correctly perceive the general orientations (e.g., learning orientation) expected by their role. Understanding what their job requires of them and the ability to activate consistent behaviors when facing the challenge of reconciling dual demands is thus critical to unlock higher performance (Gupta et al. 2006; Raisch et al. 2009). In our focus on industrial salespeople participating in a supplier-provided training program, ambidexterity refers to the simultaneous existence of a selling orientation and customer orientation within the individual reseller salesperson.

\section{Bottom-Line Mentality}

In addition to factors at the individual employee level, organizational factors should also be relevant to the role of disengagement in channel partner programs. One factor that holds particular relevance is whether the reseller firm has a strong bottom-line mentality. Usually, attaining bottom-line outcomes is considered beneficial to the organization and its profitability (Brenner and Molander 1977; Treviño et al. 2003). Therefore, employees are often rewarded based on this (Crotts et al. 2005; Drucker 1963; Latham and Locke 2007). However, treating the bottom-line as the only objective to strive for may bear several problems, especially considering the fact that organizations today are complex, multivalent systems (Greenbaum et al. 2012). A bottom-line mentality is defined as "one-dimensional thinking that revolves around securing bottom-line outcomes to the neglect of competing priorities" (Greenbaum et al. 2012, p. 344). The bottom-line is often referred to in terms of financial consequences (Wolfe 1988b); however, in a more 
general sense it should be considered what "is worth paying attention to while everything else is discarded" (p. 145).

One reason a BLM may be relevant and problematic is that singularly pursuing the bottom-line brings with it unintended side effects on competing organizational priorities. For example, employees may become so focused on meeting productivity requirements that they compromise product quality and hence risk releasing underperforming or even potentially harmful products (Greenbaum et al. 2012). In addition, when employees treat every situation as if the bottom-line is the only relevant outcome, they are at risk of approaching these situations with a high level of competitiveness (Callahan 2007; Wolfe 1988a), creating a one-dimensional, win-lose mentality (Greenbaum et al. 2012). This, in turn, leads to social undermining in the organization as a way of making coworkers more likely to fail. Previous literature has conceptually alluded to the potential drawbacks of a BLM (Barsky 2008; Shah et al. 2002). However, while initial empirical research has suggested that it influences employee behavior, BLM as a construct of interest has until very recently not been fully conceptualized or its antecedents and effects fully investigated (Greenbaum et al. 2012). It is therefore unknown at this point how firm-level BLM influences the individual employee and specifically the role of disengagement in channel partner programs.

\section{HYPOTHESES DEVELOPMENT}

\section{The Effect of Balancing Selling and Customer Orientations on Disengagement}

As psychological states have an influence on individuals' internal work motivations (Hackman and Oldham 1980), disengagement should be higher the less psychologically available an employee is, for example due to different personal priorities, and the less they find their roles meaningful (Kahn 1992; Rich et al. 2010). A salesperson's understanding of the sales role should therefore influence their disengagement from rolebehaviors such as participating in learning modules in a channel partner program.

Customer oriented salespeople help their customers to identify and evaluate alternatives, and identify optimal solutions (Boles et al. 2001b; Jaramillo et al. 2007). Highly sales oriented salespeople, on the other hand, focus primarily on "getting the sale" in the short term (Guenzi et al. 2011; Schultz and Good 2000). These orientations affect important dimensions such as commitment to the organization (Pettijohn et al. 2002; Siguaw and Honeycutt 1995) and salesperson motivation (Pettijohn et al., 2002). Recent research further found that $\mathrm{CO}$ increased engagement in front line employees (Rod and Ashill 2010). Through focusing an employee's effort on customer need satisfaction, as well as by enabling them to succeed in helping others through their jobs, it increases the employees' fit with the demands and values relevant to the front-line employee or salesperson (Edwards 1996; Edwards and Cable 2009; Hobfoll 2001). As customeroriented salespeople strive to deliver superior service to their customers and meet customer needs, we thus expect these salespeople to stay engaged in the training longer. 
In contrast, salespeople high in selling orientation should be more likely to disengage. While highly sales-oriented people may generally be less patient and interested in training as opposed to learning on the job, they should certainly perceive less marginal benefit to the modules after having gained the most relevant knowledge during initial training modules. Consequently, over the course of having taken several modules over time, they should shift their attention back to immediate-term selling activities while becoming more disengaged from the training. We thus expect that:

H1: Selling orientation (a) promotes disengagement, while (b) customer orientation prevents disengagement

How well salespeople are able to reconcile these two orientations may be a further key factor in preventing disengagement. In recent years, a small number of studies have assessed ambidexterity at the individual-employee level (Bonesso et al. 2014). This ability of individuals to simultaneously pursue diverging goals has been shown to have a positive impact on employee performance (Jasmand et al. 2012). In an industrial sales force, it is not uncommon for salespeople to exhibit a strong selling orientation (Boles et al. 2001), while a customer orientation is beneficial to performance (Guenzi 2011) and thus frequently encouraged by managers. We predict that these two orientations, despite their seeming contradiction, are compatible and complementary with regards to learning. Selling-oriented salespeople are mainly engaged in selling activities that emphasize closing the sale (Boles et al., 2001; Schultz and Good, 2000). Customer-oriented salespeople on the other hand could be seen as solution providers, who aim to understand their customers' needs (Jaramillo 2007). Both selling-oriented and customer-oriented salespeople need knowledge to be able to successfully sell, however. As selling-oriented sellers may be impatient and too focused on core selling behaviors to engage in learning in the long-term, sellers who are also high in customer orientation might benefit from the increased focus on acquiring knowledge that this orientation encourages. Analogous to the pursuit of contrarian coals, we thus argue that it is beneficial for continued learning when salespeople supplement their natural drive of wanting to close the sale with having the customer's best interest at heart. We thus view selling orientation and customer orientation as complementary and expect salesperson ambidexterity regarding customer and selling orientations to prevent disengagement from training over time.

H2: Ambidexterity regarding customer and selling orientations prevents disengagement

\section{Effects of Disengagement on Relationships and Performance}

Disengaged employees exhibit behavior that can be described as robotic (Hochschild 2003), detached (Kahn 1992) or without effort (Hackman and Oldham 1980). These employees defend their "self" by hiding their true identity, thoughts and feelings during their role performances (Kahn 1992), often to the detriment of both their own and their organization's outcomes. Interpersonal relationship literature is one of the few research streams to have actively studied disengagement, commonly conceptualizing disengage- 
ment in terms of avoidance and withdrawal (Gottman 1999; Kayser 1993; Snyder and Regts 1982). One key recognized aspect of disengagement is an emotional indifference to the partner, leading to strategies to increase distance to the partner such as being less engaged in their partners' lives (Barry et al. 2008), speaking with their partners less frequently (Kayser 1993), and being less attentive to and less intimate with their partners (Gottman 1999; Kayser 1993). High levels of disengagement are even seen as an indicator of a "point of no return", after which couples are unlikely to recover, by some scholars (Gottman 1999; Kayser 1993). Disengagement therefore seems to be an important precursor to future relationship problems or even relationship dissolution. In the context of B2B relationships, we expect disengagement to be related to a decrease in relationship quality, as evidenced by lower rates of relationship satisfaction.

H3: Disengagement leads to lower partner relationship satisfaction

Beyond this, extant literature suggests engagement to be closely related to further relevant salesperson behaviors and outcomes in channel partnerships. For instance, selfexpression - and thus, engagement - underlies and promotes creativity (Perkins and Perkins 2009), emotional expression (Rafaeli and Sutton 1987), authenticity (Baxter 1980) and ethical behavior (Toffler 1991), all of which are favorable in a selling context. Investigating the relationship between engagement and job performance, recent research has shown that engaged individuals are "psychologically present, fully there, attentive, feeling, connected, integrated, and focused in their role performances" (Rich et al 2010, p. 619). This leads to benefits such as greater levels of effort (Kahn 1990; Kahn 1992; Rich et al. 2010), being more attentive and focused during their work (Kahn 1990; Weick and Roberts 1993), and an increased connection among coworkers in pursuing organizational goals (Ashforth and Humphrey 1995; Rich et al. 2010). In contrast to this, disengaged employees withhold their physical, cognitive and emotional energies, which is reflected in a passive and detached way of dealing with role tasks (Kahn 1990; Rich et al. 2010). Employees who are disengaged from learning should experience decreases in knowledge gains from the training over time, which should lead to a lower perceived sales ability. In the context of channel partner sales training, we thus expect that:

H4: Disengagement leads to lower perceived sales ability

\section{Moderating Effects of Bottom Line Mentality}

Another situational factor related to disengagement from training is a pronounced bottom-line mentality at the firm the salesperson operates in. As discussed, onedimensional thinking revolving around bottom-line outcomes to the neglect of competing priorities bears potential problems (Greenbaum et al. 2012). BLM can be found at all levels in the organization, which is important as firm-level variables have an effect on how successful the salesperson can become at generating sales. Social-cognitive theory (Bandura 1986; Bandura 1977) predicts that supervisor and firm attitudes have an impact on the employee. According to this theory, human behavior can be explained 
in terms of observational learning and that individuals learn through observing and modeling the behavior of others (Bandura 1977). In organizations, individual employees observe the attitudes and behaviors of their co-workers and supervisors and construct their own realities based on these observations (Greenbaum et al. 2012). Social influences such as supervisors' and co-workers' behaviora, as well as firm-wide climate thus shape employees' beliefs and values. As firm-BLM tends to focus managers and employees on bottom-line goals, this increases their refocusing on core activities of the sales role, possibly at the expense of non-core or relationship building activities. This focus should make it more salient to a disengaged employee the very fact that they have been disengaging from the training. According to self-perception theory (Bem 1972), one way that individuals determine their attitudes is by observing and interpreting their own behavior. Then, similar to how customers who recommend a product to others consequently evaluate that product and brand more positively (Ryu and Feick 2007), becoming more aware of their disengagement from the supplier's training should exaggerate the effect of the salesperson's disengagement on relationship satisfaction. In addition, as sellers become increasingly aware of their disengagement from training because of this bottom-line focus, their perceived effectiveness and ability to sell the manufacturer's products should decrease as well. We thus expect firm-level BLM to exaggerate the effects of employee disengagement from the CPP on relationship satisfaction.

H5: Firm Bottom line mentality increases the negative effect of disengagement on the reseller's (a) relationship satisfaction and (b) perceived sales ability

\section{EMPIRICAL STUDY}

Cooperating with a global Fortune 100 computer technology service and solutions provider, we collected a database containing multi-wave survey and secondary data from reseller salespeople who participated in the firm's channel partner program. All surveyed partners participated in the learning modules provided within the program. These modules are short, online training modules lasting approximately 15-20 minutes and cover general topics, such as general sales and customer relationship management knowledge, as well as content specific to the manufacturers products and services. Partners can freely choose the number and type of modules they wish to complete. At the end of each module, the partner has to pass a brief test based on the content of the module in order for counted as complete. Consequently, points are awarded to the partner, which later be redeemed for prizes within the partner program.

In total, 2,664 reseller salespeople were randomly selected from the international database of active program participants. We invited these salespeople to participate and offered bonus points in the channel partner program as incentive. Three survey waves were carried out during one program year in order to test our hypotheses (measures, scale sources, and item loadings are in Appendix 3.1 and Appendix 3.2). This particular channel partner program re-launches every year, incorporating new content and com- 
munications. The first wave of our survey was sent out shortly after the program relaunch; the second wave was sent out approximately three months later and the third one approximately seven months after the second one. While the main measures in our study are derived from waves one and three, we also measured our dependent variables in wave two and control for the lagged terms in our analysis. The final sample consisted of 278 reseller salespeople who fully completed the three matched questionnaires and relevant items, yielding a response rate of $10.4 \%$.

In the survey, salespeople responded to scales that measured their satisfaction with the partner relationship, as well as their own perceived sales ability. This measure is based on a measure by Plouffe et al (2009) and assesses the individual's performance relative to other salespeople in the company. In addition, the respondents also rated their satisfaction with the CPP, and indicated for how long they had been in a relationship with the manufacturer who provides the program. We measured disengagement using 9 items adapted from Rich et al. (2010). These 9 items represent the three sub-dimensions of physical, emotional and cognitive engagement with 3 items each. We operationalize the construct of engagement using measures at two points in time, i.e. in the first and the third wave and took the composite of the deltas between each individual item of the scale to form our central construct of disengagement. That is, disengagement represents the reduction in physical, emotional and cognitive engagement over a period of approximately 10 months. We chose to operationalize disengagement in this way for two reasons. First, despite diverse conceptualizations in the literature, viewing engagement as being comprised of physical, emotional and cognitive dimensions is accepted in current literature (Rich et al. 2010). Second, according to Kahn (1992) disengagement can be viewed as a reduction in levels of engagement. Rather than creating a new scale for disengagement, taking the difference between two engagement-states is therefore deemed to be more efficient as well as highly concordant with theorizing in extant literature. Sales orientation and customer orientation were measured using the established SOCO Scale, which assess achieving sales objectives (SO-component) while enhancing customer value (CO-component) (Gillis et al. 1998; Saxe and Weitz 1982). This scale and its items have been validated in several studies, which generally indicate acceptable reliability and validity (Michaels and Day 1985; Swenson and Herche 1994; Thomas et al. 2001). We measure both components as we assume these not to be mutually exclusive. Boles et al. (2001) concluded that the sales orientation is not necessarily harmful to enhancing the customer value as customers expect some degree of "selling" from a salesperson. This should certainly be true in B2B sales channels. Several studies confirm the presence of two separate factors (Brown et al. 1991; Jaramillo et al. 2007). In one of the few studies specifically differentiating between the $\mathrm{SO}$ and $\mathrm{CO}$ subdimensions of the SOCO scale, Plouffe et al. (2009) compare one-factor and two-factor perspectives of SOCO and ultimately use the two-dimensional version, due to better performance compared to the one factor solution.

In addition to the survey measures, we also collected objective data on the sales training modules completed by the participants in the 12 months prior to the first wave 
of the survey. On average, sellers in our sample completed 23.04 online learning modules in the 12 months prior to wave one of the survey.

We evaluated the psychometric properties of the constructs in our field study using SmartPLS version 2.0 (Ringle et al. 2005). The results can be seen in Table 3.1. Loadings of the indicator items on the latent variables were greater than .7 whereas the composite reliability scores were greater than .9 , in support of good indicator reliability and good internal consistency, respectively (Nunnally and Bernstein 1994). The average variances extracted (AVE) of the constructs were greater than .6 (Hair et al. 2011), indicating good indicator reliability. We employed Fornell and Larcker's criterion (1981) to assess the measurement model's discriminant validity. As each latent construct shared more variance with its assigned indicators than with any other latent variable in the structural model, the discriminant validity of our conceptual model is supported.

Table 3.1: Quality Measures

\begin{tabular}{|c|c|c|c|c|c|c|}
\hline Constructs & AVE & $\begin{array}{l}\text { Composite } \\
\text { Reliability }\end{array}$ & R Square & $\begin{array}{c}\text { Cronbachs } \\
\text { Alpha }\end{array}$ & Communality & Redundancy \\
\hline Selling Orientation & 0.83 & 0.94 & & 0.90 & 0.83 & \\
\hline Customer Orientation & 0.81 & 0.93 & & 0.89 & 0.81 & \\
\hline State Disengagement & 0.69 & 0.96 & 0.30 & 0.96 & 0.69 & -0.02 \\
\hline Firm Bottom Line Mentality & 0.86 & 0.96 & & 0.96 & 0.86 & \\
\hline Relationship Satisfaction & 0.95 & 0.98 & 0.40 & 0.98 & 0.95 & -0.03 \\
\hline Sales Ability & 0.84 & 0.96 & 0.43 & 0.94 & 0.84 & -0.01 \\
\hline $\begin{array}{l}\text { Relationship Length } \\
\text { (control)X }\end{array}$ & 1.00 & 1.00 & & 1.00 & 1.00 & \\
\hline Program Satisfaction (control) & 0.85 & 0.95 & & 0.92 & 0.85 & \\
\hline Sales Ability Lag (control) & 0.85 & 0.96 & & 0.94 & 0.85 & \\
\hline
\end{tabular}

\section{RESULTS}

We tested our conceptual model, which is presented in Figure 3.1, using a partial least squares (PLS) model. SmartPLS v2.0 (Ringle et al. 2005) was used for both the measurement and the structural model (Hair et al. 2012). We chose PLS path modeling as it is suitable for estimating complex models (Chin 1998) and has shown superior performance compared with covariance-based methods to estimate structural models while testing moderating hypotheses. In addition, it has been argued to have superior predictive performance (Chin et al. 2003). We obtained 1000 bootstrap replications to obtain the standard errors with which we tested for statistical significance of the parameter estimates (t-values). 


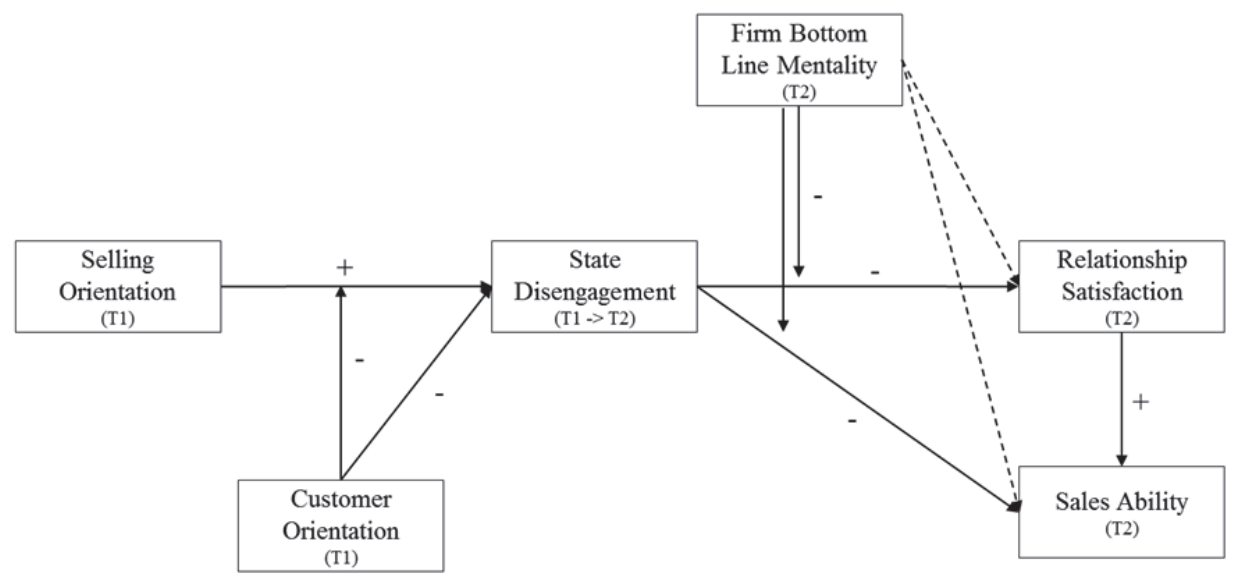

Figure 3.1: Conceptual Model

NB: Control Variables on Endogenous Variables : Program Satisfaction, Relationship Length, Relative Sales Effort (RSE) Lag for RSE

Model quality, as assessed by the R-square values for the endogenous variables was acceptable as it exceeded the cutoff value of .26 (Cohen 1988). We calculated StoneGeisser's Q2 measure for the endogenous variables in our model to assess the predictive validity of the independent variables and mediators (Hair et al. 2012). The crossvalidated redundancy measures $\left(\mathrm{Q}^{2}\right)$ were equal to or greater than .23 , indicating the predictive relevance of the variables. Following Tenenhaus et al. (2005), we calculated a global goodness-of-fit (GoF) criterion, using the geometric mean of the average communality and average R-square. The GoF index is 0.58 , indicating a large overall effect size for our model (Wetzels et al. 2009).

Having established reliability, validity and fit of our models, we proceed to discuss the results of our hypothesis tests below. The results of the analyses to test our conceptual model can be seen in Table 3.2. 
Table 3.2: Analysis Results

\begin{tabular}{|c|c|c|c|c|c|c|}
\hline \multirow[t]{2}{*}{ Constructs } & \multicolumn{2}{|c|}{$\begin{array}{l}\text { State } \\
\text { Disengagement }\end{array}$} & \multicolumn{2}{|c|}{$\begin{array}{l}\text { Relationship } \\
\text { Satisfaction }\end{array}$} & \multicolumn{2}{|c|}{ Sales Ability } \\
\hline & $\beta$ & $\bar{t}$ values & $\beta$ & t values & $\beta$ & $\mathrm{t}$ values \\
\hline Customer Orientation & -0.26 & 3.36 & & & & \\
\hline Selling Orientation & 0.39 & 6.16 & & & & \\
\hline Customer Orientation * Selling Orientation & -0.29 & 5.11 & & & & \\
\hline State Disengagement & & & -0.38 & 6.20 & -0.17 & 2.60 \\
\hline Bottom Line Mentality & & & 0.11 & 1.34 & 0.06 & 0.75 \\
\hline $\begin{array}{l}\text { State Disengagement } * \text { Bottom Line } \\
\text { Mentality }\end{array}$ & & & -0.10 & 2.08 & -0.05 & 0.79 \\
\hline Relationship Satisfaction & & & & & 0.33 & 4.34 \\
\hline Program Satisfaction (control) & 0.07 & 0.95 & 0.41 & 6.71 & 0.19 & 3.22 \\
\hline Relationship Length (control) & 0.09 & 1.19 & -0.05 & 0.71 & 0.07 & 0.99 \\
\hline Sales Ability Lag (control) & & & & & 0.24 & 4.62 \\
\hline R Square & 0.30 & & 0.40 & & 0.43 & \\
\hline
\end{tabular}

Salesperson Selling and Customer Orientations and their effects on disengagement

Regarding the effects of salesperson selling and customer orientations on disengagement, our results show that selling orientation increases state disengagement $(\beta=.51, \mathrm{t}$ $=6.22, p<.01$ ). At the same time, we found customer orientation to decrease state disengagement $(\beta=-.19, \mathrm{t}=2.06, p<.05)$. This provides support for H1a and H1b, respectively. The interaction term between customer orientation and selling orientation, representing ambidexterity, had a significant and negative effect on state disengagement $(\beta=-.45, \mathrm{t}=5.09, p<.01)$. Ambidexterity thus prevents disengagement, in line with H2. In order to more accurately evaluate and interpret this interaction effect between customer orientation and selling orientation, we performed a spotlight analysis using the MODPROBE macro in SPSS (Hayes and Matthes 2009). The results of this analysis is illustrated in Figure 3.2, which shows the effect of selling orientation on disengagement at levels of customer orientation of one standard deviation above and below the mean, as well as average levels. 


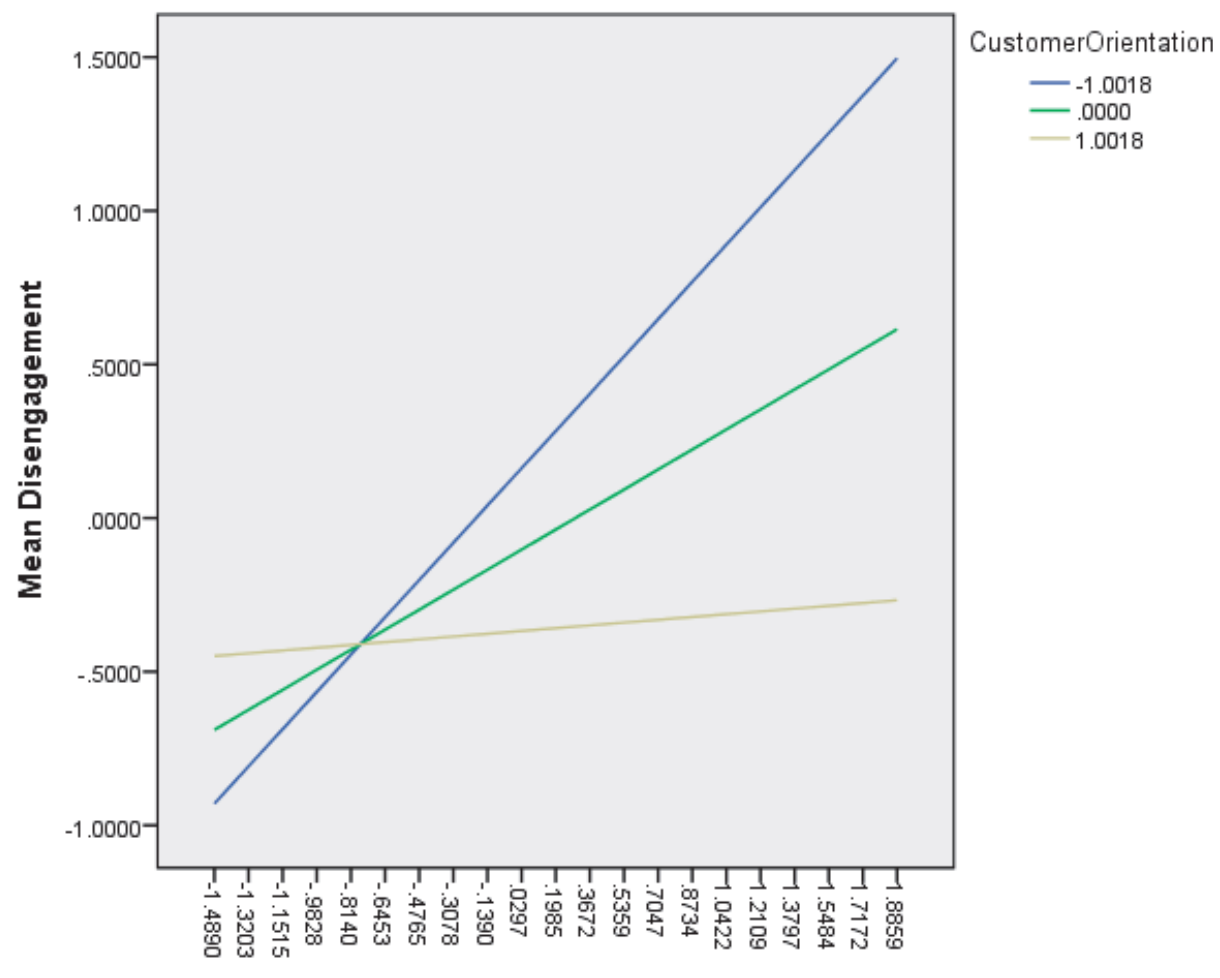

SellingOrientation

Figure 3.2: Spotlight Analysis - Interaction of Selling Orientation and Customer Orientation

As Figure 3.2 illustrates, a higher selling orientation leads to higher disengagement on average. However, at higher levels of customer orientation, this effect is dramatically reduced.

\section{Effects of Disengagement on Relationships and Performance}

Regarding the effects of state disengagement on relationships and performance, we found that disengagement exerted a significant, negative, main effect on both dependent variables: relationship satisfaction $(\beta=-.38, \mathrm{t}=6.39, p<.01)$ and the partner's perceived sales ability $(\beta=-.17, \mathrm{t}=2.69, p<.01)$. This supports $\mathrm{H} 3$ and $\mathrm{H} 4$, respectively.

\section{Moderating Effects of Bottom Line Mentality on Outcomes of Disengagement}

Concerning the role of a firm's BLM, we observe that a high BLM increases the negative effect of disengagement on relationship satisfaction $(\beta=-.10, t=2.00, p<.05)$, which constitutes evidence in support of H5a. BLM, however, did not significantly moderate the effect of disengagement on perceived sales ability $(p>0.1)$, in contrast 
with H5b. We also tested for main effects of bottom line mentality on the dependent variables of relationship satisfaction and perceived sales ability. These effects were, however, also statistically insignificant in both cases $(\mathrm{p}>0.1)$.

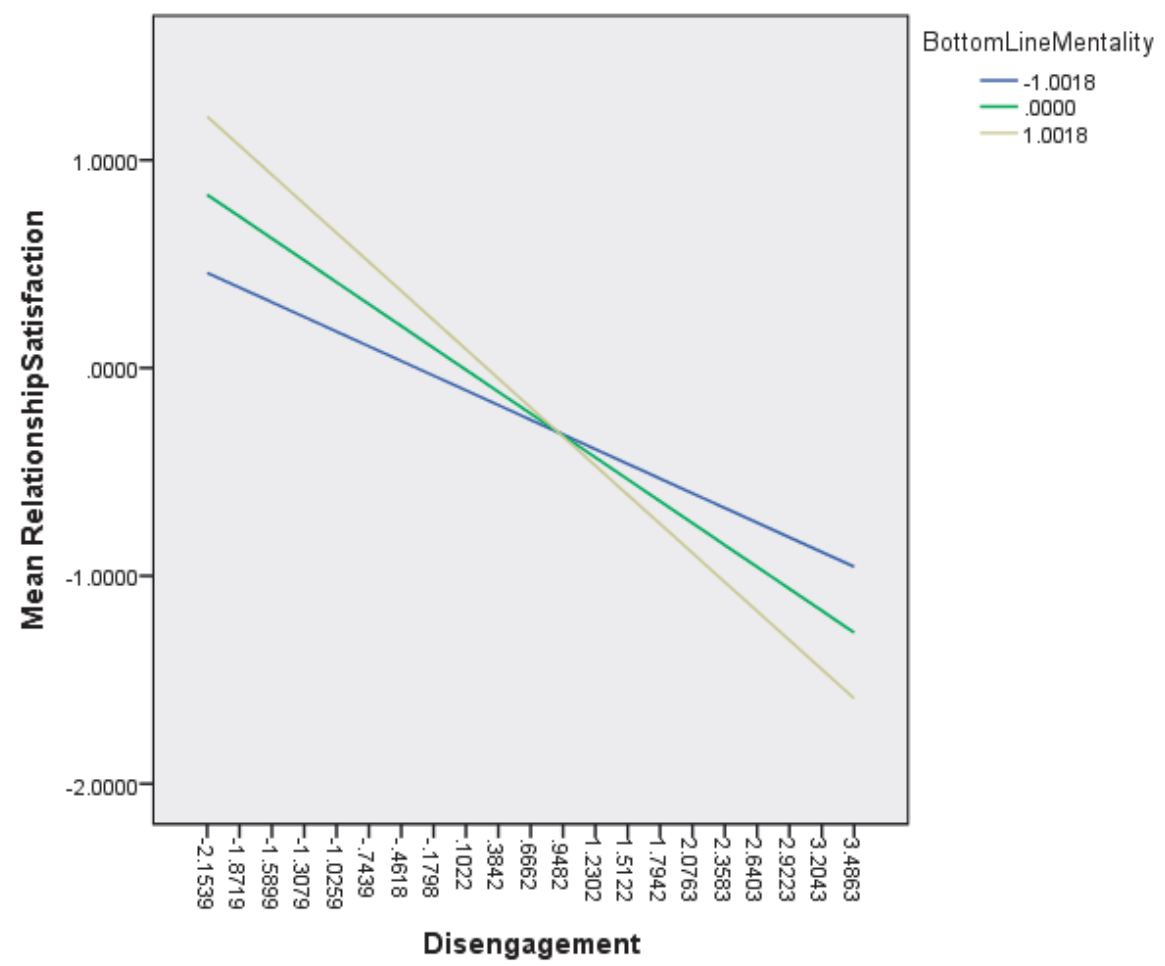

Figure 3.3: Spotlight Analysis - Interaction of State Disengagement and Firm Bottom-Line Mentality on Relationship Satisfaction

In a similar way as for H2, we performed a spotlight analysis (Hayes and Matthes 2009) to further probe as well as graph the interaction. As shown in Figure 3.3, disengagement exhibits a stronger negative association with relationship satisfaction at higher levels of bottom-line mentality. This provides further support for our H5a.

\section{The Effect of Relationship Satisfaction on Perceived Sales Ability}

In addition to these hypothesis tests, we also estimated a path from relationship satisfaction on the salespersons' perceived sales ability compared to other sellers in his or her company. In line with earlier literature in the field, we found relationship satisfaction to relate positively to perceived sales ability $(\beta=.33, \mathrm{t}=4.43, \mathrm{p}<0.01)$. The coefficients of all results are summarized in Figure 3.4. 


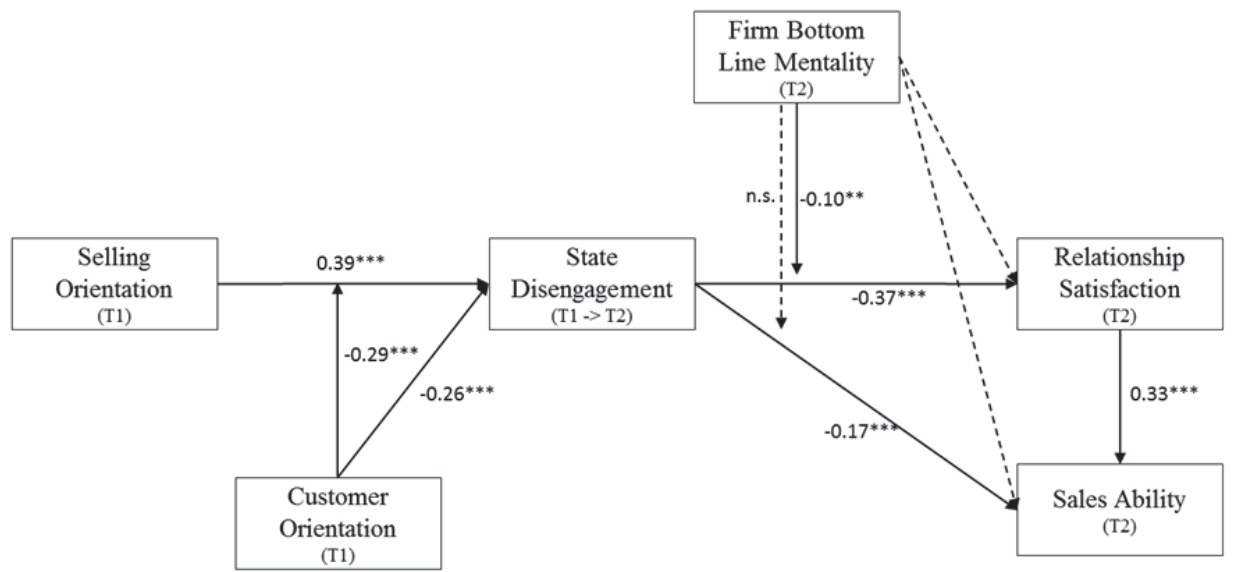

Figure 3.4: Conceptual Model Including Results

NB: Control Variables on Endogenous Variables : Program Satisfaction, Relationship Length, Relative Sales Effort (RSE) Lag for RSE

\section{POST-HOC ANALYSES}

In addition to the self-reported data collected in the three waves of our field study, we also collected additional objective data on the participants' module completion during the 12 months before the first wave of our study. In order to test whether module completion had any effect on the following year's disengagement, we inserted this objective count variable into our model. We thereby assessed its main effect on disengagement, as well as possible interaction effects with the partner's customer and selling orientations.

Assessing these effects of prior module completion, we found that it has a positive effect on disengagement $(\beta=.14, \mathrm{t}=2.12, p<.05)$. Thus, partners who have completed more modules in the prior year are more likely to disengage. We further found evidence of a three-way interaction between customer orientation, selling orientation and prior module completion on state disengagement $(\beta=.24, \mathrm{t}=1.77, p<.10)$. We also tested for two-way interaction effects between customer orientation and module completion ( $\beta$ $=-.10, \mathrm{t}=1.19, p>.1)$, as well as between selling orientation and module completion on state disengagement $(\beta=-.08, \mathrm{t}=1.03, p>.1)$. These were, however, not statistically significant.

In order to interpret the three-way interaction, we split our sample of channel partners with a median-split based on the partners' prior module completion count. We then performed spotlight analyses of the interaction between customer orientation and selling orientation for each of the resulting subsamples using the MODPROBE macro in SPSS (Hayes and Matthes 2009). The results of these spotlight analyses are illustrated in Figure 3.5 for the group high in prior module completion, and in Figure 3.6 for the group low in prior module completion. 


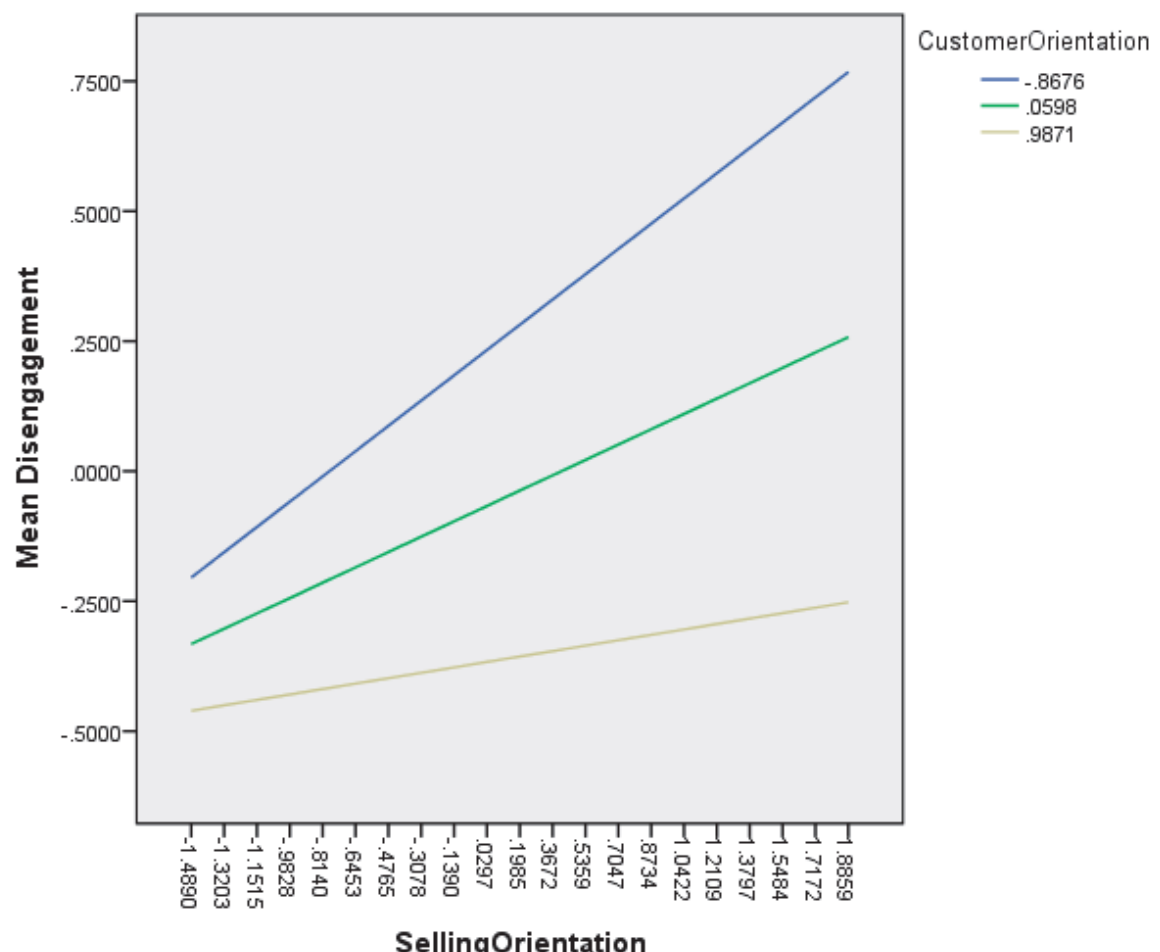

Figure 3.5: Spotlight Analysis - Interaction of Selling Orientation and Customer Orientation for High Module Completion Subsample

As can be seen in Figure 3.5, for partners who have completed the most modules in the year prior, it is obvious that a strong selling orientation leads to disengagement. Similar to the interaction observed in the full sample, this effect is less pronounced for partners high in customer orientation. Customer orientation thus seems to protect against the negative impact of a sales orientation regarding partner learning. 


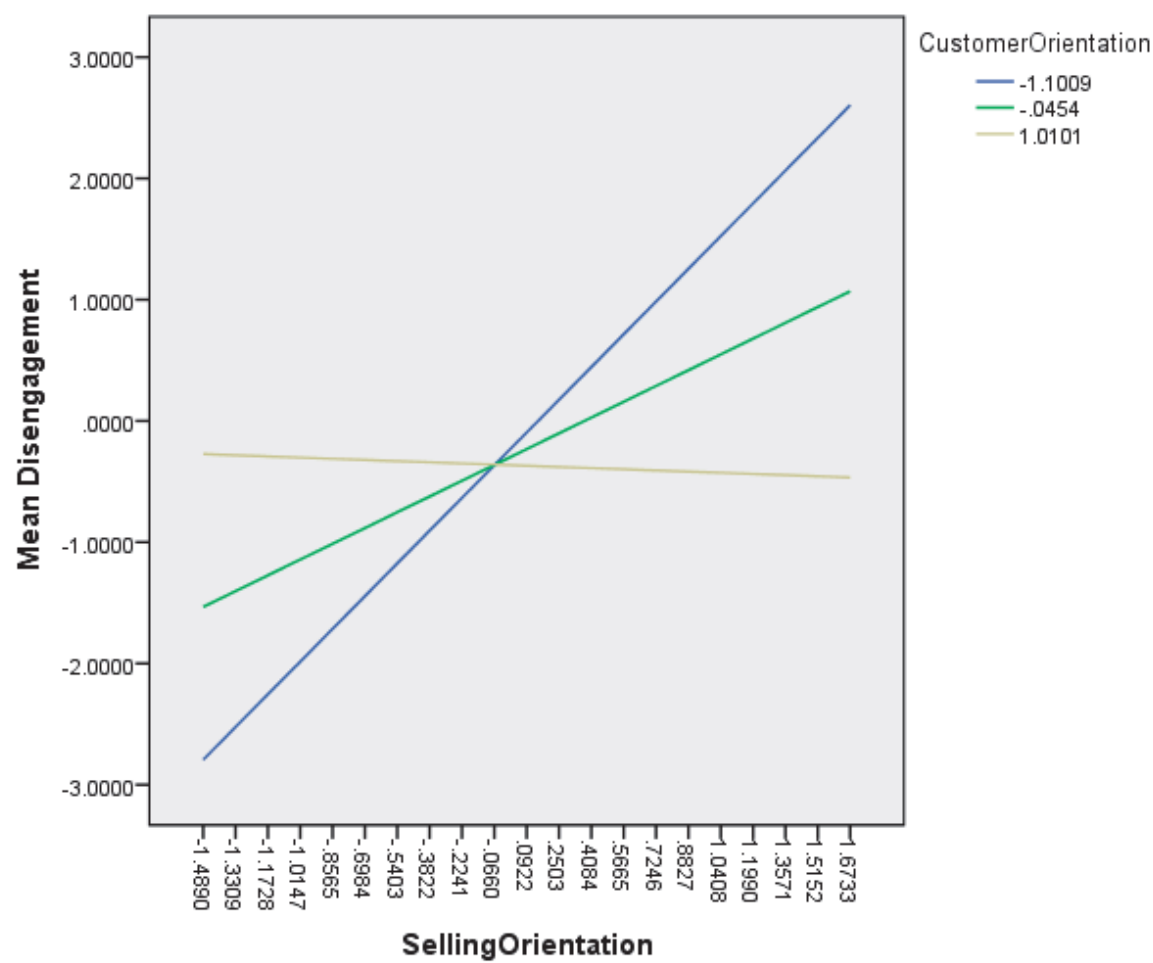

Figure 3.6: Spotlight Analysis - Interaction of Selling Orientation and Customer Orientation for Low Module Completion Subsample

As illustrated in Figure 3.6, this interaction changes for partners who completed fewer modules in the past year. For these partners, selling orientation also promotes disengagement when partners exhibit low or average levels customer orientation. However, when customer orientation is high (i.e., one standard deviation above the mean), a higher selling orientation tends to slightly decrease disengagement. One further insight gained from this graph is that for sellers who have completed fewer modules in the prior year, and whose selling orientation is low, customer orientation actually promotes disengagement.

\section{GENERAL DISCUSSION}

The main objective of this research is to highlight the effects of disengagement from learning on channel relationships and performance, as well as to investigate the roles of firm and employee orientations in determining disengagement. Sales training has become a priority for firms as they look for ways to help salespeople navigate the increasingly dynamic marketplace they find themselves in (Sager et al. 2014; Sarin et al. 2010). 
With indirect sales channels becoming more important (Bairstow and Young 2012), suppliers often also train their distributors' salespeople (Bettencourt et al. 2002) in addition to their own employees. Despite these significant investments, supplier firms observe disengagement from these programs and fear that returns may not be optimal.

In an international field study, we investigate the role of disengagement in channel partner programs. The proposed conceptual model, including drivers, outcomes, and moderating variables, is strongly supported in our analysis. First, we illustrate the validity and importance of disengagement over time as a phenomenon that occurs in sales training. Second, we illustrate how customer orientation and selling orientation influence disengagement. In addition, we find that whether salespeople are able to reconcile these possibly conflicting orientations will determine their continued engagement in the provided training modules. We further show that how the balance SOCO affects disengagement depends on the partner's prior module completion in the program. Third, we show that disengagement from supplier-provided training impacts relationship satisfaction and business performance. We further investigate heterogeneity in the form of BLM at the reseller firm (Greenbaum et al. 2012) and find it to increase the impact of disengagement on the reseller's satisfaction with the supplier relationship.

\section{Disengagement}

Prior literature has argued that engaged employees "employ and express themselves physically, cognitively, and emotionally during role performances" (Kahn 1990, p. 694). However, prior literature has largely ignored disengagement, which is a phenomenon that receives increasing attention in the practitioner literature. In line with Kahn (1990), we focus on task-specific disengagement from learning, and on whether remove themselves from this particular aspect of channel partner programs.

As a first contribution to the literature, our results show that disengagement from voluntary training does occur in the context of channel partner programs. We thereby operationalize disengagement as a decrease in engagement over time. Our study shows that this approach is psychometrically valid and conceptually sound. Our findings contradict assumptions made in prior literature that engagement was a relatively enduring state (cf., Macey and Schneider 2008) and shows that rather, engagement is bound in time like other psychological states (Weiss \& Kurek 2003). So far, little research has explicitly focused on disengagement, while some researchers have even explicitly excluded disengagement from consideration (e.g., Macey and Schneider 2008). Kahn (1992) theorizes disengagement to be the "simultaneous withdrawal and defense of a person's preferred self in behaviors that promote a lack of connections, physical, cognitive, and emotional absence, and passive, incomplete role performances" (p. 701). Our results lend empirical support to this notion. 


\section{Antecedents of Disengagement}

As a second major contribution, we investigate antecedents of disengagement in channel partner learning. Knowledge about the antecedents of engagement in general is scarce (Wollard and Shuck 2011). Our results show that the channel partner's customer orientation and selling orientation have a major impact on disengagement from the training. In line with our expectations in $\mathrm{H} 1 \mathrm{a}$ and $\mathrm{H} 1 \mathrm{~b}$, we find that a higher selling orientation promotes disengagement, while a strong customer orientation actually prevents disengagement. These findings are interesting in light of earlier studies. For instance, while Wachner, Plouffe, and Grégoire (2009) expected a similar result pattern, they actually found both $\mathrm{CO}$ and $\mathrm{SO}$ to have a positive impact on performance. Further, in the study by Boles et al. (2001), SO was not related to job performance, which they interpreted such that customers may have expected some degree of selling-oriented behaviors of the salespeople. Based on these findings, Guenzi et al. (2011) suggest that the bad reputation selling orientation has gotten may not have been justified. While it may in fact be true that customers in some markets do expect a certain degree of salesperson selling orientation - certainly in competitive B2B markets - our study does find negative effects of selling orientation. This might be due to the fact that our study actually examined both orientations simultaneously.

In addition, and in line with our predictions in $\mathrm{H} 2$, our results indicate that the degree to which salespeople are able to reconcile these - in some ways conflicting - orientations may determine their continued engagement in training. In the face of role ambiguity and conflicting demands (Peterson et al. 2014), some salespeople may indeed be overly focused on short-term sales at the expense of customer service and thus opt out of the training after an initial period. It has been argued that employees evaluate whether to themselves in a certain situation based on the potential return on investments in the role or task performance. They could ask how meaningful and safe it was for them bring themselves into this performance, as well as how available they were to do so (Kahn 1992). Our results are consistent with the theory, as salespeople's customer and selling orientations might influence their judgments of whether it was meaningful for them to engage in the training modules, and it could certainly influence their availability of doing so. In finding this, our study also answers calls in earlier literature (Guenzi et al. 2011) to examine the relationship between selling orientation and its outcomes. We show that disengagement from learning can result when sellers are overly focused on selling. It should be noted though, that customer orientation mitigates this disengagement-promoting impact of selling orientation.

In a post-hoc analysis, we investigate the effects of prior module completion on disengagement, in interrelation with our perspective on SOCO. First, we observe that prior module completion actually promotes disengagement. This can be interpreted in the light of prior assertions that employees consider how meaningful it would be for them to bring themselves into a role performance and how available they are to do so (Kahn 1990). Because of the time they have invested prior, and the things they have already learned - thus decreasing marginal knowledge gains - employees who recently ab- 
solved various modules should be both less available to engage in more training and also find it less meaningful to do so. Thus, it is not surprising that employees are found to be less likely to invest their physical, cognitive and emotional energies (Kahn 1990, Rich 2010) into further training. Second, observing a three-way interaction of SO, CO and module completion on disengagement, we find further support for the disengagement-mitigating effect of $\mathrm{CO}$ for partners who have completed a relatively high number of modules. However, we also see that when selling orientation is lower than average in partners who completed comparatively few modules, a low customer orientation actually leads to lower disengagement rates and would thus be preferable. Thus; when prior module completion as well as selling orientation are low, customer orientation actually promotes disengagement. This represents a boundary condition for the positive ambidexterity effect reported earlier and should be explored further in future research.

Relating these findings to earlier literature on SOCO and the reported equivocal findings regarding the performance impact of these orientations, Jaramillo and Grisaffe (2009) suggested that the link between SOCO and performance might only be significant in the long-term. Our results are generally in line with this, as we do find effects of SOCO on disengagement form learning using a longitudinal design. These findings further underline the suggestion that future research may aim to avoid static perspectives when assessing the impact of salespeople's orientations.

\section{Effects of Disengagement from Channel Partner Programs}

As a third contribution to the literature, we investigate how disengagement over time impacts channel partnership success. Research on engagement has most often taken a static perspective (cf., Bakker and Bal 2010; Ouweneel et al. 2013). Recent relationship marketing studies, however, suggest that assessing developments over time might be more predictive of future outcomes (Palmatier et al. 2013). We follow this approach by assessing the effects of disengagement on important relationship outcomes.

Our results show that salesperson disengagement from supplier-provided training is a key indicator of future relationship satisfaction and business performance. As predicted in $\mathrm{H} 3$, disengagement is indicative of lower relationship satisfaction. Interpersonal relationship literature has conceptualized disengagement as avoidance and withdrawal behaviors (Barry 2008), which are strategies to increase psychological or physical distance to the partner. In this stream of literature, high levels of disengagement are even seen as an indicator of a "point of no return" (Gottman, 1999; Kayser, 1993). Our results show disengagement to be an important precursor to future relationship satisfaction and thus potentially problems or even relationship dissolution at a later point in time.

Regarding performance concerns, recent literature argued more research was needed to examine how exactly engagement contributes to performance advantages for organizations (Rich et al 2010). We show that, as predicted in H4, disengagement also leads to lower perceived sales ability in partners. This supports the assertion that engagement in sales training is critical to salespeople's long-term performance (Pettijohn et al. 2009). It 
further empirically supports the notion that while employee engagement leads to beneficial outcomes (Bakker et al. 2012; Christian et al. 2011), disengagement should entail opposite effects (Kahn 1990).

As argued by Sonnentag (1993), engagement varies around an average level. However, there is significant within-person variation of the strength of engagement over time. Resources available to employees for engagement is finite (Kahn 1992) and our results suggest that prolonged engagement in an activity such as voluntary training modules may not be a reasonable assumption for firms or academics to make. We thus show the occurrence of disengagement, illustrate its effects, and add to the understanding of the concept and its' important role in channel partnerships.

\section{Firm Bottom-Line Mentality as a Moderator of Disengagement Effects}

We address heterogeneity by investigating the role of the reseller firm as little research has examined the boundary conditions for the effects of (dis-)engagement on marketing outcomes (Kane-Frieder et al. 2013). In particular, we examine how a prevailing BLM (Greenbaum et al. 2012) at the level of the reseller firm is important in determining the impact of disengagement on the future relationship between the reseller salesperson and the supplier. In line with $\mathrm{H} 4 \mathrm{a}$, we find that firm BLM increases the negative effect of disengagement on relationship satisfaction.

The environment in which a salesperson carries out his or her tasks is certainly of influence to the individual, as prior literature has shown (e.g., Barney 1986; Langerak 2001). As one dimension of the firm environment, a strong organizational BLM has been linked to negative outcomes such as unethical behavior and social undermining in the workplace (e.g. Barsky, 2008; Shah, Friedman, \& Kruglanski, 2002, Shah \& Kruglanski, 2002). As of yet however, BLM as a consequential concept has understudied in marketing. It is clear though, that B2B companies do tend to put their focus on a narrow set of success measures including sales and market share (O'Boyle et al. 2013). This creates an environment in which the salesperson's engaging in non-core activities become scrutinized, to the detriment of long-term development.

This finding also highlights a new perspective on a series of work conditions identified in the Gallup research program (Harter et al. 2003) which correlated with unit performance - presumably through creating more engaged employees (Macey and Schneider 2008). These performance-enhancing conditions included work attributes, characteristics of the superior, the availability of resources, coworker characteristics, as well as potential career progress. We complement this perspective as work conditions - such as firm BLM - also influence the relationship impact of disengagement. However, we do not find a significant impact of BLM on the relationship between disengagement and reseller perceived sales ability, which ultimately reflects performance. It may be the case that $\mathrm{B} 2 \mathrm{~B}$ reselling is so relational in nature that disengagement effects on sales ability are only indirect - through relationship satisfaction, which in turn impacts the resellers perceived ability to sell the suppliers products. This may prove a fruitful avenue for future research. 


\section{MANAGERIAL IMPLICATIONS}

Channel partner programs play a strategic role for firms as they enable their channel partners to cope with the demands presented in their markets and help to make better use of these growth opportunities. Our findings offer several managerial implications that can help to avoid disengagement and thus promote program and relationship success.

First, our results from a sample of worldwide channel partner salespeople shows that disengagement from training is a real phenomenon in channel partner programs with important implications. More concretely, it is an early indicator of deteriorating relationship health and has a negative impact on perceived sales ability and thus performance. Managers must therefore be aware of disengaging employees and in order to do this they would ideally track engagement over time. For instance, a brief engagement survey could be distributed periodically, in order to alert managers of occurring disengagement.

Second, our findings show that customer orientation and selling orientation influence disengagement from supplier provided sales training in a CPP. Specifically, a selling orientation promotes disengagement whereas a high customer orientation - even simultaneously - mitigates these effects. Managers thus need to be aware of the salespeople's orientations towards the sales role. In addition, managers should aim to actively foster customer orientation among the reseller sales force. In doing this, they should highlight that the goal should still be to make the sale, but to do so in a way that meets the customer's wants and needs. This way of balancing customer orientation with sales orientation not only builds long-term relationships (Christmann 2015), but also prevents disengagement. Managers could achieve this through the online training modules, stressing importance of working with the customer and fulfilling their needs (Pettijohn 2009). Besides reaching their reseller salespeople in this way, manufacturers should involve reseller firms directly, as local-level leadership is key to successfully implementing a customer orientation (Kennedy et al. 2003). Channel partners may opt to organize events together and hold local sales workshops on the topic.

Related to this, we found a boundary condition for the disengagement-mitigating effect of customer orientation as partners who have both low module completion rates and low sales orientation actually are less likely to disengage when they have a low customer orientation. This implies that program managers should be aware of their partners' prior training completion and may tailor the above-mentioned measures specifically according to a segmentation based on prior training.

Third, our results highlight the role of the reseller firm environment and show that a prevailing firm BLM (Greenbaum et al. 2012) increases the impact of disengagement on the future relationship between the reseller salesperson and the supplier. Specifically, disengaged sellers who work in firms with a strong bottom line mentality become even less satisfied with the relationship to their supplier. It is therefore important for manufacturers to work with their partner firms to make them less focused only bottom line outcomes. This could be achieved through trainings with managers, collaboratively working on long-term goals beyond sales and profit, as well as possibly devising different incentive structures. 


\section{LIMITATIONS AND DIRECTIONS FOR FUTURE RESEARCH}

We draw our data from a random sample of participating salespeople across multiple channel partner firms and geographies. Yet, our study is based on one CPP, operated by one supplier in the high-tech sector, which may limit the generalizability of our findings to other industries. Other researchers should aim to replicate our findings across different industries and programs to establish their validity in a range of channel partnerships and program designs. Further, our measure of disengagement consisted of the difference in overall state engagement at two different points in time. Each measurement thereby reflected the three subdimensions of physical, emotional and cognitive engagement. As suggested by Rich et al. (2010), these dimensions of engagement may be harder to distinguish for knowledge workers. Our empirical findings support this assertion as we observe high inter-item correlations and factor loadings on the general factor with our sample of salespeople. As model performance did not increase with a multi-factorial solution, we treated engagement as a single factor. It might be value adding to examine these subdimensions more closely in other industries and samples however.

Regarding the measurement of prior module completion employed in our additional post-hoc analysis, we believe a strong point of our study was the fact that we used behavioral data over 12 months prior to the first wave of our survey. Due to data availability concerns, we were not able to attain respective behavioral data for points in time after the survey. Future research should observe longer time periods of actual training participation and possibly assess the co-development of behavioral and state engagement and disengagement in this way (Macey and Schneider 2008). In addition, our measure of disengagement focused on disengaging from the voluntary sales training offered as part of the CPP. According to our findings, as well as interviews with managers at the manufacturer we partnered with, this is an important program element. However, salespeople disengaging from other elements of the program may be just as much cause for concern. Future research should investigate this potential issue.

In examining drivers of disengagement, we focused on the salesperson's selling and customer orientations, as well as prior module completion. Although our explanatory power of disengagement was substantial (R-square $=.34$ ), other significant drivers likely exist. Additional research might try to identify other influential factors, possibly by considering multiple partner programs. A fruitful avenue to research may be the effect of program design factors in determining disengagement. While overall program satisfaction did not predict disengagement in our model, certain elements of the program, as well as its usability and content may still be of influence. Regarding the effect of SO$\mathrm{CO}$, we find that whereas $\mathrm{SO}$ promotes disengagement, $\mathrm{CO}$ prevents disengagement and reduces the impact of $\mathrm{SO}$ and hence argued for managers to increase $\mathrm{CO}$. Recent research suggests an effect of sales training on customer orientation (Pettijohn 2009). We did not investigate this in this study; future research however should assess this interrelation. Lastly, additional research should replicate our finding of prior module completion as a boundary condition to the ambidexterity effects of customer and selling orientation and test whether this effect applies to activities other than sales training modules. 
Overall, in this paper we find that salesperson disengagement from supplierprovided training in a CPP over time is a predictor of lower relationship satisfaction and negatively affects business performance. We observe that the degree to which salespeople manage to reconcile the possibly conflicting orientations of customer orientation and selling orientation will determine their continued engagement in the sales training modules. Particularly, customer orientation mitigates the state-disengagement promoting effects of selling orientation. This provides further support for the positive impact of a customer orientation on channel partner relationships and their performance. We further find that a pronounced bottom line mentality at the level of the reseller firm (Greenbaum et al. 2012) increases the impact of disengagement on the reseller's satisfaction with the supplier relationship, adding to our understanding of the negative impact of this construct. 


\section{Chapter Four Conclusion}




\section{SYNOPSIS}

In recent years, channel partners have attained prime importance for firms operating in global markets. These partners enable manufacturers to effectively serve bigger markets worldwide and thus have the potential to improve bottom line results. However, reduced control and the lack of immediate access to final customers lead to challenges for manufacturers, such as maintaining high levels of customer service by securing partner knowledge, as well as ensuring partner firm loyalty.

To address these challenges, firms have increasingly turned to channel partner programs that incorporate incentives as well as a focus on partner development through training. This training has been shown to be beneficial for partners who engage in it. Yet, disengagement is a prevalent issue in today's channels, as partners may not see the importance of training, or may simply lack the time and mental energy to engage as they face the various demands of their job.

For firms, channel partner programs constitute significant investments, which can lead to great returns under the assumption that partners appreciate the program and act upon this appreciation. However, it is not always obvious that this is the case as some partners may feel obligated rather than grateful, or simply expect such a level of support. In these cases, manufacturers may not see the increased returns they had hoped for.

This dissertation addresses the issues of disengagement and indebtedness in channel partner programs, and more generally, in customer and partner relationships. Our research presented in chapters two and three integrates and advances concepts from marketing and psychology. In order to achieve this, we collect and examine multiple data sources including longitudinal field studies as well as secondary data and a laboratory experiment. Our results yield new theoretical insights into channel relationships, which translate into actionable implications for managers. We thereby contribute to the important body of literature on relationship marketing.

\section{DISENTANGLING INDEBTEDNESS FROM GRATITUDE IN RESPONSES TO B2B CHANNEL PARTNER PROGRAMS}

To refine and expand current perspectives on relational exchanges focusing on gratitude (e.g., Palmatier et al. 2009), chapter two of this dissertation highlights a related but distinct construct, indebtedness, as an important element with the potential to decrease relationship and performance outcomes. In a multi-wave field study, we assess its direct effects as well as its interplay with gratitude.

First, we show that indebtedness does occur as a response to channel partner programs and in fact plays a unique and central role in this context. We disentangle disengagement from gratitude and show that these two constructs are distinct states in response to a benefit. In our study, gratitude has significant, positive effects on the partners' commitment to the supplier, as well as their sales effort. Indebtedness, in contrast, has a negative impact on these outcomes. These results are in line with prior psychology 
studies, which suggest that indebted individuals avoid their benefactors and are less likely to help them on unrelated dimensions (Greenberg 1980; McCullough, Kimeldorf, and Cohen 2008). Previous literature further suggests that positive emotions have the potential to undo the deleterious impact of negative emotions (Fredrickson et al. 2000). Our research builds on this notion and, by considering them simultaneously, shows that gratitude acts as a buffer against the negative effects of indebtedness.

Second, we demonstrate that certain conditions favor the dominance of either gratitude or indebtedness. In line with prior literature, our findings confirm the influence of benefit value, as higher perceived program value significantly increases channel partner gratitude. In addition, our research confirms the influence of perceived motives on gratitude while we also investigate their role in producing indebtedness - an issue on which little prior empirical evidence exists. In doing this, we adopt a nuanced view of the multiple motives at play in channels. This means that unlike research regarding motives on a continuum from benevolent to ulterior (e.g., Tsang 2006), we allow for the simultaneous perception of benevolent and self-serving motives. We show that benevolent motives increase gratitude, while ulterior motives do not detract from it. In a businessto-business setting, partners therefore appear to allow for some measure of self-interest by suppliers. We also find that perceived motives for benefit provision determine the level of indebtedness felt by the channel partners. That is, benevolent motives increase indebtedness, in line with early predictions (Greenberg 1980). Yet, in contrast with gratitude, ulterior motives also increase indebtedness. Perceiving self-serving motives seems to make the exchange nature of the relationship more salient to the partner and triggers different relationship norms and expectations (Clark and Mills 1979), leading to an implicit expectation of having to repay the supplier (Watkins et al. 2006).

Third, we address sources of heterogeneity in this context and investigate the role of channel partner entitlement. We find that entitlement influences how partners respond to the channel partner program, as it mitigates the positive effects of perceived program value on the partner's gratitude. In addition, because entitlement likely alters partners' perceptions and expectations, we investigate the combined effect of entitlement and perceived ulterior motives on indebtedness. Our results suggest that entitled channel partners simply expect to receive benefits from the supplier. Therefore, even when they value these benefits, they are less grateful compared to partners who feel less entitled. Regarding indebtedness, we find that partners with a strong sense of entitlement are more prone to interpret suppliers' ulterior motives as a sign of an exchange relationship and thus feel indebted. Entitlement thus impacts indebtedness in a different way. Yet, we can conclude that entitlement indirectly and negatively affects the relational and performance outcomes of partner programs. 


\section{BALANCING CUSTOMER AND SALES ORIENTATIONS TO PREVENT DISENGAGEMENT IN CHANNEL PARTNER PROGRAMS}

Chapter three of this dissertation centers on sustaining the partners' engaged participation in the partner program. Engagement has become a central concept in the literature on employee commitment and performance (e.g., Christian et al. 2011; Rich et al. 2010). However, research on disengagement is limited. This chapter thus focuses on disengagement in particular as it investigates how the partner's ability to balance seemingly conflicting orientations prevents disengagement from occurring.

First, we review the construct of disengagement and investigate its role in the context of supplier-provided training in channel partner programs. Prior research has typically viewed engagement to be persistent over time (Schaufeli et al. 2002). Psychological states are inherently bound in time however (Weiss and Kurek 2003), which suggests purely static perspectives to be incomplete. Operationalizing disengagement as a reduction in state engagement (Rich et al. 2010) over time, we show that disengagement from voluntary training does occur in the context of channel partner programs. Prior research (Kahn 1992) theorizes disengagement to be the "simultaneous withdrawal and defense of a person's preferred self in behaviors that promote a lack of connections, physical, cognitive, and emotional absence, and passive, incomplete role performances" (p. 701). Our results lend empirical support to this notion.

Second, we elucidate the role of partners' customer and selling orientations in determining partner disengagement within the context of a channel partner program. We uncover that a pronounced selling orientation promotes partner disengagement, while a strong customer orientation actually prevents partners from disengaging. Whereas highly sales oriented sellers are prone to disengaging after completing the initial training stages, highly customer-oriented salespeople are less likely to disengage even then. Rather, they strive to learn and continually update their knowledge in order to offer the best possible service to clients and customers.

Importantly, the degree to which salespeople are able to reconcile these seemingly conflicting orientations also influences their likelihood of disengaging from the program as customer orientation mitigates the disengagement-promoting impact of selling orientation. In addition, we find that whether and how strongly this balance prevents disengagement depends on the partner's prior module completion in the program. We thus supplement recent work on performance-promoting effects of customer orientation (Zablah et al. 2012) while also extending research on ambidexterity at the individual level.

Third, we establish disengagement from supplier-provided training as an important predictor of the future health of the partner relationship as well as performance. Unlike prior work on engagement that adopted a static perspective, we assess these effects by examining the decrease in engagement over a period of time. In line with interpersonal relationship literature, our results show that salesperson disengagement is a predictor of lower relationship satisfaction. Disengagement also leads to lower perceived sales ability in partners. Supporting the notion that sales training is critical to salespeople's long- 
term performance (Pettijohn et al. 2009) this highlights the importance of maintaining employee and partner engagement in training. In addition, we investigate the role of the reseller firm and find that a pronounced bottom-line mentality (Greenbaum et al. 2012) further increases the negative impact of disengagement on the salesperson's satisfaction with the supplier relationship.

\section{RECOMMENDATIONS FOR FURTHER RESEARCH}

We made specific suggestions for further research in each of the prior two chapters. Nevertheless, we would like to discuss several general themes and questions for future research, basing on the insights gained through our studies.

\section{Indebtedness and the buffering effect of gratitude on indebtedness' negative consequences}

In chapter two, we disentangle the effects of indebtedness and gratitude on channel partner relationship outcomes. The buffering effect of gratitude on the negative effects of indebtedness appears to be a particularly promising avenue for further research in a more generalized setting, including business-to-consumer contexts. Morales' research (2005) yields initial insight into this issue, yet more research on the interaction of gratitude and indebtedness would help in gaining a broader understanding of the interplay of these psychological responses.

In addition, further research on the construct of indebtedness could prove fruitful for marketers and academics. The research in this dissertation increases our understanding of the conditions for an individual to feel indebted. Yet, compared to other psychological constructs, relatively little is known about these conditions or any boundary effects. Likewise, it seems interesting to examine not only how customer and partner indebtedness influences the company. Inspired by research such as Raggio's (2009) exploration of the effects of extending thanks to consumers, it could also be examined what the effects are of letting customers and partners know that the company owes them for their business, for instance.

One thing certainly does become clear from the research presented in chapter two of this dissertation: Future marketing research focusing on gratitude should incorporate indebtedness in order to gain a more complete understanding of relational exchanges and individuals' responses to them.

\section{The effects of perceived supplier motives}

Another question with important implications is whether self-serving and benevolent motives are opposite ends of a spectrum or are orthogonal. As outlined in chapter two, in a business-to-business setting, channel partners appear to allow for a certain measure of self-interest of their suppliers. In cognitive and social psychology research, there has 
been a development to increasingly question the view of such psychological constructs as opposite ends of a continuum. Our research can be viewed as supportive of this development as we do not see benevolent and self-serving motives as mutually exclusive. Instead, we find that channel partners ascribe both types of motives to their suppliers simultaneously to a certain degree.

Future research should explore boundary conditions for this effect and determine whether it holds in consumer settings as well. Furthermore, individual differences likely account for part of this effect and should therefore be investigated. Relevant factors likely include whether the individual exhibits a pronounced exchange orientation rather than a communal one (Clark and Mills 1979) as this might color the interpretation of benefits received in a relationship and the motives ascribed to the benefactor. In addition, strong opportunistic tendencies in dealing with others might also have similar effects.

\section{Disengagement}

As discussed in chapter three, disengagement from supplier-provided training in a channel partner program is an indicator of lower relationship satisfaction. In addition, it negatively impacts business performance. The fact that disengagement does occur over time in this context and that it has such a negative impact makes it relevant to academicians as well as practitioners. Our findings contradict earlier assumptions that engagement was a relatively enduring state (cf., Macey and Schneider 2008). Future research should investigate additional forms of disengagement, such as behavioral disengagement, as well as examine disengagement in different contexts. The relatively young body of research on customer engagement (van Doorn et. al 2009), for instance, could also benefit from explicitly investigating disengagement over time, which in turn would yield a more generalized and generalizable understanding of disengagement.

\section{Ambidexterity at the individual level}

The research presented in chapter three has demonstrated how individual ambidexterity benefits channel partner programs and relationships. In our study, the degree to which salespeople were able to reconcile the possibly conflicting orientations of customer orientation and selling orientation determined their continued engagement in the training modules. There is, however, a need for more research on ambidexterity - in particular at the individual level. Most research on ambidexterity has thus far focused on its benefits for companies. Yet, the positive results observed thus far make it worthwhile to examine what positive effects could be gained for the individual. Furthermore, there is not much known about the determinants of individual ambidexterity. Future research should therefore set out to shed light on the actions individuals could take to become more ambidextrous. 


\section{MANAGERIAL IMPLICATIONS}

Each year, companies spend billions of dollars on building and maintaining channel partner relationships, which are integral to achieving a strong position in the global marketplace. Many suppliers invest in channel partner programs to foster partner relationships and help their partners to become more effective sellers. Having gained a deeper understanding of the complexities of such programs, we would like to point out several broad themes for managers to ensure the effectiveness of their channel relationships which summarize and complement the recommendations in the individual chapters.

First, our study of worldwide channel partner salespeople shows that gratitude plays an important role in unlocking the full benefits of partner programs. This may come as a surprise to practitioners as gratitude is simply an emotional response to a benefit received. Even more unexpected may be the fact that indebtedness also occurs in response to such programs. This has detrimental effects on program returns for the supplier. Managers therefore need to be aware that channel partners respond to benefits in different ways and should proactively manage these responses. The motives ascribed to suppliers, as well as how the benefits are communicated can have a strong impact on whether the outcome will ultimately be positive.

Second, and closely related, partner entitlement impacts the responses to these channel partner programs. Psychological entitlement is part of a narcissistic personality and in a channel partner context may be developed when partners receive special treatment during early stages of the relationship (Boyd and Helms 2005; Wetzel, Hammerschmidt, and Zablah 2014). Managers need to be aware of this characteristic in their partners and devise plans to manage "prima donnas" (Davis 2013). Yet, the issue is not limited to top performing sellers, as we find that exclusive resellers in general tend to feel more entitled than multivendor partners. Thus, proactively managing channel partner expectations seems mandatory.

Third, our research positions disengagement as an important issue for the health of the channel relationship and its performance. Managers need to be aware of partners disengaging and should therefore monitor engagement closely. Our results show that a partner's customer orientation has the potential to prevent disengagement while mitigating the disengagement-promoting effect of a pronounced selling orientation. Thus, the degree to which salespeople manage to reconcile these seemingly conflicting orientations also determines their continued engagement in training. Next to promoting customer orientation in employees and channel partners, organizations need to be aware of role ambiguity and conflicting demands facing the salesperson (Peterson et al. 2014). This is important as salespeople may focus on short-term sales at the expense of customer service and thus opt out of the training after an initial period. Managers need to enable employees and partners to focus on important, long-term investments like training in addition to the short-term demands of selling to their customers.

This, finally, also ties in with the overall environment that the reseller salesperson operates in. Our results suggest that a prevailing bottom line orientation (Greenbaum et al. 2012) at the reseller firm increases the negative impact of disengagement on the 
future relationship between the reseller salesperson and the supplier. Managers are therefore advised to work with their channel partners to avoid a singular orientation on bottom line results. Perhaps counterintuitively, this should lead to superior results for the supplier as well as the reseller in the long-run. 


\section{References}

Adler, Mitchel G and Nancy S Fagley (2005), "Appreciation: Individual Differences in Finding Value and Meaning as a Unique Predictor of Subjective Well-Being," Journal of Personality, 73 (1), 79-114.

Algoe, Sara B., Jonathan Haidt, and Shelly L. Gable (2008), "Beyond reciprocity: Gratitude and relationships in everyday life," Emotion, 8 (3), 425-29.

Andrews, Mike (2013), "Why Aren’t My Channel Partners Selling More?!". www.heinzmarketing.com/2013/ 10/arent-channel-partners-selling/. Accessed 01 March 2015.

Ashby, F Gregory and Alice M Isen (1999), "A neuropsychological theory of positive affect and its influence on cognition," Psychological review, 106 (3), 529-550.

Ashforth, Blake E and Ronald H Humphrey (1995), "Emotion in the workplace: A reappraisal," Human relations, 48 (2), 97-125.

Babin, Barry J, Christine Gonzalez, and Christina Watts (2007), "Does Santa have a great job? Gift shopping value and satisfaction," Psychology \& Marketing, 24 (10), 895-917.

Bagozzi, Richard P. (1981). "Evaluating Structural Equation Models with Unobservable Variables and Measurement Error: A Comment." Journal of Marketing Research, 18 (3), 375-81.

Bagozzi, Richard P. and Utpal Dholakia (1999), "Goal Setting and Goal Striving in Consumer Behavior," Journal of Marketing, 63 (Special issue), 19-32.

Bairstow, Nigel and Louise Young (2012), "How channels evolve: A historical explanation," Industrial Marketing Management, 41 (3), 385-93.

Bakker, Arnold B and Matthijs P Bal (2010), "Weekly work engagement and performance: A study among starting teachers," Journal of Occupational and Organizational Psychology, 83 (1), 189-206.

Bakker, Arnold B, Evangelia Demerouti, and Lieke L ten Brummelhuis (2012), "Work engagement, performance, and active learning: The role of conscientiousness," Journal of Vocational Behavior, 80 (2), 555-64.

Bandura, Albert (1986), Social foundations of thought and action. Englewood

Cliffs, NJ: Prentice-Hall.

Bandura, Albert (1977), Social learning theory. Englewood Cliffs, NJ: Prentice-Hall.

Barney, Jay B (1986), "Organizational culture: can it be a source of sustained competitive advantage?," Academy of management review, 11 (3), 656-65.

Barry, Robin A, Erika Lawrence, and Amie Langer (2008), "Conceptualization and assessment of disengagement in romantic relationships," Personal Relationships, 15 (3), 297-315.

Barsky, Adam (2008), "Understanding the ethical cost of organizational goal-setting: A review and theory development," Journal of Business Ethics, 81 (1), 63-81.

Bartlett, Monica Y and David DeSteno (2006), "Gratitude and Prosocial Behavior Helping When It Costs You," Psychological Science, 17 (4), 319-25.

Bateman, Kayleigh (2009), "Microsoft catches dirty dozen in channel crackdown," CRN Channelweb UK.

Baxter, BKM (1980), "Alienation and authenticity: consequences for organized work," University of Lancaster.

Belk, Russell W. and Gregory S. Coon (1993), "Gift Giving as Agapic Love: An Alternative to the Exchange Paradigm Based on Dating Experiences," Journal of Consumer Research, 20 (3), 393-417.

Bem, Daryl J (1972), "Self-perception theory," Advances in experimental social psychology, 6, 1-62.

Bettencourt, Lance A, Amy L Ostrom, Stephen W Brown, and Robert I Roundtree (2002), "Client CoProduction in Knowledge-Intensive Business Services," California Management Review, 44 (4).

Bhattacharya, C. B., Hayagreeva Rao, and Mary Ann Glynn (1995), "Understanding the Bond of Identification: An Investigation of Its Correlates among Art Museum Members," Journal of Marketing, 59 (4), 46-57.

Blau, Peter M (1968). "Interaction: Social Exchange." Pp 452-58 in International Encyclopedia of the Social Sciences, D. L. Sills (ed). New York: MacMillan. 
Boles, James S, Barry J Babin, Thomas G Brashear, and Charles Brooks (2001), "An examination of the relationships between retail work environments, salesperson selling orientation-customer orientation and job performance," Journal of Marketing Theory and Practice, 9 (3), 1-13.

Bonesso, Sara, Fabrizio Gerli, and Annachiara Scapolan (2014), "The individual side of ambidexterity: Do individuals' perceptions match actual behaviors in reconciling the exploration and exploitation tradeoff?," European Management Journal, 32 (3), 392-405.

Bonnie, Kristin E and Frans BM de Waal (2004). "Primate Social Reciprocity and the Origin of Gratitude." Pp 213-29 in The Psychology of Gratitude, Robert A. Emmons and Michael E. McCullough (eds). New York: Oxford University Press.

Bono, Giacomo and Michael E McCullough (2006), "Positive responses to benefit and harm: Bringing forgiveness and gratitude into cognitive psychotherapy," Journal of Cognitive Psychotherapy, 20 (2), 147-58.

Boyd III, Henry C and Janet E Helms (2005), "Consumer entitlement theory and measurement," Psychology \& Marketing, 22 (3), 271-86.

Brehm, Jack W and Ann H Cole (1966), "Effect of a favor which reduces freedom," Journal of Personality and Social Psychology, 3 (4), 420.

Brenner, Steven N and Earl A Molander (1977), "Is ethics of business changing," Harvard Business Review, 55 (1), 57-71.

Brown, Gene, Robert E Widing, and Ronald L Coulter (1991), "Customer evaluation of retail salespeople utilizing the SOCO scale: a replication, extension, and application," Journal of the Academy of Marketing Science, 19 (4), 347-51.

Brown, Steven P. and Robert A. Peterson (1994), "The Effect of Effort on Sales Performance and Job Satisfaction," Journal of Marketing, 58 (2), 70-80.

Brown, Steven P (1996), "A meta-analysis and review of organizational research on job involvement," Psychological bulletin, 120 (2), 235.

Butori, Raphaëlle (2010), "Proposition for an improved version of the consumer entitlement inventory," Psychology \& Marketing, 27 (3), 285-97.

Callahan, David (2007), The cheating culture: Why more Americans are doing wrong to get ahead. Boston: Houghton Mifflin Harcourt.

Campbell, Margaret C and Amna Kirmani (2000), "Consumers' use of persuasion knowledge: The effects of accessibility and cognitive capacity on perceptions of an influence agent," Journal of Consumer Research, 27 (1), 69-83.

Campbell, W Keith, Angelica M Bonacci, Jeremy Shelton, Julie J Exline, and Brad J Bushman (2004), "Psychological entitlement: Interpersonal consequences and validation of a self-report measure," Journal of Personality Assessment, 83 (1), 29-45.

Cazalot, Clement (2013), "3 Steps to a Successful Channel Partner Program," Salesforce.com. https://www.salesforce.com/blog/2013/09/channel-partner-program.html. Accessed 20 March, 2014.

Chin, Wynne W (1998), "The partial least squares approach for structural equation modeling." in Modern methods for business research: Methodology for business and management. Marcoulides, George A. (Ed), Mahwah, NJ, US: Lawrence Erlbaum Associates Publishers, 295-336.

Chin, Wynne W, Barbara L Marcolin, and Peter R Newsted (2003), "A partial least squares latent variable modeling approach for measuring interaction effects: Results from a Monte Carlo simulation study and an electronic-mail emotion/adoption study," Information Systems Research, 14 (2), 189-217.

Christian, Michael S, Adela S Garza, and Jerel E Slaughter (2011), "Work engagement: A quantitative review and test of its relations with task and contextual performance," Personnel Psychology, 64 (1), 89-136.

Christiansen, Tim, Kenneth R Evans, John L Schlacter, and William G Wolfe (1996), "Training differences between services and goods firms: impact on performance, satisfaction, and commitment," Journal of Professional Services Marketing, 15 (1), 47-70.

Christmann, Samantha Maziarz (2015), "Buyers Avoid Pushy Salespeople." New York: SalesHQ. http://saleshq. monster.com/training/articles/3003-buyers-avoid-pushy-salespeople. Accessed 28 December, 2015.

Clark, Margaret S and Judson Mills (1979), "Interpersonal attraction in exchange and communal relationships," Journal of Personality and Social Psychology, 37 (1), 12.

Cohen, Jack (1988), Statistical power analysis for the behavioral sciencies. CITY: Routledge. 
Crotts, John C, Dundan R Dickson, and Robert C Ford (2005), "Aligning organizational processes with mission: the case of service excellence," The Academy of Management Executive, 19 (3), 54-68.

CSO Insights (2013), "The Business Case For Sales Training."

Dahl, Darren W, Heather Honea, and Rajesh V Manchanda (2003), "The nature of self-reported guilt in consumption contexts," Marketing Letters, 14 (3), 159-71.

Davis, Kevin (2012). "When the Rock Star Sales Rep Becomes a Prima Donna." http://www.toplineleadership. com/2012/12/when-the-rock-star-sales-rep-becomes-a-prima-donna/. Accessed 20 December, 2013.

Davis, Kevin (2013), "Sales Performance: How to Manage Prima Donna Sales Performers ": Monster.com.

De Ruyter, Ko, Luci Moorman, and Jos Lemmink (2001), "Antecedents of commitment and trust in customersupplier relationships in high technology markets," Industrial Marketing Management, 30 (3), 271-86.

De Ruyter, K. and M. Wetzels (2000), "With a little help from my fans-Extending models of pro-social behaviour to explain supporters' intentions to buy soccer club shares," Journal of Economic Psychology, 21 (4), 387-409.

Dodds, William B., Kent B. Monroe, and Dhruv Grewal (1991). "Effects of Price, Brand, and Store Information on Buyers' Product Evaluations." Journal of Marketing Research, 28 (3), 307-19.

Van Doorn, J., Lemon, K. N., Mittal, V., Nass, S., Pick, D., Pirner, P., \& Verhoef, P. C. (2010). Customer engagement behavior: Theoretical foundations and research directions. Journal of Service Research, 13(3), 253-266.

Drucker, Peter F (1963), "Managing for business effectiveness," Harvard Business Review.

Dubinsky, Alan J (1999), "Salesperson failure: sales management is the key," Industrial Marketing Management, 28 (1), 7-17.

Edwards, Jeffrey R (1996), "An examination of competing versions of the person-environment fit approach to stress," Academy of management journal, 39 (2), 292-339.

Edwards, Jeffrey R and Daniel M Cable (2009), "The value of value congruence," Journal of Applied Psychology, 94 (3), 654.

Ehret, Michael (2004), "Managing the trade-off between relationships and value networks. Towards a valuebased approach of customer relationship management in business-to-business markets," Industrial Marketing Management, 33 (6), 465-73.

Emmons, Robert A (1984), "Factor analysis and construct validity of the narcissistic personality inventory," Journal of Personality Assessment, 48 (3), 291-300.

Emmons, Robert A. (2004), "An Introduction.," in The psychology of gratitude, Robert A. Emmons and M.E. McCullough, eds. New York: Oxford University Press.

Emmons, Robert A and Cheryl A Crumpler (2000), "Gratitude as a human strength: Appraising the evidence," Journal of Social and Clinical Psychology, 19 (1), 56-69.

Emmons, Robert A, Michael E McCullough, and Jo-Ann Tsang (2003). "The Assessment of Gratitudein Handbook of Positive Psychology Assessment, S. J. Lopez and C. R. Snyder (eds). Washington, DC: American Psychological Association, 327-41

Erickson, TJ (2005), "Testimony submitted before the US Senate Committee on Health," Education, Labor and Pensions, May, 26.

Feather, Norman T. (2003), "Distinguishing between deservingness and entitlement: Earned outcomes versus lawful outcomes," European Journal of Social Psychology, 33 (3), 367-85.

Filipczak, R, B Geber, and BL Thompson (1991), "Training today: six signs of the future; get in line soldier!; focus shifts to core skills," Training, 28, 12-16.

Fiorletta, Alicia (2011). "Survey Reveals Low Satisfaction Rates with Current Visibility into Channel Incentive Programs." http://channelmarketerreport.com/2011/08/survey-reveals-low-satisfaction-rates-withcurrent-visibility-into-channel-incentive-programs/. Accessed October 12, 2013.

Fiorletta, Alicia (2012), "Partner Enablement Comes Into Focus," Channel Marketer Report. http://channelmarketerreport.com/2012/11/partner-enablement-comes-into-focus/. Accessed November $11,2014$.

Fiorletta, Alicia (2013), "Dell Channel Exec Shares Marketing And Enablement Strategies, Key Focus Areas For 2013," Channel Marketer Report. http://channelmarketerreport.com/2013/02/dell-channel-execshares-marketing-and-enablement-strategies-key-focus-areas-for-2013/. Accessed August 10, 2015.

Fitzsimons, Gavan J (2008), "Editorial: Death to dichotomizing," Journal of Consumer Research, 35 (1), 5-8.

Frankola, K. (2001). Why online learners drop out. Workforce, 80(10), 53-59. 
Fredrickson, Barbara L. (2001), "The role of positive emotions in positive psychology: The broaden-and-build theory of positive emotions," American Psychologist, 56 (3), 218.

Fredrickson, Barbara L. (2004). "The Broaden-and-Build Theory of Positive Emotions." Philosophical Transactions of the Royal Society B: Biological Sciences, 359 (1449), 1367-78.

Fredrickson, Barbara and Robert W Levenson (1998), "Positive emotions speed recovery from the cardiovascular sequelae of negative emotions," Cognition \& Emotion, 12 (2), 191-220.

Fredrickson, Barbara L, Roberta A Mancuso, Christine Branigan, and Michele M Tugade (2000), "The undoing effect of positive emotions," Motivation and emotion, 24 (4), 237-58.

Frijda, Nico H (1986). The Emotions. Cambridge University Press.

Ganesan, Shankar (1994), "Determinants of Long-Term Orientation in Buyer-Seller Relationships," Journal of Marketing, 58 (2), 1-19.

Gergen, Kenneth J, Phoebe Ellsworth, Christina Maslach, and Magnus Seipel (1975), "Obligation, donor resources, and reactions to aid in three cultures," Journal of Personality and Social Psychology, 31 (3), 390.

Geyskens, Inge, Jan-Benedict EM Steenkamp, and Nirmalya Kumar (1998), "Generalizations about trust in marketing channel relationships using meta-analysis," International Journal of Research in Marketing, 15 (3), 223-48.

Gilliland, David I. (2004), "Designing channel incentives to overcome reseller rejection," Industrial Marketing Management, 33 (2), 87-95.

Gillis, Claire, Leyland Pitt, Matthew J Robson, and Pierre Berthon (1998), "Communication in the salesperson/customer dyad: an empirical investigation," Marketing Intelligence \& Planning, 16 (2), 100-06.

Goei, Ryan and Franklin J. Boster (2005), "The Roles of Obligation and Gratitude in Explaining the Effect of Favors on Compliance," Communication Monographs, 72 (3), 284-300.

Gottman, John Mordechai (1999), The marriage clinic: A scientifically-based marital therapy: WW Norton \& Company.

Goodhue, Dale, William Lewis, and Ronald Thompson (2007), "Research note-statistical power in analyzing interaction effects: questioning the advantage of PLS with product indicators," Information Systems Research, 18 (2), 211-27.

Gouldner, Alvin W. (1960). "The Norm of Reciprocity: A Preliminary Statement." American Sociological Review, 25 (2), 161-78.

Greenbaum, Rebecca L, Mary Bardes Mawritz, and Gabi Eissa (2012), "Bottom-line mentality as an antecedent of social undermining and the moderating roles of core self-evaluations and conscientiousness," Journal of Applied Psychology, 97 (2), 343.

Greenberg, M.S. (1980), "A Theory of Indebtedness," in Social Exchange: Advances in theory and research. New York: Plenum.

Greenberg, Martin S and David M Frisch (1972), "Effect of intentionality on willingness to reciprocate a favor," Journal of Experimental Social Psychology, 8 (2), 99-111.

Greenberg, Martin S. and P. Shapiro Solomon (1971). "Indebtedness: An Adverse Aspect of Asking for and Receiving Help." Sociometry, 34 (2), 290-301.

Guenzi, Paolo, Luigi M De Luca, and Gabriele Troilo (2011), "Organizational Drivers of Salespeople's Customer Orientation and Selling Orientation," Journal of Personal Selling and Sales Management, 31 (3), 269-86.

Gupta, Anil K, Ken G Smith, and Christina E Shalley (2006), "The interplay between exploration and exploitation," Academy of management journal, 49 (4), 693-706.

Hackman, J Richard and Greg R Oldham (1980). Work Redesign. Addison-Wesley Reading, MA.

Hair, Joseph F, G Tomas M Hult, Christian Ringle, and Marko Sarstedt (2014), A Primer on Partial Least Squares Structural Equation Modeling (PLS-SEM) Sage Publications.

Hair, Joe F, Christian M Ringle, and Marko Sarstedt (2011), "PLS-SEM: Indeed a silver bullet," Journal of Marketing Theory and Practice, 19 (2), 139-52.

Hair, Joe F, Marko Sarstedt, Christian M Ringle, and Jeannette A Mena (2012), "An assessment of the use of partial least squares structural equation modeling in marketing research," Journal of the Academy of Marketing Science, 40 (3), 414-33. 
Haisley, Emily and George Loewenstein (2011), "It's Not What You Get but When You Get It: The Effect of Gift Sequence on Deposit Balances and Customer Sentiment in a Commercial Bank," Journal of Marketing Research, 48 (1), 103-15.

Harris, E. G., Mowen, J. C., \& Brown, T. J. (2005). Re-examining salesperson goal orientations: personality influencers, customer orientation, and work satisfaction. Journal of the Academy of Marketing Science, 33(1), 19-35.

Harter, James K, Frank L Schmidt, and Corey LM Keyes (2003), "Well-being in the workplace and its relationship to business outcomes: A review of the Gallup studies," Flourishing: Positive psychology and the life well-lived, 2, 205-24.

Harvey, Paul and Mark J Martinko (2009), "An empirical examination of the role of attributions in psychological entitlement and its outcomes," Journal of Organizational Behavior, 30 (4), 459-76.

Hayes, Andrew F and Jörg Matthes (2009), "Computational procedures for probing interactions in OLS and logistic regression: SPSS and SAS implementations," Behavior research methods, 41 (3), 924-36.

Heider, Fritz (1958), The psychology of interpersonal relations. CITY: Psychology Press.

Hobfoll, Stevan E (2001), "The influence of culture, community, and the nested-self in the stress process: advancing conservation of resources theory," Applied Psychology, 50 (3), 337-421.

Hochschild, Arlie Russell (2003), The managed heart: Commercialization of human feeling, With a new afterword: Univ of California Press.

Homans, G.C. (1961). Social Behaviour: Its Elementary Forms. Routledge \& Kegan Paul.

Incentivecentral.org (2008). "Channel Partners: Overview." http://www.incentivecentral.org/channel_part ners/channel partners.1841.html. Accessed 2 August, 2013.

Ingram, Thomas, Raymond LaForge, Ramon Avila, Charles Schwepker, and Michael Williams (2007), Professional selling: A trust-based approach: Cengage Learning.

Isen, Alice M (1987), "Positive Effect, Cognitive Processes, and Social Behavior," in Advances in Experimental Social Psychology, Leonard Berkowitz (ed), New York, NY: Academic Press, 203-51

Jaramillo, Fernando, Daniel M Ladik, Greg W Marshall, and Jay Prakash Mulki (2007), "A meta-analysis of the relationship between sales orientation-customer orientation (SOCO) and salesperson job performance," Journal of Business \& Industrial Marketing, 22 (5), 302-10.

Jasmand, Claudia, Vera Blazevic, and Ko de Ruyter (2012), "Generating sales while providing service: A study of customer service representatives' ambidextrous behavior," Journal of Marketing, 76 (1), 20-37.

Johnson, Paul E. (2015). rockchalk: Regression Estimation and Presentation. R package version 1.8.91. http://CRAN.R-project.org/package=rockchalk

Johnston, Mark W and Greg W Marshall (2008), Relationship selling: McGraw-Hill/Irwin.

Jones, Gareth R and Jennifer M George (1998), "The experience and evolution of trust: Implications for cooperation and teamwork," Academy of Management Review, 23 (3), 531-46.

Joshi, Ashwin W and Sanjay Sharma (2004), "Customer knowledge development: antecedents and impact on new product performance," Journal of Marketing, 68 (4), 47-59.

Joy, Annamma (2001), "Gift giving in Hong Kong and the continuum of social ties," Journal of Consumer Research, 28 (2), 239-56.

Junni, Paulina, Riikka Sarala, Vas Taras, and Shlomo Tarba (2013), "Organizational ambidexterity and performance: A meta-analysis," The Academy of Management Perspectives, amp. 2012.0015.

Kahn, William A (1992), "To be fully there: Psychological presence at work," Human relations, 45 (4), 321-49.

Kahn, William A. (1990), "Psychological Conditions of Personal Engagement and Disengagement at Work," The Academy of Management Journal, 33 (4), 692-724.

Kalyanam, Kirthi and Surinder Brar (2009), "From Volume to Value: Managing The Value-Add Reseller Channel At Cisco Systems," California management review, 52 (1), 94-119.

Kane-Frieder, Rachel E, Wayne A Hochwarter, and Gerald R Ferris (2013), "Terms of engagement: Political boundaries of work engagement-work outcomes relationships," Human Relations, 0018726713495068.

Kayser, Karen (1993), When love dies: The process of marital disaffection: Guilford Press.

Kennedy, Karen Norman, Jerry R Goolsby, and Eric J Arnould (2003), "Implementing a customer orientation: Extension of theory and application," Journal of Marketing, 67 (4), 67-81.

Komter, Aafke Elisabeth (2004), "Gratitude and Gift Exchange," in The Psychology of Gratitude, Robert A. Emmons and Michael E. McCullough (eds).,New York: Oxford University Press, 195-213. 
Kumar, V, Sarang Sunder, and Robert P Leone (2015). "Who's Your Most Valuable Salesperson?" Harvard Business Review, 96 (4), 62-68.

Lambert, Nathaniel M, Steven M Graham, and Frank D Fincham (2009), "A prototype analysis of gratitude: Varieties of gratitude experiences," Personality and Social Psychology Bulletin, 35 (9), 1193-207.

Lamkin, Robert (2013), "10 Benefits of Through-Partner Marketing Automation Software." Centerville, MA.

Lane, Jeneva and Norman H Anderson (1976), "Integration of intention and outcome in moral judgment," Memory \& Cognition, 4 (1), 1-5.

Langerak, Fred (2001), "Effects of market orientation on the behaviors of salespersons and purchasers, channel relationships, and performance of manufacturers," International Journal of Research in Marketing, 18 (3), 221-34.

Larsen, Derek and John J Watson (2001), "A guide map to the terrain of gift value," Psychology \& Marketing, 18 (8), 889-906.

Latham, Gary P and Edwin A Locke (2007), "New developments in and directions for goal-setting research," European Psychologist, 12 (4), 290.

Lazarus, R.S. and B.N. Lazarus (1994), Passion and reason: Making sense of our emotions. Oxford: University Press.

Lerner, Melvin J (1987), "Integrating societal and psychological rules of entitlement: The basic task of each social actor and fundamental problem for the social sciences," Social Justice Research, 1 (1), 107-25.

Lusch, Robert F, Stephen L Vargo, and Matthew O’Brien (2007), "Competing through service: Insights from service-dominant logic," Journal of Retailing, 83 (1), 5-18.

Macey, William H. and Benjamin Schneider (2008), "The Meaning of Employee Engagement," Industrial and Organizational Psychology, 1 (1), 3-30.

Marcoux, Jean-Sébastien (2009), "Escaping the gift economy," Journal of Consumer Research, 36 (4), 671-85.

McAdams, Dan P and Jack J Bauer (2004). "Gratitude in Modern Life: Its Manifestations and Development." Pp 81-99 in The Psychology of Gratitude, Robert A. Emmons and Michael E. McCullough (eds). New York: Oxford University Press.

McCullough, Michael E., Robert A. Emmons, and Jo-Ann Tsang (2002), "The grateful disposition: A conceptual and empirical topography," Journal of Personality and Social Psychology, 82 (1), 112-27.

McCullough, Michael E., Marcia B. Kimeldorf, and Adam D. Cohen (2008), "An adaptation for altruism? The social causes, social effects, and social evolution of gratitude," Current Directions in Psychological Science, 17 (4), 281-85.

McIntyre, Roger P, Reid P Claxton, Kenneth Anselmi, and Edward W Wheatley (2000), "Cognitive style as an antecedent to adaptiveness, customer orientation, and self-perceived selling performance," Journal of Business and Psychology, 15 (2), 179-96.

Menguc, Bulent, Seigyoung Auh, Michelle Fisher, and Abeer Haddad (2013), "To be engaged or not to be engaged: The antecedents and consequences of service employee engagement," Journal of business research, 66 (11), 2163-70.

Michaels, Ronald E and Ralph L Day (1985), "Measuring Customer Orientation of Salespeople: A Replication With Industrial Buyers," Journal of Marketing Research (JMR), 22 (4).

Microsoft (2010), "Microsoft Learning - Resellers."

Mimouni-Chaabane, Aîda and Pierre Volle (2010), "Perceived benefits of loyalty programs: Scale development and implications for relational strategies," Journal of Business Research, 63 (1), 32-37.

Mittal, Banwari (1990), "The Relative Roles of Brand Beliefs and Attitude toward the Ad as Mediators of Brand Attitude: A Second Look," Journal of Marketing Research, 27 (2), 209-19.

Mittal, Vikas, Eugene W Anderson, Akin Sayrak, and Pandu Tadikamalla (2005), "Dual emphasis and the long-term financial impact of customer satisfaction," Marketing Science, 24 (4), 544-55.

Morales, Andrea C. (2005), "Giving Firms an "E" for Effort: Consumer Responses to High-Effort Firms," Journal of Consumer Research, 31 (4), 806-12.

Morgan, Robert M. and Shelby D. Hunt (1994), "The Commitment-Trust Theory of Relationship Marketing," Journal of Marketing, 58 (3), 20.

Moses, Moheb (2008), "Profitable Partners Are Loyal Partners ": Channel Dynamics.

Movethechannel.com (2015), "Channel Conduit 7: Get the Reward Right," Movethechannel.com.

Naito, Takashi, Janjira Wangwan, and Motoko Tani (2005), "Gratitude in university students in Japan and Thailand," Journal of Cross-Cultural Psychology, 36 (2), 247-63. 
Netemeyer, Richard G, William O Bearden, and Subhash Sharma (2003), Scaling procedures: Issues and applications. CITY: Sage.

Nosella, Anna, Silvia Cantarello, and Roberto Filippini (2012), "The intellectual structure of organizational ambidexterity: A bibliographic investigation into the state of the art," Strategic Organization, 10 (4), 450-65.

Nunnally, JC and IH Bernstein (1994), Psychometric Theory. New York: McGraw-Hill.

O’Boyle, Ed, John Fleming, and Bryant Ott (2013), "Finding the Right Measure of Success for B2Bs," Gallup Business Journal.

O'Reilly, Charles A and Michael L Tushman (2004), "The ambidextrous organization," Harvard business review, 82 (4), 74-83.

O'Reilly, Charles and Michael Tushman (2013), "Organizational ambidexterity: Past, present and future," The Academy of Management Perspectives, amp. 2013.0025.

Ouweneel, Else, Wilmar B Schaufeli, and Pascale M Le Blanc (2013), "Believe, and You Will Achieve: Changes over Time in Self-Efficacy, Engagement, and Performance," Applied Psychology: Health and Well-Being, 5 (2), 225-47.

Palmatier, Robert, Rajiv P. Dant, Dhruv Grewal, and Kenneth R. Evans (2006). "Factors Influencing the Effectiveness of Relationship Marketing: A Meta-Analysis." Journal of Marketing, 70 (4), 136-53.

Palmatier, Robert, Rajiv P. Dant and Dhruv Grewal (2007), "A Comparative Longitudinal Analysis of Theoretical Perspectives of Interorganizational Relationship Performance,” Journal of Marketing, 71 (October), 172-194.

Palmatier, Robert, Cheryl Burke Jarvis, Jennifer R. Bechkoff, and Frank R. Kardes (2009). "The Role of Customer Gratitude in Relationship Marketing." Journal of Marketing, 73 (5), 1-18.

Palmatier, Robert, Mark Houston, Rajiv P. Dant and Dhruv Grewal (2013), "Relationship Velocity: Towards A Theory of Relationship Dynamics," Journal of Marketing, 77 (1), 13-20.

Parker, Sharon K and Mark A Griffin (2011), "Understanding active psychological states: Embedding engagement in a wider nomological net and closer attention to performance," European Journal of Work and Organizational Psychology, 20 (1), 60-67.

Patterson, Paul, Ting Yu, and Narumon Kimpakorn (2014), "Killing two birds with one stone: Cross-selling during service delivery," Journal of Business Research, 67 (9), 1944-52.

Periatt, Jeffery A, Stephen A LeMay, and Subhra Chakrabarty (2004), "The selling orientation-customer orientation (SOCO) scale: Cross-validation of the revised version," Journal of Personal Selling \& Sales Management, 24 (1), 49-54.

Perkins, David N and David N Perkins (2009), The mind's best work: Harvard University Press.

Pettijohn, Charles E, Linda S Pettijohn, and Albert J Taylor (2002), "The influence of salesperson skill, motivation, and training on the practice of customer-oriented selling," Psychology \& Marketing, 19 (9), 743-57.

Pettijohn, Linda S, Charles E Pettijohn, and AJ Taylor (2009), "Retail Sales Training: Activities and Effects on Job Satisfaction, Organizational Commitment, Turnover and Customer-Orientation," Marketing Management Journal, 19 (1).

Petty, Richard E, David W Schumann, Steven A Richman, and Alan J Strathman (1993), "Positive mood and persuasion: Different roles for affect under high-and low-elaboration conditions," Journal of Personality and Social Psychology, 64 (1), 5-20.

Plouffe, Christopher R, John Hulland, and Trent Wachner (2009), "Customer-directed selling behaviors and performance: a comparison of existing perspectives," Journal of the Academy of Marketing Science, 37 (4), 422-39.

Podsakoff, Philip M, Scott B MacKenzie, Jeong-Yeon Lee, and Nathan P Podsakoff (2003), "Common method biases in behavioral research: a critical review of the literature and recommended remedies," Journal of applied psychology, 88 (5), 879-903.

Powell, William (2001), "Train today, sell tomorrow," Training And Development, 55 (9), 40-51.

Prahalad, Coimbatore K and Venkat Ramaswamy (2004), "Co-creation experiences: The next practice in value creation," Journal of interactive marketing, 18 (3), 5-14.

Rafaeli, Anat and Robert I Sutton (1987), "Expression of emotion as part of the work role," Academy of management review, 12 (1), 23-37. 
Raggio, Randle D, Anna M Walz, Mousumi Bose Godbole, and Judith A G Folse (2013), "Gratitude in Relationship Marketing: Theoretical Development and Directions for Future Research," European Journal of Marketing, 48 (1/2), 2-24.

Raisch, Sebastian and Julian Birkinshaw (2008), "Organizational ambidexterity: Antecedents, outcomes, and moderators," Journal of Management.

Raisch, Sebastian, Julian Birkinshaw, Gilbert Probst, and Michael L Tushman (2009), "Organizational ambidexterity: Balancing exploitation and exploration for sustained performance," Organization Science, 20 (4), 685-95.

Rapp, Adam, Lauren Bietelspacher, Dhruv Grewal and Doug Hughes (2013), "Understanding Social Media Effects Across Seller, Retailer, and Consumer Interactions," Journal of the Academy of Marketing Science, 41 (September), 547-566.

Revelle, W. (2015) psych: Procedures for Personality and Psychological Research, Northwestern University, Evanston, Illinois, USA, http://CRAN.R-project.org/package=psych, Version = 1.5.1.

Rich, Bruce Louis, Jeffrey A Lepine, and Eean R Crawford (2010), "Job engagement: Antecedents and effects on job performance," Academy of Management Journal, 53 (3), 617-35.

Rifon, Nora J, Sejung Marina Choi, Carrie S Trimble, and Hairong Li (2004), "Congruence effects in sponsorship: the mediating role of sponsor credibility and consumer attributions of sponsor motive," Journal of Advertising, 33 (1), 30-42.

Ringle, CM, S Wende, and A Will (2005), "Smart PLS 2.0 M3, University of Hamburg."

Ringle, Christian M, Sven Wende, and Jan-Michael Becker (2014), "SmartPLS 3." Boenningstedt: SmartPLS GmbH, http://www.smartpls.com "

Rod, Michel and Nicholas J Ashill (2010), "The effect of customer orientation on frontline employees job outcomes in a new public management context," Marketing Intelligence \& Planning, 28 (5), 600-24.

Román, Sergio, Salvador Ruiz, and José Luis Munuera (2002), "The effects of sales training on sales force activity," European Journal of Marketing, 36 (11/12), 1344-66.

Rosing, Kathrin, Michael Frese, and Andreas Bausch (2011), "Explaining the heterogeneity of the leadershipinnovation relationship: Ambidextrous leadership," The Leadership Quarterly, 22 (5), 956-74.

Rothbard, Nancy P. (2001), "Enriching or Depleting? The Dynamics of Engagement in Work and Family Roles," Administrative Science Quarterly, 46, 655-84.

Rouse, Margaret (2014), "Partner Program." SearchITChannel: TechTarget.

Rust, Roland T, Christine Moorman, and Peter R Dickson (2002), "Getting return on quality: revenue expansion, cost reduction, or both?," Journal of marketing, 66 (4), 7-24.

Ryu, Gangseog and Lawrence Feick (2007), "A penny for your thoughts: Referral reward programs and referral likelihood," Journal of Marketing, 71 (1), 84-94.

Sager, Jeffrey K, Alan J Dubinsky, Phillip H Wilson, and Chris Shao (2014), "Factors Influencing the Impact of Sales Training: Test of a Model," International Journal of Marketing Studies, 6 (1), p1.

Sarin, Shikhar, Trina Sego, Ajay K Kohli, and Goutam Challagalla (2010), "Characteristics that enhance training effectiveness in implementing technological change in sales strategy: A field-based exploratory study," Journal of Personal Selling \& Sales Management, 30 (2), 143-56.

Samaha, Stephen A, Robert W Palmatier, and Rajiv P Dant (2011), "Poisoning relationships: Perceived unfairness in channels of distribution," Journal of Marketing, 75 (3), 99-117.

SAS \& Loyalty 360 (2012), "Facing the Challenges of Building Loyalty and Retention: The New Strategic Imperative," SAS \& Loyalty 360.

Saxe, Robert and Barton A Weitz (1982), "The SOCO scale: a measure of the customer orientation of salespeople," Journal of marketing research, 343-51.

Schaufeli, Wilmar B., Marisa Salanova, Vicente Gonzalez-Roma, and Arnold B. Bakker (2002), "The Measurement of Engagement and Burnout: A Two Sample Confirmatory Factor Analytic Approach," Journal of Happiness Studies, 3, 71-92.

Schaumberg, Rebecca and Francis J. Flynn "Differentiating between Grateful and Indebted Reactions to Receiving Help." Pp 105-32 in Altruism and Prosocial Behavior in Groups.

Schmid, John and John M Leiman (1957), "The development of hierarchical factor solutions," Psychometrika, 22 (1), 53-61.

Schmit, Dora E (2012), "Examining Customer Felt Gratitude and Indebtedness in Exchanges: Their Conceptualizations, Causes and Consequences," University of Wisconsin-La Crosse. 
Schultz, Roberta J and David J Good (2000), "Impact of the consideration of future sales consequences and customer-oriented selling on long-term buyer-seller relationships," Journal of Business \& Industrial Marketing, 15 (4), 200-15.

Schwepker Jr, Charles H (2003), "Customer-oriented selling: A review, extension, and directions for future research," Journal of Personal Selling \& Sales Management, 23 (2), 151-71.

Shah, James Y, Ron Friedman, and Arie W Kruglanski (2002), "Forgetting all else: on the antecedents and consequences of goal shielding," Journal of personality and social psychology, 83 (6), 1261.

Sharir, Eitan (2014), "Culture of Sales Excellence: The Secret to Creating a High Performance Sales Team."

Siguaw, Judy A and Earl D Honeycutt (1995), "An examination of gender differences in selling behaviors and job attitudes," Industrial Marketing Management, 24 (1), 45-52.

Simsek, Zeki (2009), "Organizational ambidexterity: Towards a multilevel understanding," Journal of Management Studies, 46 (4), 597-624.

Singh, Ramendra and Abraham Koshy (2010), "Determinants of B2B salespersons' performance and effectiveness: a review and synthesis of literature," Journal of Business \& Industrial Marketing, 25 (7), 535-46.

Snider, Emma (2015). " For Savvy Salespeople, School Never Ends [Q\&a with Jill Konrath] ". http://blog.hub spot.com/sales/for-savvy-salespeople-school-never-ends-jill-konrath. Accessed March 24, 2015.

Snyder, Douglas K and John M Regts (1982), "Factor scales for assessing marital disharmony and disaffection," Journal of Consulting and Clinical Psychology, 50 (5), 736.

Spiller, Stephen A, Gavan J Fitzsimons, John G Lynch Jr, and Gary H McClelland (2013), "Spotlights, floodlights, and the magic number zero: Simple effects tests in moderated regression," Journal of Marketing Research, 50 (2), 277-88.

Singer, Eleanor (1981). "Reference Groups and Social Evaluations." Pp 66-93 in Social Psychology: Sociological Perspectives, Morris Rosenberg and Ralph H Turner (eds). New York: Basic Books.

Spellecy, Mike (2014), "Do Channel Partner Incentives Really Work?," Channel Partners Online. http://www.channelpartnersonline.com/blogs/channel-management-blog/2014/01/do-channel-partnerincentives-really-work.aspx. Accessed 14 August, 2015.

Steindl-Rast, David (2004). "Gratitude as Thankfulness and as Gratefulness." Pp 282-89 in The Psychology of Gratitude, Robert A. Emmons and Michael E. McCullough (eds). New York: Oxford University Press.

Steinhoff, Lena and RobertW Palmatier (2014), "Understanding Loyalty Program Effectiveness: Managing Target and Bystander Effects," Journal of the Academy of Marketing Science, forthjcoming.

Swenson, Michael J and Joel Herche (1994), "Social values and salesperson performance: an empirical examination," Journal of the Academy of Marketing Science, 22 (3), 283-89.

Tenenhaus, Michel, Vincenzo Esposito Vinzi, Yves-Marie Chatelin, and Carlo Lauro (2005), "PLS path modeling," Computational statistics \& data analysis, 48 (1), 159-205.

Tesser, Abraham, Robert Gatewood, and Michael Driver (1968), "Some determinants of gratitude," Journal of Personality and Social Psychology, 9 (3), 233-236.

Thomas, Raymond W, Geoffrey N Soutar, and Maria M Ryan (2001), "The selling orientation-customer orientation (SOCO) scale: a proposed short form," Journal of Personal Selling \& Sales Management, 21 (1), 63-69.

Tsang, Jo-Ann (2006), "The effects of helper intention on gratitude and indebtedness," Motivation and Emotion, 30 (3), 199-205.

Tsang, Jo-Ann (2007), "Gratitude for small and large favors: A behavioral test," Journal of Positive Psychology, 2 (3), 157-67.

Toffler, Barbara Ley (1991), Managers talk ethics: making tough choices in a competitive business world: John Wiley \& Sons Incorporated.

TSL Marketing (2013). "Systematic Channel Partner Recruitment - Tsl Marketing - an Introduction." http://www.businesszone.co.uk/blogs/tslmarketing/tsl-marketing-business-business-leadgeneration/systematic-channel-partner-recrui. Accessed 01 August, 2013.

Treviño, Linda Klebe, Michael Brown, and Laura Pincus Hartman (2003), "A qualitative investigation of perceived executive ethical leadership: Perceptions from inside and outside the executive suite," Human relations, 56 (1), 5-37.

Tugade, Michele M. and Barbara L. Fredrickson (2004), "Resilient individuals use positive emotions to bounce back from negative emotional experiences," Journal of personality and social psychology, 86 (2), 320 . 
Tugade, Michele M and Barbara L Fredrickson (2007), "Regulation of positive emotions: Emotion regulation strategies that promote resilience," Journal of Happiness Studies, 8 (3), 311-33.

van Dijk, Eric and David De Cremer (2006), "Self-benefiting in the allocation of scarce resources: Leaderfollower effects and the moderating effect of social value orientations," Personality and Social Psychology Bulletin, 32 (10), 1352-61.

Vizard, Michael (2012). "Time to Dismantle the Channel Welfare State." http://www.channelinsider.com/ c/a/Commentary/Time-to-Dismantle-the-Channel-Welfare-State-886996. Accessed 10 March 2015.

Watkins, Philip, Jason Scheer, Melinda Ovnicek, and Russell Kolts (2006), "The debt of gratitude: Dissociating gratitude and indebtedness," Cognition \& Emotion, 20 (2), 217-41.

Watkins, Philip C, Kathrane Woodward, Tamara Stone, and Russell L Kolts (2003), "Gratitude and happiness: Development of a measure of gratitude, and relationships with subjective well-being," Social Behavior and Personality: an international journal, 31 (5), 431-51.

Weick, Karl E and Karlene H Roberts (1993), "Collective mind in organizations: Heedful interrelating on flight decks," Administrative science quarterly, 357-81.

Weiss, Howard M and Katherine E Kurek (2003), "Dispositional influences on affective experiences at work," Personality and work: Reconsidering the role of personality in organizations, 121-49.

Wetzel, Hauke A., Maik Hammerschmidt, and Alex R. Zablah (2014). "Gratitude Versus Entitlement: A Dual Process Model of the Profitability Implications of Customer Prioritization." Journal of Marketing, 78 (2), 1-19.

Wetzels, Martin, Gaby Odekerken-Schroder, and Claudia Van Oppen (2009), "Using PLS path modeling for assessing hierarchical construct models: guidelines and empirical illustration," Management Information Systems Quarterly, 33 (1), 177-195.

Whiting, Rick (2013), "SAP Grants Channel Partners Sales Exclusivity For 'General Business' Customers," CRN.com. http:/www.crn.com/news/channel-programs/240152286/sap-grants-channel-partners-salesexclusivity-for-general-business-customers.htm. Accessed 10 December, 2013.

Wilke, Henk and JT Lanzetta (1982), "The obligation to help: Factors affecting response to help received," European Journal of Social Psychology, 12 (3), 315-19.

Wolfe, Donald M (1988), "Is there integrity in the bottom line," in Executive integrity: The search for high human values in organizational life, S Srivastva, ed. San Francisco, CA: Jossey-Bass.

Wolff, Hans-Georg and Katja Preising (2005), "Exploring item and higher order factor structure with the Schmid-Leiman solution: Syntax codes for SPSS and SAS," Behavior Research Methods, 37 (1), 48-58.

Wollard, Karen Kelly and Brad Shuck (2011), "Antecedents to Employee Engagement A Structured Review of the Literature," Advances in Developing Human Resources, 13 (4), 429-46.

Wood, Alex M, Jeffrey J Froh, and Adam WA Geraghty (2010), "Gratitude and well-being: A review and theoretical integration," Clinical Psychology Review, 30 (7), 890-905.

Xia, Lan, Monika Kukar-Kinney, and Kent B. Monroe (2010), "Effects of Consumers' Efforts on Price and Promotion Fairness Perceptions," Journal of Retailing, 86 (1), 1-10.

Young, Louise (2006), "Trust: looking forward and back," Journal of Business \& Industrial Marketing, 21 (7), 439-45.

Yu, Ting, Paul G Patterson, and Ko de Ruyter (2013), "Achieving service-sales ambidexterity," Journal of Service Research, 16 (1), 52-66.

Zablah, Alex R, George R Franke, Tom J Brown, and Darrell E Bartholomew (2012), "How and when does customer orientation influence frontline employee job outcomes? A meta-analytic evaluation," Journal of Marketing, 76 (3), 21-40. 
Appendix 
Appendix 2.1: Construct Measures in Field Study

Constructs/Measures (Scale Sources)

Avg. Item

Loadings

Program Value (adapted from Mimouni-Chaabane and Volle 2010, two new items added)

My overall evaluation of the (NAME) training program is good

All in all, I am satisfied with the (NAME) training program

0.82

Knowledge gained from the (NAME) training enables me to better serve my customers (new)

0.83

Knowledge gained from the (NAME) training is useful to perform my job (new)

0.88

Ulterior Motives (adapted from Rifon et al. 2004)

(SUPPLIER) provides the (NAME) program to persuade me to sell their products

0.80

(SUPPLIER) provides the (NAME) program because ultimately they only care about their own profits

(SUPPLIER) provides the (NAME) program mostly because they want to increase their sales

Benevolent Motives (adapted from Rifon et al. 2004)

(SUPPLIER) provides the (NAME) program because ultimately they care about their resellers

(SUPPLIER) has a genuine concern for the welfare of their resellers

(SUPPLIER) provides the (NAME) program because they truly want to support their resellers

Entitlement (adapted from Boyd and Helms 2005, one new item added)

I feel that (SUPPLIER)'s employees should cater to my every whim

In this modern age of technology, I should be able to ask a salesperson any question and have it answered instan

As a valuable customer, I have earned the right to deal exclusively with my supplier's most talented staff memb

I feel that (SUPPLIER) should go the extra mile for me (new)

Gratitude (Palmatier et al. 2009, based on McCollough et al. 2002)

I feel grateful to (SUPPLIER) for providing (NAME) training

I feel thankful to (SUPPLIER) for providing (NAME) training

I feel appreciative to (SUPPLIER) for providing (NAME) training

Indebtedness (based on Tsang 2006 and Watkins et al. 2006)

I feel indebted to (SUPPLIER) for providing (NAME) training

I feel obligated to (SUPPLIER) for providing (NAME) training

0.96

I feel I owe something to (SUPPLIER) for providing (NAME) training

0.91

Commitment (Mogran and Hunt 1994)

My relationship with (SUPPLIER):

$\ldots$ is one that I am very committed to.

....is very important to me.

...is one that I really care about.

....is worth my effort to maintain.

Sales Effort (adapted from Brown and Peterson 1994)

Please rate how your overall effort in the sales task compares to the other salespeople in your company: (1-"Among the least in the company"; 7 - "Among the most in the company")

Please rate how your number of hours worked compares to the other salespeople in your 
Please rate how your number of calls made compares to the other salespeople in your company:

(1- "Among the least in the company"; 7 - "Among the most in the company")

Supplier Identification (control, Bhattacharya, Rao, and Glynn 1995)

When someone criticizes (SUPPLIER), it feels like a personal insult.

I am very interested in what others think about (SUPPLIER).

When I talk about (SUPPLIER), I usually say 'we' rather than 'they'.

(SUPPLIER)'s successes are my successes.

Market Turbulence (control, Joshi and Sharma 2004)

Customers' preferences for product features have changed quite a bit over time.

We are witnessing demand for our products from customers who never bought them before.

New customers tend to have product-related needs that are different from those of our existing customers.

Sales Experience (control)

I have been working in sales for (please round to nearest full year):

N.A.

Notes: All items are measured using seven-point scales anchored by $1=$ "strongly disagree" and 7 = "strongly agree" unless otherwise noted. 
Appendix 3.1: Construct Measures

Constructs/Measures (Scale Sources)

Avg. Item

Loadings

Selling Orientation (Thomas et al. 2001)

$\begin{array}{ll}\text { I pretend to agree with a customer to please them } & 0.88\end{array}$

It is necessary to stretch the truth in describing a product to a customer $\quad 0.94$

I begin talking about the product/service before exploring a customer's need with him or her $\quad 0.91$

Customer Orientation (Thomas et al. 2001)

$\begin{array}{ll}\text { A good salesperson has to have the customer's best interest in mind. } & 0.79\end{array}$

I offer the product/service that is best suited to the customer's problem. 0.95

I try to find out what kind of products/services will be most helpful to a customer. 0.94

Module Completion (12m before Survey)

Objective data: number of learning modules completed per month

N.A.

Disengagement From the Training (difference terms between wave one and three Engagement scale items, adapted from Rich 2010)

I exert my full effort to the (NAME) training (physical engagement) 0.84

I devote a lot of energy to the (NAME) training (physical engagement) 0.73

I try my hardest to pass the (NAME) training modules (physical engagement) 0.87

I strive as hard as I can to complete the (NAME) training modules (physical engagement) 0.78

$\begin{array}{ll}\text { I am enthusiastic about the (NAME) training (emotional engagement) } & 0.89\end{array}$

$\begin{array}{ll}\text { I feel energetic when doing a (NAME) module (emotional engagement) } & 0.81\end{array}$

$\begin{array}{ll}\text { I feel positive about the (NAME) training (emotional engagement) } & 0.87\end{array}$

$\begin{array}{ll}\text { I am excited about the (NAME) training (emotional engagement) } & 0.79\end{array}$

When doing a (NAME) module, my mind is focused on the training (cognitive engagement) 0.87

When doing a (NAME) module, I focus a great deal of attention on the training (cognitive 0.81 engagement)

When doing a (NAME) module, I am absorbed by the training (cognitive engagement) 0.87

When doing a (NAME) module, I pay a lot of attention to the training (cognitive engagement) $\quad 0.79$

Notes: All items are measured using seven-point scales anchored by $1=$ "strongly disagree" and 7 = "strongly agree" unless otherwise stated. 
Appendix 3.2: Construct Measures (continued)

Constructs/Measures (Scale Sources)

Avg. Item

Loadings

Firm Bottom-Line Mentality (Greenbaum et al. 2012)

My company is solely concerned with meeting the bottom line.

My company only cares about the business.

0.96

My company treats the bottom line as more important than anything else.

0.88

My company cares more about profits than employee well-being.

Relationship Satisfaction (adapted from De Wulf et al. 2001)

As a business partner, I have a high-quality relationship with (COMPANY).

I am happy with the efforts (COMPANY) is making towards business partners like me.

I am satisfied with the relationship I have with (COMPANY).

Sales Ability (Plouffe et al. 2009)

Please rate your performance on the following, compared to the other salespeople in your company:

My ability to sell products with higher profit margins. (1- "much worse than the other salespeople in this company"; 7- "much better than the other salespeople in this company")

My ability to generate a high dollar amount of sales in my territory. (1- "much worse than the other salespeople in this company"; 7- "much better than the other salespeople in this company")

My ability to exceed the sales targets and objectives that are assigned to me. (1- "much worse than the other salespeople in this company"; 7- "much better than the other salespeople in this company")

My ability to identify and sell to major accounts in my territory. (1- "much worse than the other salespeople in this company"; 7- "much better than the other salespeople in this company")

Satisfaction With the Program (NAME) (adapted from Mimouni-Chaabane 2010)

My overall evaluation of the (NAME) training program is good

All in all, I am satisfied with the (NAME) training program

The advantages I receive in the (NAME) training program meet my expectations

Relationship Length

How long have you been selling (COMPANY) products (please round to nearest full year)?

N.A.

Notes: All items are measured using seven-point scales anchored by $1=$ "strongly disagree" and $7=$ "strongly agree" unless otherwise stated. 



\section{Valorization Addendum}


This dissertation focuses on channel partner programs and the complexities of ensuring their effectiveness. In today's globalized marketplace, companies no longer operate as isolated entities. Instead, they increasingly rely on actors outside the firm to contribute to their service and sales processes (Prahalad and Ramaswamy 2004). Building and nurturing channel partnerships is an important growth strategy as successful partnerships can decrease time to market and provide access to a wider range of global customers (Cazalot 2013). In the information technology sector, for instance, $67 \%$ of sales for the largest suppliers in 2007 were achieved through channel partnerships (Lamkin 2013).

However, managing relationships with a global network of partners is highly complex and challenging. Firms such as Microsoft, Dell, Intel, and others, increasingly turn to channel partner programs that incentivize selling and learning to manage and enhance these relationships. This dissertation highlights the fact that unlocking the benefits of such programs is not always easy and while channel partner programs offer significant potential for positive return-on-investment, there are potential risks as well. In this section, I discuss the relevance of the research presented in this dissertation to companies and program managers.

\section{CHAPTER 2: I OWE YOU ONE ... BUT THANKS ANYWAY! DISENTANGLING INDEBTEDNESS FROM GRATITUDE IN RESPONSES TO B2B CHANNEL PARTNER PROGRAMS}

According to recent market surveys, only a third of senior sales and marketing executives are satisfied with their programs' performance (Fiorletta 2011; SAS \& Loyalty 360 2012). It appears that despite the partners showing appreciation for these programs (Bateman 2009), they remain somewhat suspicious of the manufacturer's true intentions and sense an obligation to repay in some way. Chapter two of this dissertation focuses on these issues and highlights the fact that indebtedness has negative effects on the partner's commitment to the supplier, as well as their sales effort. At the same time, gratitude acts as a buffer against indebtedness' negative effects. In conjunction with our findings about the causes and consequences of indebtedness and gratitude, several important implications thus arise:

First, managers need to understand that the channel partners' evaluation of the program, as well as their concurrent emotional responses, have important implications for the program's effectiveness. For instance, our study of worldwide channel partner salespeople affirms that gratitude appears culturally neutral, with robust effects the resellers commitment to the supplier, as well as their sales effort. Program managers should make use of this knowledge and confidently invest in these programs. In particular, features that invoke partner gratitude, such as more valuable training, should be prioritized. Other investments that do not trigger gratitude to a comparable extent, or which do not contribute to gratitude additionally such as simply increasing rewards, should be under-emphasized. In addition, program managers should emphasize the fact 
that their primary motives for providing these programs are to help the partners succeed, thereby promoting gratitude.

Second, managers must realize that indebtedness - a state of obligation to repay someone for received benefits (Greenberg 1980) - is another central element of channel partner programs and has negative effects on the partner's commitment to the supplier as well as their sales effort. Thus, channel partner programs need to be managed in a way that is conducive to gratitude but unlikely to make program participants feel indebted. Managers should therefore avoid any communication regarding the expectation of repayment by the partner. In addition, managers need to avoid giving the impression of ulterior motives behind providing the program as these promote indebtedness. Communications with channel partners, for instance, might be modified to include explicit statements such as "There is absolutely no obligation," to frame the situation appropriately and positively.

Third, channel program managers need to recognize the diversity of their target audience and act accordingly. High-performing and self-confident salespeople (Davis 2012), for instance, hold widely varying expectations of their suppliers. These partners can act like prima donnas (Davis 2013) and have a strong sense of entitlement, which decreases long-term returns on the program. Managers should therefore identify their most entitled partners as well as their overly inflated expectations; Exclusive resellers feel more entitled than multivendor partners and surveys could be used to identify other resellers who exhibit similar tendencies. In dialogue with entitled partners, managers should encourage them to share expectations while at the same time highlighting the relational and long-term character of the relationship.

Another initiative companies can implement is the explicit recognition of top performers' achievements. Instead of simply praising top performers for achieved performance though, managers should explicitly highlight the partners' invested effort (such as training module completion, sales, etc.) to achieve the earned rewards or a particular status in the program. This is also the foundation for gamification programs where participants earn badges or points, often are ranked in a leaderboard which further fuels engagement, and ultimately get rewarded for their performed actions. Air Canada's Earn Your Wings program is one example in which participants earn points for taking flights with Air Canada and other actions. Those who are ranked highest on the leaderboard qualify to win additional prizes (Tierney 2015). By reducing the emphasis on credentials, status, and hierarchy, such programs put a stronger focus on effort or performed actions, which should in turn reduce the sense of entitlement. 


\section{CHAPTER 3: WHEN THEY'VE LOST THAT LEARNING FEELING... BALANCING CUSTOMER AND SALES ORIENTATIONS TO PREVENT DISENGAGEMENT IN CHANNEL PARTNER PROGRAMS}

Chapter three of this dissertation addresses a key issue many manufacturers face: disengagement from sales training in channel partner programs. Training has become a top priority for manufacturers in an effort to help salespeople to cope in today's complex and dynamic marketplace (Sager et al. 2014; Sarin et al. 2010). Despite growing investments in training and incentive programs however, industry surveys report mixed results with only short-term performance increases (Sharir 2014) as partners disengage quickly. This manuscript offers guidance for managers on how to address these issues:

First, managers should institute periodical surveys and other methods for tracking their channel partners' engagement in the training closely. Some successful companies, including Toyota, even utilize daily employee feedback to measure engagement continuously (Bersin 2014). In tracking engagement, disengagement should be operationalized as a reduction in levels of engagement over time. Disengagement needs to be tracked closely as it functions as an early indicator of deteriorating relationship health and has a negative impact on the resellers perceived sales ability. For instance, brief engagement surveys distributed frequently could warn management of declining engagement levels and downstream performance issues.

Second, managers should work to foster a strong customer orientation among their resellers' sales force as it helps to prevent disengagement whereas a strong selling orientation promotes it. Managers could achieve a stronger customer orientation through training modules by emphasizing the importance of working with the customer and focusing on fulfilling their needs (Pettijohn 2009). Companies who have successfully implemented this include commercial real estate provider Jones Lang LaSalle and Best Buy (Gulati 2007). Such training should still support making the sale while at the same time emphasizing the importance of doing so in a way that meets the customer's wants and needs. In addition, manufacturers should work directly with reseller management on this issue, as local-level leadership plays a critical role in ensuring a continual focus on customer orientation (Kennedy et al. 2003).

Third, manufacturers also need to institute programs and work with their resellers to make them less focused on singular, bottom-line outcomes. As a strong bottom-line mentality at the level of the reseller firm (Greenbaum et al. 2012) exaggerates the negative impact of disengagement on the reseller's satisfaction with the relationship, avoiding such a mentality should be a priority. Trainings with local management, the collaborative development of non-monetary long-term goals, as well as revised incentive structures are important ingredients to ensure success for the channel partner program as well as the channel relationship in the long run. 


\section{REFERENCES}

Bateman, Kayleigh (2009), "Microsoft catches dirty dozen in channel crackdown," CRN Channelweb UK.

Bersin, J. (2014). It's Time To Rethink The Employee Engagement Issue. Forbes. Retrieved from http://www.forbes.com/sites/joshbersin/2014/04/10/its-time-to-rethink-the-employee-engagement-issue. Accessed 20 December, 2015.

Cazalot, Clement (2013), "3 Steps to a Successful Channel Partner Program," Salesforce.com.

Davis, Kevin (2012). "When the Rock Star Sales Rep Becomes a Prima Donna." http://www.toplineleader ship.com/2012/12/when-the-rock-star-sales-rep-becomes-a-prima-donna/. Accessed 20 December, 2013.

Davis, Kevin (2013), "Sales Performance: How to Manage Prima Donna Sales Performers ": Monster.com.

Greenberg, M.S. (1980), "A Theory of Indebtedness," in Social Exchange: Advances in theory and research. New York: Plenum.

Gulati, R. (2007). Silo busting. Harvard Business Review, 85(5), 98-108.

Fiorletta, Alicia (2011). "Survey Reveals Low Satisfaction Rates with Current Visibility into Channel Incentive Programs." http:/channelmarketerreport.com/2011/08/survey-reveals-low-satisfaction-rateswith-current-visibility-into-channel-incentive-programs/. Accessed October 12, 2013.

Greenbaum, Rebecca L, Mary Bardes Mawritz, and Gabi Eissa (2012), "Bottom-line mentality as an antecedent of social undermining and the moderating roles of core self-evaluations and conscientiousness," Journal of Applied Psychology, 97 (2), 343.

Kennedy, Karen Norman, Jerry R Goolsby, and Eric J Arnould (2003), "Implementing a customer orientation: Extension of theory and application," Journal of Marketing, 67 (4), 67-81.

Lamkin, Robert (2013), "10 Benefits of Through-Partner Marketing Automation Software." Centerville, MA.

Pettijohn, Linda S, Charles E Pettijohn, and AJ Taylor (2009), "Retail Sales Training: Activities and Effects on Job Satisfaction, Organizational Commitment, Turnover and Customer-Orientation," Marketing Management Journal, 19 (1).

Prahalad, C. K., \& Ramaswamy, V. (2004). Co-creation experiences: The next practice in value creation. Journal of Interactive Marketing, 18(3), 5-14.

Sager, Jeffrey K, Alan J Dubinsky, Phillip H Wilson, and Chris Shao (2014), "Factors Influencing the Impact of Sales Training: Test of a Model," International Journal of Marketing Studies, 6 (1), p1.

Sarin, Shikhar, Trina Sego, Ajay K Kohli, and Goutam Challagalla (2010), "Characteristics that enhance training effectiveness in implementing technological change in sales strategy: A field-based exploratory study," Journal of Personal Selling \& Sales Management, 30 (2), 143-56.

SAS \& Loyalty 360 (2012), "Facing the Challenges of Building Loyalty and Retention: The New Strategic Imperative," SAS \& Loyalty 360.

Sharir, Eitan (2014), "Culture of Sales Excellence: The Secret to Creating a High Performance Sales Team."

Tierney, J. (2015). Air Canada Flies off with Top Honors for Best Loyalty or Rewards Program. Loyalty360. Retrieved from http://loyalty360.org/resources/article/air-canada-flies-off-with-top-honors. Accessed 20 December, 2015. 



\section{Curriculum Vitae}

Jan Pelser was born in Meerbusch, Germany, on June 14, 1983. From 1993 on, he attended the Gymnasium Fabritianum in Krefeld, Germany, where he attained his Abitur in 2002.

He completed his Bachelor of Science in International Business at Maastricht University in the Netherlands in 2007. During his Bachelor studies, he also spent a semester at BI Norwegian Business School in Oslo, Norway, where he studied and worked as a teaching assistant. Jan completed his Master of Science in International Business with a specialization in Strategic Marketing at Maastricht University in 2009. From 2008 to 2009, he also worked as a full-time employee in Strategic Marketing at ThyssenKrupp Stainless International GmbH in Krefeld, Germany.

Jan then joined Maastricht University as a PhD Candidate in October 2009 to write his dissertation under the supervision of Professor Dr. Ko de Ruyter, Professor Dr. Martin Wetzels, as well as Professor Dr. Dhruv Grewal of Babson College, MA, USA. During his $\mathrm{PhD}$, Jan was a consortium fellow of the AMA-Sheth Doctoral Consortium 2011 and spent three months as a visiting scholar with Professor Dr. Paul Patterson at the University of New South Wales in Sydney, Australia, in 2012. He also served as a mentor in Maastricht University's honors program PREMIUM. His dissertation research has been presented at several international conferences, including the Marketing Science Conference and the European Marketing Academy Conference, and has been published in the Journal of Retailing.

In May 2015, Jan has joined Convidera GmbH in Cologne, Germany, where he currently works as a consultant in the field of digital business and marketing. 